\title{
Igualdad de oportunidades: un avance hacia su medición para Argentina
}

\author{
Monserrat Serio
}

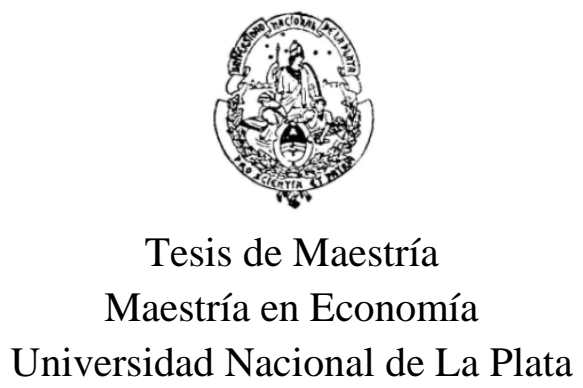

Director de Tesis: Dr. Leonardo Gasparini

Código JEL: D31, D63 


\title{
Igualdad de oportunidades: un avance hacia su medición para Argentina
}

\author{
Monserrat Serio*
}

\begin{abstract}
Resumen
En este trabajo se analiza la desigualdad de oportunidad en ingreso de los jóvenes argentinos. Para la medición de este fenómeno se utiliza información de las encuestas permanentes de hogares realizadas en el país desde el 2004 hasta la actualidad. Se considera el sesgo de selección por co-residencia y dentro del empleo de la muestra, y se lo intenta corregir empleando un modelo de selección múltiple. Para medir el grado de desigualdad de oportunidad se utiliza la metodología presentada en Bourguignon, Ferreira y Menéndez (2007). Los resultados sugieren que mientras la desigualdad de ingresos ha disminuido no parece haber un patrón claro en la desigualdad de oportunidades.
\end{abstract}

Palabras claves: igualdad de oportunidad, desigualdad de ingresos, Argentina

\begin{abstract}
This paper studies inequality of opportunity on earnings among young argentines. It aims to contribute to measure this phenomenon and it uses information from household surveys conducted in Argentina from 2004 to the present. Sample selection into employment and coresidence selection is dealt with a multiple selection model. We consider some econometrics methods implemented by Bourguignon, Ferreira y Menéndez (2007) to measure the degree of inequality of opportunity. The results suggest that while income inequality has decreased there seems no clear pattern of inequality of opportunity.
\end{abstract}

Keywords: inequality of opportunity, income inequality, Argentina

JEL: D31, D63

\footnotetext{
*Agradezco la valiosa guía y apoyo de mi director Leonardo Gasparini, así como los comentarios y sugerencias de Walter Sosa Escudero, Guillermo Cruces, Pablo Glüzmann y Cecilia Rumi. Finalmente, agradezco a Natalia Porto y Mariana Marchionni como Directoras de la Maestría de la UNLP por su apoyo y aliento.

Correo electrónico: monserratserio@yahoo.com
} 


\section{Índice}

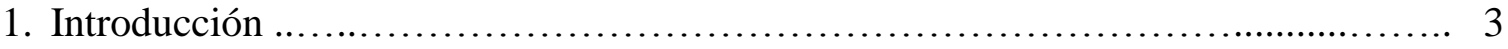

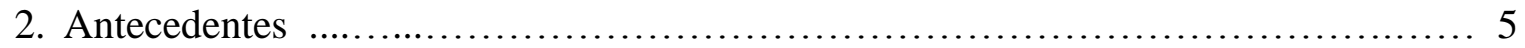

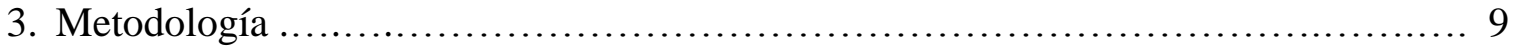

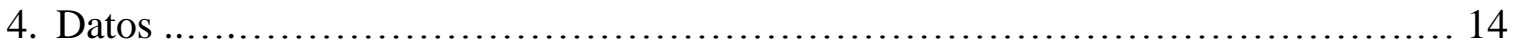

5. Problemas de selección muestral ................................................ 19

6. Resultados de estimaciones ................................................ 22

7. Análisis de igualdad de oportunidades .................................... 28

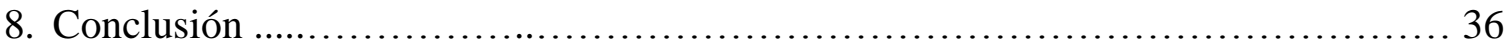

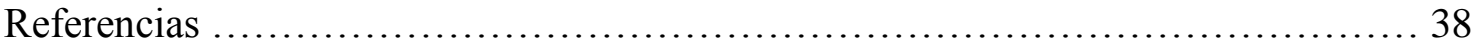

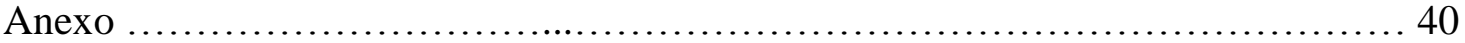




\section{1- Introducción}

El principio fundamental de la teoría de igualdad de oportunidad consiste en que ninguna persona sea privada de obtener un resultado por condiciones consideradas socialmente injustas. Es decir, que todas las personas deberían poseer la misma oportunidad de éxito en la vida. Una situación es injusta, por ejemplo cuando existe un trato diferencial entre personas de distinta raza (discriminación racial) o sexo (discriminación de género). No obstante, el concepto de desigualdad de oportunidades va más allá del concepto de discriminación (Roemer, 1998), ya que hace referencia a las posibilidades que afrontan las diferentes personas.

En general, las sociedades toleran un grado de desigualdad de resultados cuando éste no es consecuencia de situaciones injustas socialmente no aceptables. Por lo tanto, las personas deberían enfrentar las mismas oportunidades para que la sociedad no considere la desigualdad de resultados como un mal. Conocer el grado de desigualdad de oportunidad de una sociedad es importante per se, pero también por las posibles consecuencias en las discusiones y diseño de políticas de redistribución e inclusión social. Debido a que las perspectivas de desigualdad y redistribución varían entre los ciudadanos así como en el tiempo resulta difícil llegar a un consenso en políticas redistributivas sobre cómo y cuánto disminuir la desigualdad de resultados; y es más factible diseñar políticas que avancen hacia la igualdad de oportunidades por ser un concepto ampliamente aceptado (Barros y otros, 2009).

Este tema ha sido estudiado por diferentes autores, Checchi y Peragine (2005) estudian la desigualdad de oportunidad en Italia, Lefranc, Pistolesi y Trannoy (2008) amplían el número de países desarrollados además de Italia como Francia, Alemania, Gran Bretaña, Holanda, Noruega, Suecia, Bélgica y Estados Unidos, y Ashish Singh (2010) estudia el caso particular de la India. Respecto a América Latina, se pueden mencionar los trabajos de igualdad de oportunidades de Ferreira y Gignoux, (2011) para Brasil, Guatemala, Perú, Panamá, Colombia, Ecuador; de Barros y otros (2009) que incorporan a México además de los países anteriores, y el de Bourguignon, Ferreira y Menéndez (2007) que consideran sólo a Brasil.

A pesar de ser un fenómeno reconocido y tema central de debates, existen escasos estudios que proveen mediciones sistemáticas de desigualdad de oportunidades en la Argentina (Gasparini, 2002; Garlatti, 2011; Fachini, 2011), por lo que este trabajo intenta contribuir a su medición. 
La desigualdad de ingresos en el país, en los noventa, era creciente y alcanzó su máximo nivel en el 2001, año de crisis económica. Los índices de desigualdad de ingreso más usuales de la literatura como los índices Gini, Atkinson y Theil, muestran una considerable disminución luego de la crisis (Gasparini y Cruces, 2008). Los datos del Socio-Economic Database for Latin America and the Caribbean (CEDLAS y Banco Mundial, 2010), no sólo muestran que la desigualdad de ingresos ha disminuido en la última década sino también que su tendencia ha sido a la baja a partir del 2003. Ante esta situación resulta interesante analizar si existe desigualdad de oportunidades en Argentina y cuál ha sido su tendencia en esta última década. En el caso que la disminución de desigualdad de ingresos sea causa de una menor desigualdad de oportunidades, se podría decir que la sociedad está mejor en términos de oportunidades de ingresos. En cambio, en el caso que la desigualdad de oportunidades persistiera o aumentara, si bien la sociedad es más igualitaria en términos de ingreso la misma no estaría mejor en términos distributivos según la teoría de oportunidad.

Para la medición de este fenómeno, en este trabajo, se utiliza la información de las Encuestas Permanente de Hogares del 2004 al 2010 de los jóvenes entre 26 y 35 años de edad, se clasifican las variables en socialmente aceptables y no aceptables y se analiza los efectos directos e indirectos de las mismas en la desigualdad de ingreso. Las variables aceptables consideradas son años de educación y migración, y las variables no aceptables son género, región de nacimiento, educación y ocupación de los padres. El método implementado es el utilizado en Bourguignon y otros (2007) y consiste en simular la disminución en la desigualdad de ingresos medida a través del índice de Gini y de Theil, si no existieran diferencias en los valores de las variables no aceptables de la muestra. La desigualdad de oportunidad resulta de la diferencia entre la desigualdad real y la contrafactual proveniente de igualar las variables no aceptables.

Las estimaciones encontradas en este documento sugieren que las variables socialmente no aceptables influyen en la desigualdad de ingresos. Si bien la desigualdad de ingresos presenta una leve tendencia a la baja, la desigualdad de oportunidad ha oscilado durante el período.

El documento está organizado de la siguiente manera, en la sección 2 se presentan los antecedentes del tema. En la sección 3 se expone la metodología de trabajo y se discute el modelo teórico. En la sección 4 se describe brevemente la fuente de información y la muestra, en la sección 5 se analizan los posibles problemas de selección muestral y de estimación. Para luego presentar, en las secciones 6 y 7 las estimaciones del modelo y 
los principales resultados de desigualdad de oportunidad en ingresos, respectivamente. Finalmente se exponen las conclusiones sobresalientes del trabajo.

\section{2- Antecedentes}

En el marco de las teorías distributivas de la filosofía política moderna, Arnerson (1989), Cohen (1989) y Roemer (1998) han sido pioneros en desarrollar el concepto de desigualdad de oportunidades. Según Arnerson (1989), la idea de igualdad de oportunidades es la mejor interpretación de una igualdad distributiva ideal. Para el autor la igualdad de oportunidades debe ser medida en términos de bienestar. La misma se obtiene cuando todas las personas enfrentan opciones equivalentes; de este modo cualquier desigualdad de bienestar solamente se debe a factores que se encuentran bajo el control de cada individuo.

Por su parte Choen (1989), presenta la idea de igualdad de acceso a ventajas, donde el concepto de ventaja es considerado en un sentido amplio incluyendo el bienestar. De esta manera, una sociedad igualitaria bajo la igualdad de acceso a ventaja, se basa en la distinción entre las elecciones y la suerte para la formación del destino de las personas. Una persona es explotada cuando sus ventajas son injustas y sufre una "suerte bruta" (mala suerte) que no es el resultado de un juego de azar que se podría haber evitado. Es así que la primera acción hacia la igualdad según este autor es eliminar la influencia de la explotación y la suerte bruta sobre la distribución de resultados.

Roemer (1998), principal exponente de la teoría de igualdad de oportunidades, formaliza el concepto en un marco económico. La idea fundamental consiste en nivelar a las personas para que todas afronten el mismo "campo de juego" para alcanzar un mismo resultado. Con lo cual la obtención de resultados sólo dependerá de las elecciones de las personas y no de factores externos. El autor propone un modelo para medir la desigualdad de oportunidades, que consiste en separar los determinantes de un resultado en aquellos que son controlables y no controlables por la persona que experimenta dicho resultado. Roemer propone dos tipos de factores que determinan los resultados de una persona: variables de circunstancia y variables de esfuerzo. Las variables de circunstancias no son controlables por los agentes y por lo tanto son factores externos que inciden en los resultados, en cambio las variables de esfuerzo son aquéllas que pueden ser controladas por los individuos a través de sus decisiones y acciones. Cuando la desigualdad de resultado proviene de las variables de circunstancia se está en presencia de desigualdad de oportunidades y cuando sólo proviene de 
variables de esfuerzo la desigualdad es nula. Es así que existe igualdad de oportunidades si la distribución del resultado es independiente de la distribución de circunstancias. Cabe señalar la posibilidad que en una sociedad exista igualdad de oportunidades y desigualdad de resultados, esto sucede cuando los esfuerzos difieren entre los individuos dadas las mismas circunstancias.

Diversos investigadores han estudiado la desigualdad de oportunidades respecto a las distribuciones de ingresos. Algunos de ellos son Checchi y Peragine (2005), quienes analizan la igualdad de oportunidad en Italia a partir de un análisis no paramétrico. Dividen a la población en tipos y tramos, donde los tipos son subconjuntos de la población que se caracterizan por la homogeneidad de circunstancias y los tramos son subgrupos de personas que han ejercido el mismo nivel de esfuerzo. Al analizar la distribución dentro y entre los tipos y tramos de la población utilizando criterios de dominancia de Lorenz e índices de desigualdad, encuentran que la región sur de Italia presenta una mayor desigualdad de oportunidad que la región norte.

Por su parte, Ashish Singh (2010) analiza la desigualdad de oportunidad en la distribución de los ingresos en las zonas urbanas y la desigualdad de oportunidad en la distribución del gasto en el consumo en las zonas rurales de la India. Siguiendo a Roemer, encuentra una desigualdad de oportunidad mínima ya que considera la variable educación de los padres como la única variable de circunstancia. Los resultados arrojan valores significativos de desigualdad de oportunidades y concluye que en las zonas urbanas la desigualdad es mayor que en las zonas rurales.

Lefranc, Pistolesi y Trannoy (2008) realizan un análisis exhaustivo del grado de desigualdad de oportunidades y la desigualdad de resultados en nueve países desarrollados durante los años 90. Para ello utilizan criterios de dominancia estocástica y proponen como medida de desigualdad de oportunidad el Índice de Gini de Oportunidad el cual es una extensión del Índice de Gini. Para el análisis eligieron la educación de los padres como variable proxy del origen social de un individuo. Concluyen que Estados Unidos e Italia son los países más desiguales en términos de oportunidades como de resultados, al contrario de los países escandinavos. También encuentran que si bien Francia y Alemania poseen desigualdades de resultados parecidas el segundo es menos desigual en términos de oportunidades.

Por otro lado, Ferreira y Gignoux (2011), estudian la desigualdad de oportunidades en América Latina. Utilizan en su análisis métodos no paramétricos y paramétricos e incorporan el concepto de Perfil de Oportunidades de Privación (Opportunity- 
Deprivation Profile). Siguiendo a Roemer, consideran como variables de circunstancias la raza, género, región de nacimiento y el contexto familiar socioeconómico. Los resultados del estudio arrojan que Brasil y América Central presentan mayor desigualdad de oportunidad que Colombia, Ecuador y Perú. También concluyen que el origen étnico y la región de nacimiento son factores más importantes para determinar la privación de oportunidades que los resultados referentes a pobreza.

Barros y otros (2009) analizan la desigualdad de oportunidades económica, en acceso a servicios básicos y en educación, y presentan un índice de Oportunidad Humano para varios países de América Latina.

Con respecto a estudios que analizan la desigualdad de oportunidades en otras variables de interés distintas al ingreso o consumo, cabe destacar Brunello y Checchi (2006) quienes argumentan que el entorno familiar y la estratificación escolar son variables determinantes en la educación y afecta a la acumulación de capital humano. La estratificación de la escuela introduce barreras ficticias a la educación superior y es vista como un dispositivo institucional que refuerza la transmisión intergeneracional de las diferentes clases sociales en los logros educativos. Hindriks, Verschelde, Rayp y Schoors (2010) afirman que la estratificación escolar a través de la segregación social genera un mayor efecto en la desigualdad de oportunidades. Referente a la política educativa, Waltenberg y Vandenberghe (2007), sugieren que para disminuir la desigualdad de oportunidades en educación una política de gasto en educación que proporciona a cada alumno una cantidad igual de presupuesto se debe complementar con políticas cuyos objetivos sean eliminar la segregación escolar e igualar el acceso a las mejores escuelas.

Gasparini y Pinto (2006) analizan qué intervenciones públicas se justifican con el argumento de igualdad de oportunidades. Utilizan como herramienta de estudio la frontera de posibilidades de utilidad. Concluyen que no hay una política única para hacer frente a la igualdad de oportunidades. En algunas regiones de la frontera de posibilidades de utilidad una transferencia de dinero es óptima, y en otros una prestación en especie o una combinación de ambos son mejores instrumentos de política. Por lo que la política óptima dependerá de las características de la economía y del grado de redistribución de la utilidad que es posible o deseable practicar.

Yalonetzky (2009) plantea una forma adicional de medir la desigualdad de oportunidades valiéndose de la literatura de segregación. Propone como índice de desigualdad de oportunidad el índice de disimilitud basado en el estadístico de Pearson. 
Su análisis empírico para Perú sugiere una reducción de la desigualdad de oportunidad en educación de los cohortes mayores a los más jóvenes.

En particular para Argentina los estudios sobre desigualdad de oportunidad son escasos. Entre los trabajos existentes cabe citar a Gasparini (2002) quien estudia la desigualdad de oportunidades en educación. El autor expone la idea que sólo las diferencias en los resultados causados por diferencias en variables socialmente inaceptables son consideradas injustas y encuentra que la tasa de asistencia del nivel secundario está estrechamente relacionada a variables socialmente no aceptables. Garlatti (2011) analiza la igualdad en la calidad de la educación argentina a través de las pruebas internacionales PISA y realiza una comparación internacional con diversos países del mundo. En la mayoría de estos la calidad de la educación es pro-rico y progresista y en algunos hay diferencias a favor de las mujeres y los inmigrantes. En Argentina, el efecto del nivel socioeconómico en la calidad de la educación es mayor que en otros países y no hay diferencias de género e inmigración. Por último, se menciona a Fachini (2011) que analiza la desigualdad de oportunidades en salud en Argentina con el uso de registros administrativos.

Relacionado a la discusión normativa sobre cuáles variables son consideradas variables de circunstancias (exógenas) y de esfuerzo (de elección), la misma no es trivial ya que algunos autores argumentan que en el extremo todas las variables de esfuerzo podrían estar fuera de control del individuo con lo cual todas las variables serían exógenas al individuo. Gasparini (2002), por otro lado clasifica las variables en socialmente aceptables y no aceptables, con el fin de evitar la discusión filosófica entre variables exógenas y de elección. Las variables aceptables son aquéllas que generan un resultado percibido por la sociedad como no injusto, por ejemplo una desigualdad en ingresos debido a la experiencia de los individuos es aceptable no así por género, y por lo tanto la desigualdad creada por esta última es considerada injusta y no es aceptada socialmente. En este documento siguiendo a Gasparini (2002) se opta por clasificar a las variables entre variables socialmente aceptables y no aceptables, no obstante esta clasificación en algunos casos tampoco es obvia.

En la siguiente sección se presenta la metodología a seguir para medir la desigualdad de oportunidades en los últimos años en Argentina; para luego mostrar los resultados encontrados. 


\section{3- Metodología}

En este estudio se sigue la metodología presentada en Bourguignon y otros (2007), la cual consiste en analizar la desigualdad de oportunidades a partir de ingresos contrafácticos. Se dividen las variables explicativas en dos categorías; aceptables $\left(X_{A}\right)$ y no aceptables $\left(X_{N A}\right)$. La variable dependiente es el ingreso laboral horario real $(w)$ y se supone la siguiente función de ingresos,

$$
w_{i}=f\left(X_{A i}, X_{N A i}, u_{i}\right) \text {, }
$$

donde i representa cada individuo $(i=1, \ldots, n), X_{A}$ es un vector de variables aceptables, $X_{N A}$ es un vector de variables no aceptables y $u_{i}$ es no observable.

Se asume que la sociedad considera injusta la desigualdad producida por las variables que consideran socialmente no aceptables y justa la generada por las variables socialmente aceptables. Sin embargo las variables aceptables, pueden estar influenciadas por las variables no aceptables y la función de ingresos se puede escribir como,

$$
w_{i}=f\left(X_{A i}\left(X_{N A i}, v_{i}\right), X_{A N i}, u_{i}\right),
$$

donde $v_{i}$ es una variable no observable.

Según Roemer (1998) existe igualdad de oportunidades cuando la distribución del ingreso es independiente de las variables exógenas del individuo. En este análisis se considera que hay igualdad de oportunidades cuando la distribución del ingreso es independiente de las variables no aceptables. Esto es:

$$
\begin{aligned}
& \text { 1- } F\left(w / X_{N A}\right)=F(w) \\
& \text { 2- } G\left(X_{A} / X_{N A}\right)=G\left(X_{A}\right)
\end{aligned}
$$

donde $F\left(w / X_{N A}\right)$ es la distribución del ingreso condicionada a las variables no aceptables y $G\left(X_{A} / X_{N A}\right)$ es la distribución de las variables aceptables condicionada a las variables no aceptables.

La primera afirmación muestra que la distribución del ingreso es independiente de las variables no aceptables, es decir que las variables $X_{N A}$ no influyen en los ingresos. Lo que implica que la distribución de los inobservables es independiente de las variables no 
aceptables. La segunda hace referencia a que las variables aceptables no son afectadas por las no aceptables.

El ingreso contrafáctico, $\widetilde{w}_{i}=f\left(X_{A_{i}}\left(\bar{X}_{N A}, v_{i}\right), \bar{X}_{N A}, u_{i}\right)$, se calcula computando el mismo valor de las variables no aceptables a toda la muestra. Si se analiza la distribución del ingreso observable $F(w)$ y del ingreso contrafáctico $F(\widetilde{w})$ a partir de indicadores de desigualdad (I), y se comparan entre sí se puede conocer el grado de desigualdad de oportunidades proveniente de las variables socialmente no aceptables ${ }^{1}$.

El porcentaje de la desigualdad de ingreso debido a la desigualdad de oportunidades, puede calcularse como:

$$
\Psi=\frac{I(F(w))-I(F(\widetilde{w}))}{I(F(w))}
$$

Este porcentaje representa cuánto podría disminuir la desigualdad de ingresos si las variables no aceptables no afectaran la distribución de los mismos.

Además es posible analizar el efecto directo de las variables no aceptables sobre la desigualdad del ingreso a partir de la siguiente distribución de ingreso contrafactual $\breve{w}_{i}^{d}=f\left(X_{A_{i}}\left(X_{N A i}, v_{i}\right), \bar{X}_{N A}, u_{i}\right)$. La participación directa de la desigualdad de oportunidades sobre la desigualdad de ingreso se calcula como:

$$
\Psi^{\mathrm{d}}=\frac{I(F(w))-I\left(F\left(\check{w}^{d}\right)\right)}{I(F(w))} .
$$

Finalmente, el efecto indirecto resulta de sustraer de la participación total la participación directa,

$$
\Psi^{\mathrm{I}}=\Psi-\Psi^{\mathrm{d}}
$$

Para calcular la participación de desigualdad de oportunidades en la distribución del ingreso se sigue la estrategia de estimación presentada en el documento de Bourguignon y otros (2007). Se estima empíricamente el siguiente modelo lineal por el método de mínimos cuadrados (MCO), teniendo en cuenta los posibles sesgos de selección que pueden existir ${ }^{2}$.

\footnotetext{
${ }^{1}$ Observar que igualar las variables no aceptables es suficiente pero no necesario para lograr igualdad de oportunidades.

${ }^{2}$ Los posibles problemas de selección muestral del modelo de igualdad de oportunidades se analizan en la sección 5 del documento.
} 


$$
\begin{aligned}
& \ln \left(w_{i}\right)=\beta_{0}+\beta_{N A} X_{N A_{i}}+\beta_{A} X_{A i}+u_{i} \\
& X_{A i}=\pi_{0}+\Pi X_{N A i}+v_{i}
\end{aligned}
$$

donde $\beta_{N A}$ es un vector de coeficientes de dimensión $k$ donde $k$ representa el número de variables no aceptables del modelo; $\beta_{A}$ es un vector de coeficientes de dimensión $h$ donde $h$ representa el número de variables aceptables del modelo; $\Pi$ es una matriz de orden $h x k$, y $u_{i}$ y $v_{i}$ son errores de ruido blanco.

No es necesario estimar el modelo estructural en sí, ya que se puede estimar la forma reducida sustituyendo (2) en (1):

$$
\begin{aligned}
& \ln \left(w_{i}\right)=\beta_{0}+\beta_{N A} X_{N A i}+\beta_{A}\left(\pi_{0}+\Pi X_{N A i}+v_{i}\right)+u_{i} \\
& \ln \left(w_{i}\right)=\left(\beta_{0}+\beta_{A} \pi_{0}\right)+\left(\beta_{N A}+\beta_{A} \Pi\right) X_{N A i}+\left(\beta_{A} v_{i}+u_{i}\right) \\
& \ln \left(w_{i}\right)=\delta_{0}+\delta X_{N A i}+\varepsilon_{i}
\end{aligned}
$$

A partir de la estimación de la ecuación (3), es posible generar los ingresos contrafactuales para el análisis. El ingreso contrafáctico total se estima como

$$
\widetilde{w}_{i}=e^{\widehat{\delta}_{0}+\widehat{\delta} \bar{X}_{N A}+\widehat{\varepsilon}_{i}}
$$

Mientras que el ingreso contrafáctico directo se calcula a partir de la estimación de la ecuación (1) como

$$
\breve{W}_{i}^{d}=e^{\widehat{\beta}_{0}+\widehat{\beta}_{N A} \bar{X}_{N A}+\widehat{\beta}_{A} X_{A i}+\widehat{u}_{i}} .
$$

Luego de estimar estos ingresos, se calculan los índices de oportunidad $\Psi, \Psi^{\mathrm{d}}$ y $\Psi^{I}$. También se puede analizar el efecto en la desigualdad de oportunidad de cada variable no aceptable, dejando constante solamente la variable no aceptable de interés y estimando el ingreso contrafactual respectivo.

En particular en este trabajo se estimará el siguiente modelo:

$$
\begin{aligned}
& \ln \left(w_{i}\right)=\beta_{0}+\beta_{N A_{1}} H_{i}+\beta_{N A_{2}} E J_{i}+\beta_{N A_{3}} I B O J_{i}+\beta_{N A_{4} I M O J_{i}}+\beta_{N A_{5}} \mathrm{COJ}_{i}+\beta_{N A_{6}} A_{O O J} \\
& +\beta_{N A} S \text { MOJ }_{i}+\beta_{N A_{8}} \text { FOJ }_{i}+\beta_{N A 9} A D O J_{i}+\beta_{N A_{10}} \text { SOJ }_{i}+\beta_{N A_{11}} \text { SDOJ }_{i} \\
& +\beta_{N A_{12}} \text { nacgba }_{i}+\beta_{N A_{13}} \text { nacnea }_{i}+\beta_{N A_{14}} \text { nacnoa }_{i}+\beta_{N A_{15}} \text { naccuyo }_{i} \\
& +\beta_{N A_{16}} \text { nacpampa }_{i}+\beta_{N A_{17}} \text { nacpata }_{i} \\
& +\beta_{A 1} \text { aed }_{i}+\beta_{A 2} \mathrm{mig}_{i}+u_{i}
\end{aligned}
$$




$$
\begin{aligned}
X_{A i}=\Pi_{0}+ & \Pi_{1} H_{i}+\Pi_{2} E_{i}+\Pi_{3} \text { IBOJ }_{i}+\Pi_{4} \text { IMOJ }_{i}+\Pi_{5 i} \text { COJ }+\Pi_{6} \text { AOJ }_{i}+\Pi_{7} \text { SMOJ }_{i} \\
& +\Pi_{8} \text { FOJ }_{i}+\Pi_{9} \text { ADOJ }_{i}+\Pi_{10} \text { SOJ }_{i}+\Pi_{11} \text { SDOJ }_{i}+\Pi_{12} \text { nacgba }_{i} \\
& +\Pi_{13} \text { nacnea }_{i}+\Pi_{14} \text { nacnoa }_{i}+\Pi_{15} \text { naccuyo }_{i}+\Pi_{16} \text { nacpampa }_{i} \\
& +\Pi_{17} \text { nacpata }_{i}+v_{i}
\end{aligned}
$$

donde

- $X_{A i}$ es un vector de las variables aceptables años de educación (aedu), y status migratorio (mig).

- $H$ es una dummy de género

- EJ es la variable años de educación del jefe de hogar

- IBOJ es una dummy de ocupación del jefe de hogar en el sector de industria baja

- IMOJ es una dummy de ocupación del jefe de hogar en el sector de industria manufacturera

- COJ es una dummy de ocupación del jefe de hogar en el sector construcción

- AOJ es una dummy de ocupación del jefe de hogar en el sector agrícola

- CMOJ es una dummy de ocupación del jefe de hogar en el sector comercio

- SMOJ es una dummy de ocupación del jefe de hogar en servicios monopólicos

- FOJ es una dummy de ocupación del jefe de hogar en el sector financiero

- ADOJ es una dummy de ocupación del jefe de hogar en el sector administrativo

- SOJ es una dummy de ocupación del jefe de hogar en el sector de servicios

- SDOJ es una dummy de ocupación del jefe de hogar en servicios doméstico

- nacgba es una dummy de región de nacimiento en Gran Buenos Aires

- nacnea es una dummy de región de nacimiento en Noreste

- nacnoa es una dummy de región de nacimiento en Noroeste

- naccuyo es una dummy de región de nacimiento en Cuyo

- nacpampa es una dummy de región de nacimiento en la Pampa

- nacpata es una dummy de región de nacimiento en Patagonia

Como se dijo anteriormente la variable dependiente de interés es el logaritmo del ingreso laboral horario real $\left(\ln w_{i}\right)$, lo que implica que las horas trabajadas es una variable aceptable, ya que la sociedad acepta que existan diferencias en ingresos a favor de aquellos que trabajan más horas. Al tomar el salario horario y no el ingreso per cápita familiar, se supone implícitamente que la sociedad considera las decisiones de conformación familiar como un factor aceptable.

En este modelo se decide considerar los años de educación como una variable aceptable, sin embargo, esta especificación puede no ser tan obvia cuando el nivel de educación de una persona está determinado por factores que no son socialmente aceptables como por ejemplo la herencia educativa inter-generacional. Sin embargo, numerosos estudios exponen que un año más de educación implica un esfuerzo para la persona y, por lo 
tanto, para la sociedad es justo que las personas con mayor nivel educativo perciban mayores salarios que las personas de menor nivel educativo.

Respecto al status de migración de la persona, ésta puede catalogarse como socialmente aceptable desde la hipótesis de asimilación. Esta hipótesis supone que los migrantes adquieren calificaciones y acumulan experiencia en el mercado de trabajo del país nativo y establecen relaciones con los nativos adaptándose a la nueva sociedad, y a medida que pasa el tiempo sus ingresos comienzan a diferenciarse de los ingresos de los migrantes recién llegados y, por otro lado, comienzan a igualarse a los ingresos de los nativos (Cerruti y Maguid, 2007). De esta manera el tiempo de residencia en el país nativo de los migrantes es un indicador de capital humano y la brecha en ingresos explicada por las distintas dotaciones de capital humano ó por el proceso temporario de adaptación es considerada justa por la sociedad. En cambio, la brecha de ingresos debido a la discriminación contra los inmigrantes no es justa para la sociedad y en ese caso la variable migrante podría considerarse socialmente no aceptable.

Si bien no es muy claro si la variable migrante es socialmente aceptable o no aceptable, si se supone que la diferencia de ingresos a favor de los migrantes puede ayudarlos atravesar el proceso de adaptación y superar las dificultades de inserción social se puede considerar como variable aceptable. Por otro lado, si se supone que una brecha de ingresos a favor de los nativos ayuda a superar los desequilibrios internos temporales puede considerarse también como aceptable. Es así que en este trabajo se clasifica el status de migración como variable socialmente aceptable, sin entrar en la discusión de cuál de las situaciones nombradas anteriormente es justa y cuál no.

Con respecto a las variables consideradas en este trabajo como no aceptables por la sociedad, se supone que la sociedad considera injusta las diferencias en ingresos por discriminación de género, esta valoración es aceptada globalmente. Se considera socialmente no aceptable que la herencia inter-generacional educativa y ocupacional determine el conjunto de oportunidades del individuo. La sociedad no acepta que el contexto familiar y socioeconómico de una persona (aproximado en este caso por la educación y ocupación de los padres) sea determinante para el éxito futuro de la persona. Una mayor movilidad inter-generacional, indica que el origen socioeconómico y el seno familiar no son determinantes para el conjunto de oportunidades de la persona y por lo tanto se prefiere vivir en sociedades con movilidad inter-generacional alta (Jiménez y Jiménez, 2009). 
Por último, la brecha de ingresos según la región de nacimiento se clasifica como socialmente no aceptable. El lugar de nacimiento no debería condicionar las oportunidades de un individuo, principalmente porque el individuo no puede elegir dónde nacer. No obstante, esta calificación como variable no aceptable puede verse comprometida si se supone que el individuo reside en el lugar en que nació y las características económicas, culturales y sociales del país están diversificadas debido a las distintas estructuras regionales dentro del país, y consecuentemente los ingresos de los ciudadanos de las distintas regiones difieren entre sí por el propio proceso económico regional.

En resumen, el tratamiento de las variables en socialmente aceptables y no aceptables da lugar a una extensa discusión normativa. Su clasificación dependerá de los juicios de valor, procesos culturales y principios de la sociedad. Las variables de este modelo fueron elegidas de la manera más objetiva posible. El criterio de elección se basa en que son las usualmente utilizadas en la literatura de igualdad de oportunidad. En la próxima sección se detalla la muestra que será analizada en este trabajo y se exponen algunas estadísticas descriptivas de la misma.

\section{4- Datos}

En este trabajo se utilizan las Encuestas Permanentes de Hogar semestrales desde el 2004 al 2010, desarrolladas en forma conjunta por el Instituto Nacional de Estadística y Censos (INDEC) y las Direcciones Provinciales de Estadística de Argentina. La cobertura geográfica de la encuesta es de 31 aglomerados urbanos y un área urbanorural, que representan dos tercios de la población total del país. Las mismas están orientadas fundamentalmente a la captación de las características demográficas y socioeconómicas de la población. Sin embargo, no relevan datos de educación y ocupación de los padres de las personas entrevistadas, datos que resultan indispensables para conocer el contexto socioeconómico que es determinante de las condiciones iniciales de las personas y así determinar el grado de desigualdad de oportunidades. Aún así se elige analizar la desigualdad de oportunidad a partir de las variables que nos brindan las encuestas a través de la estrategia que se describe en el siguiente párrafo.

Dada la información estadística, se elige una sub-muestra que consiste en individuos entre 26 y 35 años, que no asisten al sistema educativo, es decir que son potencialmente activos en el mercado de trabajo, y poseen ingresos laborales positivos. Con el fin de contar con información sobre la educación y ocupación de los padres, se procede a 
utilizar como proxy la educación y ocupación del jefe de hogar, y se le imputa a toda persona encuestada que sea hijo del jefe de hogar el valor de la variable educación y ocupación de su jefe de hogar. Es importante señalar que esta estrategia muestral es muy probable que presente sesgo de selección por co-residencia y opción de empleo, por lo que los resultados deben analizarse cautelosamente.

La variable de resultado de interés es el logaritmo del ingreso laboral horario real de los individuos. La variable aceptable de educación se mide a través de los años de educación y la variable migrante es una dummy que toma el valor 1 si ha emigrado del municipio que nació. La variable no aceptable género es una dummy llamada hombre que toma valor 1 si el sexo de la persona es masculino. Para la variable lugar de nacimiento se construyen dummies de región de nacimiento en GBA, NOA, NEA, Cuyo, Pampa, Patagonia y otro país. Para el caso de educación de padres se toma como proxy los años de educación del jefe de hogar y, por último, se construyen dummies de ocupación del jefe de hogar como proxy de la ocupación de los padres. Las dummies de ocupación del jefe de hogar son diez variables dicotómicas dependiendo del sector en que trabaja el jefe: sector agropecuario, industria de baja tecnología, industria manufacturera, construcción, comercio, servicios monopólicos (transporte, electricidad, agua, gas), financiero, administrativo, servicios generales y empleo doméstico.

La muestra total de jóvenes entre 26 y 35 años de edad, en promedio, tiene 8.600 observaciones. La muestra joven restringida para el análisis se reduce a 2.000 observaciones por año. En ambas muestras se eliminaron a aquellos individuos que no reportaban información de alguna de las variables del análisis.

A partir del Cuadro 1, se observa que la media del ingreso laboral horario real de la muestra total ha aumentado más del doble durante el período 2004-2010, de 5,69 a 13,10; hay un mayor porcentaje de hombres, alrededor del $58 \%$ y la edad media es 30 años. El jefe de hogar posee en promedio casi 11 años de educación. Los jefes de hogar están ocupados principalmente en el sector comercio, servicios y financiero.

En promedio, aproximadamente el 5\% de la muestra ha nacido en otro país, mientras que el $44 \%$ en GBA, el $24 \%$ en la Pampa, el $11 \%$ en NOA y $7 \%$ en NEA. Las regiones con menores personas nacidas de la muestra son Cuyo y Patagonia. El porcentaje de migrantes es bastante alto, alrededor de un cuarto de la muestra vive en una localidad diferente de donde nació. Finalmente los años de educación han aumentado medio año durante el período considerado, de 11,5 años a 12 años. 
Cuando se analiza el Cuadro 2 correspondiente a la muestra restringida, se observa que el ingreso real laboral horario promedio es $17 \%$ menor que el de la muestra total. Además, durante el periodo analizado la diferencia de ingreso real laboral horario entre ambas muestras se acrecentó, en el 2003 la diferencia era de 14 centavos llegando a $\$ 1,39$ a finales del 2010. La estructura de género casi no varía respecto a la muestra total, el 59\% es hombre. En el año 2010, dicho porcentaje aumenta 3 puntos a $62 \%$.

Los jóvenes de la muestra restringida son un año menor de edad que el promedio de edad de la muestra total. La edad promedio de los jóvenes que co-residen y trabajan es 29 años. Los jefes de hogar poseen en promedio menores años de educación que en la muestra total, 9 años. Los jóvenes poseen, en promedio, los mismos años de educación aproximadamente 12 años y ha sido relativamente constante durante todo el período.

Las principales ocupaciones de los jefes de hogares de la muestra restringida son el comercio en primer lugar, luego el sector servicio y la construcción. Sin embargo, a diferencia de la muestra total los porcentajes entre las ocupaciones no difieren demasiado entre sí.

Las regiones de nacimiento que prevalecen son GBA, Pampa y NOA. El porcentaje de individuos nacidos en otro país se reduce al $2 \%$ en comparación a la muestra total. Finalmente, entre el 11 y $16 \%$ de los jóvenes son migrantes. 
Cuadro 1: Estadísticas descriptivas de la muestra total, 2004-2010.

\begin{tabular}{|c|c|c|c|c|c|c|c|c|c|c|c|c|c|c|}
\hline Variable & $\mathrm{I}-2004$ & II-2004 & $\mathrm{I}-2005$ & II-2005 & I-2006 & II-2006 & $\mathrm{I}-2007$ & $\mathrm{II}-2007$ & $\mathrm{I}-2008$ & II-2008 & I-2009 & II-2009 & $\mathrm{I}-2010$ & II-2010 \\
\hline Media ingreso laboral horario & 5.69 & 5.62 & 5.88 & 6.97 & 6.63 & 7.18 & 7.93 & 8.82 & 9.34 & 10.21 & 10.75 & 11.42 & 12.02 & 13.10 \\
\hline Porcentaje hombre & $59 \%$ & $59 \%$ & $59 \%$ & $58 \%$ & $58 \%$ & $58 \%$ & $59 \%$ & $58 \%$ & $57 \%$ & $57 \%$ & $57 \%$ & $58 \%$ & $58 \%$ & $59 \%$ \\
\hline Media edad & 30.32 & 30.30 & 30.39 & 30.39 & 30.33 & 30.42 & 30.50 & 30.43 & 30.41 & 30.44 & 30.49 & 30.51 & 30.57 & 30.55 \\
\hline Media educación jefe de hoga & 10.43 & 10.52 & 10.45 & 10.56 & 10.48 & 10.65 & 10.75 & 10.83 & 10.84 & 10.83 & 10.92 & 10.95 & 11.11 & 11.30 \\
\hline \multicolumn{15}{|c|}{ Ocupación jefe de hogar en porcentaje } \\
\hline Agro & $2 \%$ & $2 \%$ & $1 \%$ & $1 \%$ & $1 \%$ & $1 \%$ & $1 \%$ & $1 \%$ & $1 \%$ & $1 \%$ & $2 \%$ & $1 \%$ & $2 \%$ & $1 \%$ \\
\hline Industria baja & $6 \%$ & $5 \%$ & $6 \%$ & $7 \%$ & $7 \%$ & $7 \%$ & $6 \%$ & $7 \%$ & $6 \%$ & $6 \%$ & $6 \%$ & $5 \%$ & $5 \%$ & $5 \%$ \\
\hline Industria manufacturera & $7 \%$ & $7 \%$ & $7 \%$ & $7 \%$ & $8 \%$ & $7 \%$ & $7 \%$ & $7 \%$ & $7 \%$ & $8 \%$ & $8 \%$ & $7 \%$ & $7 \%$ & $7 \%$ \\
\hline Construcción & $8 \%$ & $8 \%$ & $9 \%$ & $9 \%$ & $10 \%$ & $10 \%$ & $10 \%$ & $9 \%$ & $8 \%$ & $10 \%$ & $9 \%$ & $9 \%$ & $9 \%$ & $9 \%$ \\
\hline Comercio & $20 \%$ & $21 \%$ & $20 \%$ & $20 \%$ & $19 \%$ & $20 \%$ & $21 \%$ & $19 \%$ & $20 \%$ & $20 \%$ & $18 \%$ & $20 \%$ & $20 \%$ & $20 \%$ \\
\hline Servicios monopólicos & $8 \%$ & $8 \%$ & $9 \%$ & $8 \%$ & $8 \%$ & $8 \%$ & $8 \%$ & $8 \%$ & $8 \%$ & $7 \%$ & $7 \%$ & $7 \%$ & $7 \%$ & $7 \%$ \\
\hline Financiero & $9 \%$ & $9 \%$ & $9 \%$ & $9 \%$ & $9 \%$ & $9 \%$ & $11 \%$ & $8 \%$ & $11 \%$ & $10 \%$ & $11 \%$ & $10 \%$ & $10 \%$ & $10 \%$ \\
\hline Administrativo & $7 \%$ & $7 \%$ & $7 \%$ & $6 \%$ & $7 \%$ & $7 \%$ & $6 \%$ & $6 \%$ & $6 \%$ & $7 \%$ & $6 \%$ & $8 \%$ & $7 \%$ & $7 \%$ \\
\hline Servicio & $13 \%$ & $14 \%$ & $14 \%$ & $13 \%$ & $12 \%$ & $13 \%$ & $12 \%$ & $13 \%$ & $13 \%$ & $11 \%$ & $12 \%$ & $12 \%$ & $12 \%$ & $13 \%$ \\
\hline Trabajo domestico & $3 \%$ & $3 \%$ & $4 \%$ & $4 \%$ & $4 \%$ & $3 \%$ & $3 \%$ & $4 \%$ & $4 \%$ & $4 \%$ & $4 \%$ & $4 \%$ & $4 \%$ & $4 \%$ \\
\hline \multicolumn{15}{|c|}{ Región de nacimiento en porcentaje } \\
\hline Otro país & $5 \%$ & $4 \%$ & $4 \%$ & $5 \%$ & $5 \%$ & $6 \%$ & $4 \%$ & $5 \%$ & $5 \%$ & $5 \%$ & $5 \%$ & $5 \%$ & $5 \%$ & $5 \%$ \\
\hline GBA & $45 \%$ & $46 \%$ & $44 \%$ & $45 \%$ & $44 \%$ & $45 \%$ & $44 \%$ & $44 \%$ & $43 \%$ & $44 \%$ & $44 \%$ & $44 \%$ & $44 \%$ & $45 \%$ \\
\hline NEA & $7 \%$ & $7 \%$ & $7 \%$ & $7 \%$ & $7 \%$ & $7 \%$ & $7 \%$ & $7 \%$ & $7 \%$ & $7 \%$ & $7 \%$ & $7 \%$ & $6 \%$ & $6 \%$ \\
\hline NOA & $11 \%$ & $11 \%$ & $12 \%$ & $12 \%$ & $12 \%$ & $10 \%$ & $11 \%$ & $11 \%$ & $11 \%$ & $11 \%$ & $11 \%$ & $11 \%$ & $11 \%$ & $10 \%$ \\
\hline Cuyo & $6 \%$ & $6 \%$ & $6 \%$ & $6 \%$ & $7 \%$ & $6 \%$ & $7 \%$ & $7 \%$ & $7 \%$ & $6 \%$ & $6 \%$ & $6 \%$ & $7 \%$ & $6 \%$ \\
\hline Pampa & $24 \%$ & $23 \%$ & $24 \%$ & $23 \%$ & $23 \%$ & $23 \%$ & $24 \%$ & $23 \%$ & $25 \%$ & $24 \%$ & $24 \%$ & $25 \%$ & $24 \%$ & $25 \%$ \\
\hline Patagonia & $2 \%$ & $2 \%$ & $2 \%$ & $2 \%$ & $2 \%$ & $3 \%$ & $3 \%$ & $3 \%$ & $3 \%$ & $3 \%$ & $3 \%$ & $3 \%$ & $3 \%$ & $3 \%$ \\
\hline Media años de educación & 11.53 & 11.67 & 11.59 & 11.69 & 11.62 & 11.77 & 11.88 & 11.91 & 11.94 & 11.98 & 12.04 & 12.13 & 12.26 & 12.29 \\
\hline Migrante en porcentaje & $27 \%$ & $26 \%$ & $27 \%$ & $25 \%$ & $26 \%$ & $26 \%$ & $25 \%$ & $25 \%$ & $25 \%$ & $25 \%$ & $25 \%$ & $24 \%$ & $24 \%$ & $24 \%$ \\
\hline $\mathrm{N}^{\circ}$ Observaciones & 6837 & 7222 & 7109 & 7538 & 7454 & 10651 & 10160 & 6522 & 10103 & 10148 & 9899 & 10207 & 9973 & 7469 \\
\hline
\end{tabular}

Fuente: Elaboración propia en base a EPH 
Cuadro 2: Estadísticas descriptivas de la muestra restringida, 2004-2010.

\begin{tabular}{|c|c|c|c|c|c|c|c|c|c|c|c|c|c|c|}
\hline Variable & I-2004 & II-2004 & I-2005 & II-2005 & $\mathrm{I}-2006$ & II-2006 & I-2007 & II-2007 & $\mathrm{I}-2008$ & II-2008 & I-2009 & II-2009 & $\mathrm{I}-2010$ & II-2010 \\
\hline Media ingreso laboral horario & 5.65 & 5.29 & 5.68 & 5.69 & 6.09 & 6.56 & 6.82 & 7.90 & 8.33 & 8.67 & 9.71 & 10.00 & 10.55 & 11.71 \\
\hline Porcentaje hombre & $60 \%$ & $59 \%$ & $61 \%$ & $59 \%$ & $58 \%$ & $58 \%$ & $57 \%$ & $58 \%$ & $57 \%$ & $57 \%$ & $58 \%$ & $59 \%$ & $62 \%$ & $64 \%$ \\
\hline Media edad & 29.44 & 29.40 & 29.49 & 29.49 & 29.47 & 29.63 & 29.49 & 29.64 & 29.63 & 29.62 & 29.67 & 29.66 & 29.66 & 29.75 \\
\hline Media educación jefe de hoga & 8.62 & 8.70 & 8.60 & 8.54 & 8.61 & 8.77 & 8.72 & 9.01 & 8.90 & 8.69 & 8.89 & 8.85 & 9.10 & 9.26 \\
\hline \multicolumn{15}{|c|}{ Ocupación jefe de hogar en porcentaje } \\
\hline Agro & $1 \%$ & $1 \%$ & $1 \%$ & $1 \%$ & $1 \%$ & $1 \%$ & $1 \%$ & $1 \%$ & $1 \%$ & $1 \%$ & $1 \%$ & $1 \%$ & $1 \%$ & $2 \%$ \\
\hline Industria baja & $5 \%$ & $4 \%$ & $5 \%$ & $4 \%$ & $4 \%$ & $5 \%$ & $4 \%$ & $5 \%$ & $3 \%$ & $4 \%$ & $4 \%$ & $3 \%$ & $4 \%$ & $4 \%$ \\
\hline Industria manufacturera & $5 \%$ & $4 \%$ & $4 \%$ & $4 \%$ & $5 \%$ & $6 \%$ & $6 \%$ & $6 \%$ & $6 \%$ & $6 \%$ & $4 \%$ & $3 \%$ & $3 \%$ & $4 \%$ \\
\hline Construcción & $4 \%$ & $7 \%$ & $6 \%$ & $7 \%$ & $6 \%$ & $7 \%$ & $7 \%$ & $5 \%$ & $6 \%$ & $8 \%$ & $7 \%$ & $8 \%$ & $8 \%$ & $9 \%$ \\
\hline Comercio & $11 \%$ & $13 \%$ & $15 \%$ & $15 \%$ & $15 \%$ & $15 \%$ & $16 \%$ & $15 \%$ & $13 \%$ & $11 \%$ & $13 \%$ & $14 \%$ & $13 \%$ & $13 \%$ \\
\hline Servicios monopólicos & $7 \%$ & $6 \%$ & $6 \%$ & $5 \%$ & $6 \%$ & $6 \%$ & $6 \%$ & $6 \%$ & $8 \%$ & $5 \%$ & $6 \%$ & $6 \%$ & $4 \%$ & $5 \%$ \\
\hline Financiero & $6 \%$ & $6 \%$ & $5 \%$ & $6 \%$ & $5 \%$ & $4 \%$ & $5 \%$ & $6 \%$ & $6 \%$ & $4 \%$ & $5 \%$ & $4 \%$ & $6 \%$ & $4 \%$ \\
\hline Administrativo & $5 \%$ & $5 \%$ & $4 \%$ & $5 \%$ & $5 \%$ & $5 \%$ & $4 \%$ & $4 \%$ & $4 \%$ & $5 \%$ & $4 \%$ & $6 \%$ & $5 \%$ & $6 \%$ \\
\hline Servicio & $8 \%$ & $10 \%$ & $13 \%$ & $10 \%$ & $10 \%$ & $9 \%$ & $10 \%$ & $9 \%$ & $10 \%$ & $8 \%$ & $9 \%$ & $9 \%$ & $8 \%$ & $10 \%$ \\
\hline Trabajo domestico & $5 \%$ & $4 \%$ & $4 \%$ & $4 \%$ & $5 \%$ & $3 \%$ & $5 \%$ & $6 \%$ & $5 \%$ & $7 \%$ & $5 \%$ & $5 \%$ & $6 \%$ & $5 \%$ \\
\hline \multicolumn{15}{|c|}{ Región de nacimiento en porcentaje } \\
\hline Otro país & $3 \%$ & $2 \%$ & $2 \%$ & $3 \%$ & $3 \%$ & $3 \%$ & $2 \%$ & $3 \%$ & $2 \%$ & $3 \%$ & $2 \%$ & $2 \%$ & $3 \%$ & $2 \%$ \\
\hline GBA & $51 \%$ & $51 \%$ & $50 \%$ & $52 \%$ & $50 \%$ & $48 \%$ & $47 \%$ & $51 \%$ & $50 \%$ & $50 \%$ & $50 \%$ & $48 \%$ & $48 \%$ & $47 \%$ \\
\hline NEA & $4 \%$ & $4 \%$ & $5 \%$ & $5 \%$ & $5 \%$ & $5 \%$ & $5 \%$ & $4 \%$ & $5 \%$ & $6 \%$ & $5 \%$ & $5 \%$ & $4 \%$ & $6 \%$ \\
\hline NOA & $10 \%$ & $12 \%$ & $12 \%$ & $12 \%$ & $12 \%$ & $11 \%$ & $12 \%$ & $10 \%$ & $10 \%$ & $11 \%$ & $12 \%$ & $12 \%$ & $12 \%$ & $11 \%$ \\
\hline Cuyo & $7 \%$ & $7 \%$ & $7 \%$ & $7 \%$ & $7 \%$ & $7 \%$ & $7 \%$ & $6 \%$ & $7 \%$ & $6 \%$ & $6 \%$ & $6 \%$ & $7 \%$ & $6 \%$ \\
\hline Pampa & $23 \%$ & $21 \%$ & $22 \%$ & $20 \%$ & $22 \%$ & $23 \%$ & $25 \%$ & $23 \%$ & $23 \%$ & $23 \%$ & $21 \%$ & $24 \%$ & $24 \%$ & $25 \%$ \\
\hline Patagonia & $2 \%$ & $2 \%$ & $1 \%$ & $2 \%$ & $2 \%$ & $2 \%$ & $3 \%$ & $3 \%$ & $3 \%$ & $3 \%$ & $3 \%$ & $2 \%$ & $2 \%$ & $3 \%$ \\
\hline Media años de educación & 12.05 & 11.96 & 11.76 & 11.58 & 11.64 & 11.83 & 11.99 & 11.93 & 12.06 & 11.76 & 12.05 & 11.94 & 12.02 & 12.02 \\
\hline Migrante en porcentaje & $13 \%$ & $13 \%$ & $14 \%$ & $13 \%$ & $15 \%$ & $13 \%$ & $13 \%$ & $13 \%$ & $12 \%$ & $14 \%$ & $11 \%$ & $14 \%$ & $12 \%$ & $14 \%$ \\
\hline $\mathbf{N}^{\circ}$ Observaciones & 1353 & 1490 & 1576 & 1692 & 1682 & 2522 & 2463 & 1695 & 2444 & 2581 & 2344 & 2518 & 2389 & 1739 \\
\hline
\end{tabular}

Fuente: Elaboración propia en base a $E P H$ 


\section{5- Problemas de selección muestral}

\section{Selección por co-residencia y selección de empleo}

En este trabajo se selecciona una muestra de jefes de hogar e hijos co-residentes. La selección se debe a que no es posible obtener información sobre los padres que no residen con sus hijos. En el caso que la selección no sea aleatoria, los resultados de las estimaciones del análisis pueden ser sesgados. Los ingresos de los jóvenes entre 26 y 35 años que viven con sus padres pueden no representar la distribución de ingresos del total de la población joven.

Por otro lado, se seleccionan aquellos hijos que están empleados ya que se necesita contar con variables de ingresos laborales individuales de los mismos para el análisis. Esto conlleva a un problema de selección dentro del empleo, pues "según los resultados económicos estándares, es probable que la selección dentro de la fuerza laboral o dentro del empleo esté correlacionada con los ingresos laborales potenciales" (Jiménez, 2011). El efecto de ambos problemas de selección es muy claro, ya que el sesgo de selección puede sobreestimar la desigualdad de oportunidades en el caso en que los hijos adultos que continúan viviendo con sus padres no tienen ingresos suficientes para vivir en forma independiente o deben sustentar a su familia a diferencia de los que viven sin sus padres. En este caso no podrán decidir en qué mercado laboral ofrecerse ya que es muy probable que al necesitar ingresos estén dispuestos a aceptar un ingreso inferior al que les corresponde según sus cualidades y conocimientos.

Por otro lado, la desigualdad de oportunidad puede ser subestimada en el caso en que los hijos que co-residen tienen la oportunidad de optar de vivir independientemente de sus padres y aún así eligen continuar viviendo junto a ellos, no así los que no viven con sus padres. El efecto se profundiza si los hijos que viven con sus padres pueden tener la oportunidad de estar desempleados más tiempo a fin de elegir condiciones laborales y salariales mejor que aquellos que viven solos.

La mayoría de las investigaciones que consideran ambas selecciones se centran en el estudio de movilidad inter-generacional, es el caso a nivel internacional de Nicoletti (2008) y Nicoletti y Francesconi (2006), y a nivel nacional Jiménez (2011) y Jiménez y Jiménez (2009). Estos autores corrigen por ambos sesgos empleando un modelo de selección múltiple, como generalización del modelo de selección clásico de Heckman (1979). 


\section{Modelo de selección múltiple}

El modelo de múltiple selección se caracteriza por dos reglas de selección, $\mathrm{Y}_{1 \mathrm{i}}$ e $\mathrm{Y}_{2 \mathrm{i}}$, correspondientes a la selección de co-residencia y la selección dentro del empleo. Ambas variables toman el valor uno si la regla de selección se satisface y son iguales a cero en otro caso. Con el fin de corregir el problema de doble selección se sigue el método utilizado por De Luca y Peracchi (2007), basado en el procedimiento de dos etapas propuesto por Poirier (1980) y desarrollado también por Ham (1982). En este estudio el modelo a estimar es:

$$
\begin{aligned}
& w_{i}^{*}=f(X)+u_{i}, \\
& Y_{1 i}=1\left(Y_{1 i}^{*} \geq 0\right), \\
& Y_{2 i}=1\left(Y_{2 i}^{*} \geq 0\right), \\
& w_{1 i}=w_{1 i}^{*} \text { si } Y_{1 i} Y_{2 i}=1,
\end{aligned}
$$

donde $X$ son variables explicativas aceptables y no aceptables, $w^{*}$ es una variable aleatoria continua latente de la variable logaritmo del ingreso laboral horario de la muestra no restringida de hijos y padres, , $\mathrm{Y}_{1}^{*}$ es una variable aleatoria continua latente de la probabilidad de un hijo residir con su padre e $\mathrm{Y}_{2}^{*}$ es una variable aleatoria continua latente de la probabilidad de estar empleado. Estas variables están relacionadas con sus contrapartes, variables observables w y $Y_{j}(j=1,2)$, a través de las reglas de selección (5), (6) y (7).

Se supone que el término de error, $u_{i}$ tiene media cero, las variables $X_{k}$ con $k=1, \ldots n$ son exógenas y que $f(X)=\beta X$ es una función lineal. También se supone que la probabilidad de co-residir y tener empleo $Y_{1 i}^{*}$ y $Y_{2 i}^{*}$, respectivamente, son función de un conjunto de variables exógenas observables $Z\left(m_{1}\left(z_{1 k}\right)\right.$ y $\left(m_{2}\left(z_{2 k}\right)\right)$ y no observables $\left(s_{1 \mathrm{i}}\right.$ y $\left.\mathrm{s}_{2 \mathrm{i}}\right)$, estas últimas con media cero. Esto es:

$$
\begin{gathered}
Y_{1 i}^{*}=m_{1}\left(z_{1 k}\right)+s_{1 i} \\
Y_{2 i}^{*}=m_{2}\left(z_{2 k}\right)+s_{2 i}
\end{gathered}
$$

Si ambos mecanismos de selección fueran aleatorios, las estimaciones por el método de MCO serían consistentes. Pero como es probable que la selección no sea aleatoria, los estimadores de MCO son inconsistentes puesto que: 
$E\left(w_{i} \mid f(X), Y_{1 i} Y_{2 i}=1\right)=f(X)+\sigma_{w i} E\left(u_{i} \mid f(X) ; s_{1 i}>-m_{1}\left(z_{1 k}\right) ; s_{2 i}>-m_{2}\left(z_{2 k}\right)\right)$

у $\quad E\left(u_{i} \mid f(X) ; s_{1 i}>-m_{1}\left(z_{1 k}\right) ; s_{2 i}>-m_{2}\left(z_{2 k}\right)\right) \neq 0$

Nicoletti (2008), explica que se puede obtener una estimación consistente, si se cumple que:

$E\left(u_{i} \mid f(X) ; s_{1 i}>-m_{1}\left(z_{1 k}\right) ; s_{2 i}>-m_{2}\left(z_{2 k}\right)\right)=E\left(u_{i} \mid X_{i}, Z_{i}, Y_{1 i}=1, Y_{2 i}=1\right)=g\left(p_{i}\right)$

donde $p_{i}$ es la probabilidad conjunta de selección condicional en un conjunto de variables explicativas relevantes $\left(Z_{i}\right)$,

$$
p_{i}=p\left(Z_{i}\right)=\operatorname{Pr}\left(Y_{1 i}=1, Y_{2 i}=1 \mid Z_{i}\right)
$$

y $g\left(\right.$. ) es una función desconocida de la probabilidad conjunta. Si $u_{i} \perp X_{k i}$ y $u_{i} \perp Z_{i}$ y el modelo de selección doble es un modelo índice bivariado latente entonces se satisface que,

$$
u_{i} \perp X_{i}\left|Y_{1 i}, Y_{2 i}, p_{i} \quad \wedge \quad u_{i} \perp Z_{i}\right| Y_{1 i}, Y_{2 i}, p_{i}
$$

y la condición (8) se cumple. Luego bajo esta condición es posible estimar las ecuaciones (1), (2) y (3) de forma consistente de la siguiente manera,

$$
\begin{aligned}
& \ln \left(w_{i}\right)=\beta_{0}+\beta_{N A} X_{N A i}+\beta_{A} X_{A i}+g\left(p_{i}\right)+\eta_{i} \\
& X_{A i}=\pi_{0}+\Pi X_{N A i}+g\left(p_{i}\right)+\varsigma_{i} \\
& \ln \left(w_{i}\right)=\delta_{0}+\delta X_{N A i}+g\left(p_{i}\right)+\omega_{i}
\end{aligned}
$$

donde $\eta_{i}$, $\varsigma_{i}$ y $\omega_{i}$ son términos de error con media cero. Para obtener la probabilidad conjunta de selección condicional $\widehat{p}_{l}$, se estima un modelo probit bivariado y en la segunda etapa se estiman las regresiones (1'), (2’) y (3’) por MCO. Al igual que Jiménez y Jiménez (2009), se aproxima $g($.$) con un polinomio de tercer orden en \widehat{p_{l}}$ para controlar por la probabilidad conjunta de selección. Se estiman los errores estándares con la técnica de bootstrap, debido a la heterocedasticidad que genera la inclusión de regresores estimados (De Luca y Peracchi, 2007).

Finalmente, se señala que la elección del rango etario (26-35 años) es muy probable que presente problemas de validez externa y por lo tanto no sea posible generalizar los resultados a otros grupos de edad o al total de la población. 


\section{Problema de variables omitidas}

Las variables no observables $u_{i}$ y $\varepsilon_{i}\left(\eta_{i}\right.$ y $\left.\omega_{i}\right)$, pueden estar relacionadas con las demás variables del modelo, las variables omitidas son el principal problema de estimación de la teoría de oportunidad. Este problema existe cuando las variables omitidas en el término de error están correlacionadas con las variables explicativas aceptables y no aceptables del modelo, y conlleva a que los parámetros estimados $\hat{\delta}$, $\widehat{\alpha} y \hat{\beta}$ sean sesgados. Según Bourguignon y otros (2007), una estrategia de variables instrumentales no es adecuada en el modelo propuesto, en particular para la forma reducida del modelo, ya que es muy difícil encontrar una variable que esté correlacionada con una variable no aceptable pero sí con el ingreso.

Con el fin de brindar conclusiones más robustas se calcularon intervalos de confianza de los indicadores de desigualdad de ingresos y oportunidades, y para ello se adoptó el método no paramétrico de bootstrap, con 100 réplicas y se estimaron intervalos del $95 \%$ de confianza.

\section{6- Resultados de estimaciones}

En esta sección se analizan los resultados de las estimaciones del modelo de probabilidad bivariado de co-residencia y empleo y del modelo estructural y reducido de igualdad de oportunidad. En todos los casos el período considerado es 2004-2010.

Las variables explicativas del modelo probit bivariado son edad, una dummy de estado civil que tiene valor 1 si es casado, una dummy asiste que toma valor 1 si asiste a un establecimiento educativo, una dummy de género que toma valor 1 si es hombre y dummies regionales. En particular la ecuación de selección de empleo incorpora además de las variables nombradas las variables asistencia (dummy que tiene valor 1 si el individuo posee algún plan social por el cual recibe un monto de dinero), años de educación y experiencia (edad al cuadrado).

Por otro lado, la ecuación de selección por co-residencia incluye las variables número de cuartos de la vivienda, propietario de vivienda, es decir que la familia no es inquilina; y por último, la cantidad de miembros de la familia.

Los resultados de la estimación del modelo de probit bivariado se presentan en el cuadro A1 del anexo y a continuación se analizan los resultados del mismo. La probabilidad de co-residir con los padres, ceteris paribus, es menor a mayor edad. Como se esperaba también es menos probable convivir con los padres, si el individuo está casado. El 
estado civil es la variable significativa al $1 \%$ con mayor efecto en la probabilidad de coresidencia. Los hombres son más proclives a vivir junto con los padres que las mujeres. También es más probable convivir si el joven asiste a un establecimiento educativo, aunque el grado de significancia es 5\%. Las variables respecto a la vivienda son significativas al $1 \%$. Cuanto mayor número de habitaciones en la vivienda es menos probable que convivan padres e hijos. Si las viviendas con menores números de habitaciones pertenecen a familias de estratos de ingresos bajo, es más probable que los jóvenes vivan junto a su familia porque no tienen los ingresos suficientes para vivir solos ó deciden usar sus ingresos como ayuda al sustento familiar. Si la vivienda es de propiedad familiar es más probable que co-residan. En cuanto a las variables regionales, en los casos que son significativas sus signos son positivos y las regiones cuyos residentes jóvenes tienen mayor probabilidad de vivir con sus padres son Cuyo y GBA. En el caso de la ecuación de selección de empleo, los años de educación son significativos y positivos salvo en el 2008 y 2010 que no son significativos. El hombre es más probable que tenga empleo que la mujer. Asistir a un establecimiento educativo reduce la probabilidad de tener empleo, esta variable es significativa al $1 \%$ y negativa en todos los años. Poseer un plan social también reduce la probabilidad de ingresar a la PEA. Por último, las variables regiones presentan signo negativo y para algunos años no son significativas.

El Cuadro 3 presenta las estimaciones del modelo estructural corregido por doble selección incluyendo como regresor la probabilidad estimada del modelo probit bivariado. Las estimaciones del modelo estructural sugieren, ceteris paribus, que los hombres perciben mayores ingresos que las mujeres (en promedio 11\%), el coeficiente estimado es positivo y significativo al $1 \%$.

La educación del jefe de hogar influye positivamente en los ingresos de sus hijos en la mayoría de los años analizados. Un año adicional de educación del jefe de hogar aumenta un $1 \%$ el ingreso de sus hijos.

Con respecto a la ocupación del jefe de hogar, la significatividad y signos de las variables dummies son erráticos y no se observa un patrón definido. En general, los padres ocupados en el sector financiero y administrativo tienen un efecto positivo en los ingresos de sus hijos respecto a los padres ocupados en el sector comercio. Para los primeros años del período analizado se observa que los jefes de hogar ocupados en el sector servicio tienen un efecto negativo sobre los ingresos de sus hijos, pero dicho efecto se revierte en la segunda etapa del período donde el estimador pasa a ser positivo. 
Cuadro 3: Estimaciones del modelo estructural corregido por sesgo de selección, 2004-2010

\begin{tabular}{|c|c|c|c|c|c|c|c|c|c|c|c|c|c|c|}
\hline $\begin{array}{l}\text { Logaritmo Ingreso } \\
\text { Laboral Horario }\end{array}$ & $\mathrm{I}-2004$ & II-2004 & I-2005 & II-2005 & I-2006 & II-2006 & I-2007 & II-2007 & I-2008 & II-2008 & I-2009 & II-2009 & I-2010 & II-2010 \\
\hline hombre & $\begin{array}{c}0.0417 \\
(0.0385)\end{array}$ & $\begin{array}{l}0.206^{* * *} \\
(0.0411)\end{array}$ & $\begin{array}{l}0.113^{* * *} \\
(0.0402)\end{array}$ & $\begin{array}{l}0.111^{* * *} \\
(0.0320)\end{array}$ & $\begin{array}{c}0.0963^{* * *} \\
(0.0374)\end{array}$ & $\begin{array}{l}0.131^{* * *} \\
(0.0308)\end{array}$ & $\begin{array}{l}0.0615^{* *} \\
(0.0259)\end{array}$ & $\begin{array}{c}0.0947^{* * *} \\
(0.0346)\end{array}$ & $\begin{array}{l}0.145^{* * *} \\
(0.0257)\end{array}$ & $\begin{array}{l}0.150^{* * *} \\
(0.0263)\end{array}$ & $\begin{array}{l}0.166^{* * *} \\
(0.0306)\end{array}$ & $\begin{array}{l}0.141^{* * *} \\
(0.0293)\end{array}$ & $\begin{array}{c}0.0828^{* * *} \\
(0.0308)\end{array}$ & $\begin{array}{c}0.0582 \\
(0.0371)\end{array}$ \\
\hline educjefe & $\begin{array}{l}0.0165^{* * *} \\
(0.00628)\end{array}$ & $\begin{array}{c}0.0168^{* * *} \\
(0.00516)\end{array}$ & $\begin{array}{l}0.0259 * * * \\
(0.00514)\end{array}$ & $\begin{array}{l}0.00908^{* *} \\
(0.00430)\end{array}$ & $\begin{array}{l}0.0216^{* * *} \\
(0.00512)\end{array}$ & $\begin{array}{l}0.0227^{* * *} \\
(0.00403)\end{array}$ & $\begin{array}{c}0.0178 * * * \\
(0.00417)\end{array}$ & $\begin{array}{l}0.0131^{* * *} \\
(0.00443)\end{array}$ & $\begin{array}{c}0.00614 \\
(0.00444)\end{array}$ & $\begin{array}{c}0.00509 \\
(0.00390)\end{array}$ & $\begin{array}{c}0.00346 \\
(0.00359)\end{array}$ & $\begin{array}{l}0.00852^{* *} \\
(0.00352)\end{array}$ & $\begin{array}{l}0.0197^{* * * *} \\
(0.00343)\end{array}$ & $\begin{array}{l}0.0156^{* * *} \\
(0.00523)\end{array}$ \\
\hline indbajaocupjef & $\begin{array}{l}0.0496 \\
(0.116)\end{array}$ & $\begin{array}{l}0.160^{* *} \\
(0.0791)\end{array}$ & $\begin{array}{c}0.233^{* *} \\
(0.104)\end{array}$ & $\begin{array}{c}0.0952 \\
(0.0758)\end{array}$ & $\begin{array}{l}-0.0382 \\
(0.0753)\end{array}$ & $\begin{array}{c}0.0289 \\
(0.0980)\end{array}$ & $\begin{array}{c}0.153 \\
(0.0988)\end{array}$ & $\begin{array}{l}-0.0669 \\
(0.122)\end{array}$ & $\begin{array}{l}-0.127^{*} \\
(0.0691)\end{array}$ & $\begin{array}{l}-0.0424 \\
(0.0681)\end{array}$ & $\begin{array}{c}-0.124 \\
(0.0923)\end{array}$ & $\begin{array}{l}0.212^{* *} \\
(0.106)\end{array}$ & $\begin{array}{l}-0.0373 \\
(0.0981)\end{array}$ & $\begin{array}{c}0.177 \\
(0.115)\end{array}$ \\
\hline indmanufocupjef & $\begin{array}{l}-0.0814 \\
(0.0781)\end{array}$ & $\begin{array}{c}0.125 \\
(0.0947)\end{array}$ & $\begin{array}{c}0.0667 \\
(0.0827)\end{array}$ & $\begin{array}{c}0.135^{*} \\
(0.0734)\end{array}$ & $\begin{array}{c}0.0628 \\
(0.0687)\end{array}$ & $\begin{array}{c}0.0879 \\
(0.0656)\end{array}$ & $\begin{array}{l}0.268^{* * *} \\
(0.0664)\end{array}$ & $\begin{array}{c}0.0370 \\
(0.0811)\end{array}$ & $\begin{array}{r}-0.0420 \\
(0.0629)\end{array}$ & $\begin{array}{c}0.0260 \\
(0.0555)\end{array}$ & $\begin{array}{l}-0.0582 \\
(0.0886)\end{array}$ & $\begin{array}{l}0.140^{* * *} \\
(0.0715)\end{array}$ & $\begin{array}{l}-0.0102 \\
(0.0826)\end{array}$ & $\begin{array}{c}0.152 \\
(0.135)\end{array}$ \\
\hline constocupjef & $\begin{array}{c}-0.196 * * \\
(0.0907)\end{array}$ & $\begin{array}{c}-0.0696 \\
(0.0669)\end{array}$ & $\begin{array}{c}-0.0582 \\
(0.0687)\end{array}$ & $\begin{array}{l}-0.0927 \\
(0.0564)\end{array}$ & $\begin{array}{c}0.130^{*} \\
(0.0747)\end{array}$ & $\begin{array}{c}-0.0464 \\
(0.0508)\end{array}$ & $\begin{array}{r}-0.0255 \\
(0.0524)\end{array}$ & $\begin{array}{c}0.0954 \\
(0.0642)\end{array}$ & $\begin{array}{r}-0.0363 \\
(0.0483)\end{array}$ & $\begin{array}{c}0.0533 \\
(0.0537)\end{array}$ & & $\begin{array}{l}0.109^{* *} \\
(0.0497)\end{array}$ & & $\begin{array}{c}-0.0134 \\
(0.0635)\end{array}$ \\
\hline agroocupjef & $\begin{array}{l}-0.155 \\
(0.161)\end{array}$ & $\begin{array}{l}-0.252^{*} \\
(0.140)\end{array}$ & $\begin{array}{l}-0.133 \\
(0.158)\end{array}$ & $\begin{array}{c}-0.00981 \\
(0.125)\end{array}$ & $\begin{array}{l}0.0153 \\
(0.113)\end{array}$ & $\begin{array}{l}-0.0953 \\
(0.107)\end{array}$ & $\begin{array}{l}0.0799 \\
(0.101)\end{array}$ & $\begin{array}{c}0.178 \\
(0.117)\end{array}$ & $\begin{array}{c}0.102 \\
(0.102)\end{array}$ & $\begin{array}{c}0.0326 \\
(0.0968)\end{array}$ & $\begin{array}{l}0.0833 \\
(0.128)\end{array}$ & $\begin{array}{c}-0.127 \\
(0.0851)\end{array}$ & $\begin{array}{c}0.130 \\
(0.0938)\end{array}$ & $\begin{array}{l}-0.0224 \\
(0.139)\end{array}$ \\
\hline ssmonocupjef & $\begin{array}{l}-0.0365 \\
(0.102)\end{array}$ & $\begin{array}{r}-0.0423 \\
(0.0855)\end{array}$ & $\begin{array}{r}-0.0551 \\
(0.0671)\end{array}$ & $\begin{array}{r}-0.00793 \\
(0.0840)\end{array}$ & $\begin{array}{r}-0.0550 \\
(0.0757)\end{array}$ & $\begin{array}{r}-0.0753 \\
(0.0568)\end{array}$ & $\begin{array}{l}0.146^{* *} \\
(0.0578)\end{array}$ & $\begin{array}{c}0.123 \\
(0.0752)\end{array}$ & $\begin{array}{l}-0.0 \\
0.05\end{array}$ & $\begin{array}{c}0.0127 \\
(0.0548)\end{array}$ & $\begin{array}{l}-0.00749 \\
(0.0583)\end{array}$ & $\begin{array}{c}0.0296 \\
(0.0567)\end{array}$ & $\begin{array}{c}0.0339 \\
(0.0686)\end{array}$ & $\begin{array}{c}-0.110 \\
(0.0850)\end{array}$ \\
\hline fcieroocupjef & $\begin{array}{c}0.145 \\
(0.100)\end{array}$ & $\begin{array}{c}0.115 \\
(0.0716)\end{array}$ & $\begin{array}{c}0.0202 \\
(0.0963)\end{array}$ & & $\begin{array}{c}0.108^{*} \\
(0.0612)\end{array}$ & $\begin{array}{c}0.0819 \\
(0.0743)\end{array}$ & $\begin{array}{c}0.0666 \\
(0.0505)\end{array}$ & $\begin{array}{c}0.0665 \\
(0.0851)\end{array}$ & & $\begin{array}{l}0.294^{* * *} \\
(0.0740)\end{array}$ & $\begin{array}{l}0.208^{* * *} \\
(0.0743)\end{array}$ & $\begin{array}{c}0.0990 \\
(0.0728)\end{array}$ & $\begin{array}{c}0.154^{* *} \\
(0.0768)\end{array}$ & $\begin{array}{c}0.276^{* * *} \\
(0.0770)\end{array}$ \\
\hline administocupjef & $\begin{array}{c}0.0142 \\
(0.0915)\end{array}$ & $\begin{array}{r}-0.0710 \\
(0.0744)\end{array}$ & $\begin{array}{c}0.0508 \\
(0.0764)\end{array}$ & $\begin{array}{r}-0.0286 \\
(0.0634)\end{array}$ & $\begin{array}{c}0.0665 \\
(0.0656)\end{array}$ & $\begin{array}{c}0.0205 \\
(0.0567)\end{array}$ & $\begin{array}{c}0.197 * * * \\
(0.0561)\end{array}$ & & & $\begin{array}{l}0.156^{* * *} \\
(0.0479)\end{array}$ & & $\begin{array}{l}0.161^{* * *} \\
(0.0472)\end{array}$ & $\begin{array}{c}0.275^{* * *} \\
(0.0433)\end{array}$ & $\begin{array}{l}0.137^{* *} \\
(0.0652)\end{array}$ \\
\hline ssocupjef & $\begin{array}{c}0.121 * \\
(0.0679)\end{array}$ & $\begin{array}{r}-0.0855 \\
(0.0657)\end{array}$ & $\begin{array}{c}-0.151^{* * * *} \\
(0.0582)\end{array}$ & $\begin{array}{l}-0.0527 \\
(0.0514)\end{array}$ & & & & & & & & & & $\begin{array}{c}0.103 \\
(0.0638)\end{array}$ \\
\hline domesticoocupjef & $\begin{array}{l}-0.162 \\
(0.141)\end{array}$ & $\begin{array}{c}0.0246 \\
(0.0942)\end{array}$ & $\begin{array}{c}-0.483^{* * *} \\
(0.0872)\end{array}$ & $\begin{array}{l}-0.0868 \\
(0.0749)\end{array}$ & $\begin{array}{c}-0.0287 \\
(0.0618)\end{array}$ & $\begin{array}{c}0.0792 \\
(0.0625)\end{array}$ & $\begin{array}{c}-1.41 \mathrm{e}-05 \\
(0.0653)\end{array}$ & & & & $\begin{array}{c}-0.160^{* * *} \\
(0.0540)\end{array}$ & $\begin{array}{c}-0.131^{* *} \\
(0.0660)\end{array}$ & & $\begin{array}{c}0.0770 \\
(0.0677)\end{array}$ \\
\hline nacgba & $\begin{array}{l}-0.187 \\
(0.176)\end{array}$ & $\begin{array}{l}0.365^{* *} \\
(0.174)\end{array}$ & $\begin{array}{c}0.497 * * * \\
(0.144)\end{array}$ & $\begin{array}{c}0.787^{* * *} \\
(0.205)\end{array}$ & $\begin{array}{c}0.907 * * * \\
(0.173)\end{array}$ & $\begin{array}{l}0.0979 \\
(0.136)\end{array}$ & $\begin{array}{c}0.463 * * * \\
(0.117)\end{array}$ & $\begin{array}{l}-0.0126 \\
(0.141)\end{array}$ & $\begin{array}{l}0.243^{* *} \\
(0.117)\end{array}$ & $\begin{array}{l}-0.104 \\
(0.101)\end{array}$ & $\begin{array}{c}0.161 \\
(0.126)\end{array}$ & $\begin{array}{c}0.105 \\
(0.122)\end{array}$ & $\begin{array}{c}0.324^{* * *} \\
(0.112)\end{array}$ & $\begin{array}{l}0.360^{*} \\
(0.198)\end{array}$ \\
\hline nacnea & $\begin{array}{c}-0.868^{* * *} \\
(0.170)\end{array}$ & & & & $\begin{array}{r}0.44 \\
(0.1\end{array}$ & & & & & $\begin{array}{c}-0.464^{* * *} \\
(0.0970)\end{array}$ & & $\begin{array}{c}-0.343^{* * *} \\
(0.124)\end{array}$ & & \\
\hline nacnoa & $\begin{array}{c}-0.678^{* * *} \\
(0.156)\end{array}$ & & & & $\begin{array}{c}0.463^{* * *} \\
(0.166)\end{array}$ & $\begin{array}{c}-0.301^{* *} \\
(0.135)\end{array}$ & & $\begin{array}{c}-0.371 * * * \\
(0.137)\end{array}$ & & $\begin{array}{c}-0.386 * * * \\
(0.0990)\end{array}$ & & $\begin{array}{c}-0.280^{* *} \\
(0.122)\end{array}$ & & $\begin{array}{l}0.0500 \\
(0.198)\end{array}$ \\
\hline naccuyo & $\begin{array}{c}-0.618^{* * *} \\
(0.162)\end{array}$ & $\begin{array}{l}0.0917 \\
(0.175)\end{array}$ & $\begin{array}{c}0.107 \\
(0.140)\end{array}$ & $\begin{array}{c}0.520^{* * *} \\
(0.191)\end{array}$ & $\begin{array}{c}0.574^{* * *} \\
(0.174)\end{array}$ & $\begin{array}{l}-0.174 \\
(0.134)\end{array}$ & $\begin{array}{c}0.147 \\
(0.114)\end{array}$ & $\begin{array}{c}-0.327^{* *} \\
(0.131)\end{array}$ & $\begin{array}{l}0.0129 \\
(0.126)\end{array}$ & $\begin{array}{c}-0.222^{* *} \\
(0.104)\end{array}$ & & $\begin{array}{l}-0.144 \\
(0.124)\end{array}$ & & $\begin{array}{c}0.138 \\
(0.194)\end{array}$ \\
\hline nacpampa & $\begin{array}{c}-0.432^{* * * *} \\
(0.154)\end{array}$ & $\begin{array}{c}0.169 \\
(0.173)\end{array}$ & $\begin{array}{c}0.299 * * \\
(0.135)\end{array}$ & $\begin{array}{c}0.656 * * * \\
(0.190)\end{array}$ & $\begin{array}{c}0.749 * * * \\
(0.166)\end{array}$ & $\begin{array}{l}-0.0103 \\
(0.131)\end{array}$ & $\begin{array}{c}0.359 * * * \\
(0.117)\end{array}$ & $\begin{array}{c}-0.0922 \\
(0.137)\end{array}$ & $\begin{array}{c}0.135 \\
(0.114)\end{array}$ & & & & & $\begin{array}{c}0.273 \\
(0.192)\end{array}$ \\
\hline nacpata & $\begin{array}{c}-0.174 \\
(0.161)\end{array}$ & $\begin{array}{l}0.415^{* *} \\
(0.194)\end{array}$ & $\begin{array}{c}0.523^{* * *} \\
(0.146)\end{array}$ & $\begin{array}{c}0.806^{* * *} \\
(0.197)\end{array}$ & $\begin{array}{c}0.939^{* * *} \\
(0.171)\end{array}$ & $\begin{array}{c}0.205 \\
(0.128)\end{array}$ & $\begin{array}{c}0.628^{* * *} \\
(0.114)\end{array}$ & $\begin{array}{c}0.307^{* *} \\
(0.142)\end{array}$ & $\begin{array}{c}0.412 * * * \\
(0.111)\end{array}$ & $\begin{array}{l}0.0487 \\
(0.101)\end{array}$ & $\begin{array}{l}0.212^{*} \\
(0.126)\end{array}$ & $\begin{array}{l}0.261^{*} \\
(0.138)\end{array}$ & $\begin{array}{c}0.517 * * * \\
(0.119)\end{array}$ & $\begin{array}{c}0.498 * * \\
(0.194)\end{array}$ \\
\hline aedu & $\begin{array}{l}0.0623^{* * *} * \\
(0.00646)\end{array}$ & $\begin{array}{l}0.0852^{* * * *} \\
(0.00603)\end{array}$ & $\begin{array}{c}0.0625^{* * *} \\
(0.00649)\end{array}$ & $\begin{array}{c}0.0687^{* * *} \\
(0.00577)\end{array}$ & $\begin{array}{c}0.0737^{* * *} \\
(0.00589)\end{array}$ & $\begin{array}{c}0.0711^{* * *} \\
(0.00483)\end{array}$ & $\begin{array}{c}0.0682^{* * *} \\
(0.00499)\end{array}$ & $\begin{array}{c}0.0802 * * * \\
(0.00513)\end{array}$ & $\begin{array}{l}0.0709 * * * \\
(0.00437)\end{array}$ & $\begin{array}{l}0.0782^{* * * *} \\
(0.00469)\end{array}$ & $\begin{array}{c}0.0802 * * * \\
(0.00485)\end{array}$ & $\begin{array}{c}0.0666^{* * * *} \\
(0.00466)\end{array}$ & $\begin{array}{l}0.0587^{* * * *} \\
(0.00577)\end{array}$ & $\begin{array}{c}0.0632^{* * *} \\
(0.00705)\end{array}$ \\
\hline migrante & $\begin{array}{c}0.0370 \\
(0.0549)\end{array}$ & $\begin{array}{c}0.0905 \\
(0.0550)\end{array}$ & $\begin{array}{c}0.0958 \\
(0.0647)\end{array}$ & $\begin{array}{l}0.0981^{* *} \\
(0.0470)\end{array}$ & $\begin{array}{l}0.169 * * * \\
(0.0551)\end{array}$ & $\begin{array}{l}0.122^{* * *} \\
(0.0419)\end{array}$ & $\begin{array}{l}0.184^{* * *} \\
(0.0395)\end{array}$ & $\begin{array}{c}0.0105 \\
(0.0548)\end{array}$ & $\begin{array}{c}0.0651 \\
(0.0436)\end{array}$ & $\begin{array}{c}0.0469 \\
(0.0349)\end{array}$ & $\begin{array}{c}0.0645 \\
(0.0469)\end{array}$ & $\begin{array}{l}-0.0356 \\
(0.0427)\end{array}$ & $\begin{array}{c}0.130^{* * *} \\
(0.0436)\end{array}$ & $\begin{array}{c}0.188^{* * *} \\
(0.0466)\end{array}$ \\
\hline prob & & $\begin{array}{c}0.208 \\
(0.692)\end{array}$ & & $\begin{array}{l}-0.349 \\
(0.622)\end{array}$ & $\begin{array}{c}-2.245^{* * *} \\
(0.687)\end{array}$ & $\begin{array}{c}-1.224^{*} \\
(0.631)\end{array}$ & $\begin{array}{l}-0.129 \\
(0.629)\end{array}$ & & & & & & & $\begin{array}{c}-1.548^{* * *} \\
(0.573)\end{array}$ \\
\hline probcuadrado & $\begin{array}{c}-3.876^{* *} \\
(1.853)\end{array}$ & $\begin{array}{l}-0.815 \\
(1.749)\end{array}$ & & $\begin{array}{c}1.091 \\
(1.462)\end{array}$ & $\begin{array}{c}4.814^{* * *} \\
(1.647)\end{array}$ & $\begin{array}{l}3.082^{* *} \\
(1.442)\end{array}$ & $\begin{array}{c}0.555 \\
(1.445)\end{array}$ & $\begin{array}{c}1.091 \\
(1.813)\end{array}$ & $\begin{array}{l}-2.533^{*} \\
(1.329)\end{array}$ & & $\begin{array}{l}-2.082^{*} \\
(1.211)\end{array}$ & & $\begin{array}{c}2.145 \\
(1.315)\end{array}$ & $\begin{array}{c}4.224^{* * *} \\
(1.341)\end{array}$ \\
\hline probcubo & $\begin{array}{l}2.432^{*} \\
(1.284)\end{array}$ & $\begin{array}{c}0.462 \\
(1.200)\end{array}$ & $\begin{array}{l}-1.804^{*} \\
(1.072)\end{array}$ & $\begin{array}{l}-0.983 \\
(0.968)\end{array}$ & $\begin{array}{c}-3.043^{* * *} \\
(1.099)\end{array}$ & $\begin{array}{c}-2.162^{* *} \\
(0.930)\end{array}$ & $\begin{array}{l}-0.640 \\
(0.959)\end{array}$ & $\begin{array}{l}-0.925 \\
(1.159)\end{array}$ & $\begin{array}{c}1.329 \\
(0.866)\end{array}$ & $\begin{array}{l}1.656^{*} \\
(0.915)\end{array}$ & $\begin{array}{c}1.127 \\
(0.827)\end{array}$ & & $\begin{array}{c}-1.499^{*} \\
(0.836)\end{array}$ & $\begin{array}{c}-3.120^{* * * *} \\
(0.877)\end{array}$ \\
\hline constante & $\begin{array}{c}0.686^{* * *} \\
(0.190)\end{array}$ & $\begin{array}{l}-0.0669 \\
(0.196)\end{array}$ & $\begin{array}{c}0.189 \\
(0.173)\end{array}$ & $\begin{array}{l}-0.0448 \\
(0.218)\end{array}$ & $\begin{array}{l}-0.0397 \\
(0.197)\end{array}$ & $\begin{array}{c}0.602^{* * *} \\
(0.171)\end{array}$ & $\begin{array}{l}0.294^{*} \\
(0.154)\end{array}$ & $\begin{array}{c}0.671^{* * *} \\
(0.180)\end{array}$ & $\begin{array}{c}0.748^{* * *} \\
(0.154)\end{array}$ & $\begin{array}{c}0.915^{* * *} \\
(0.126)\end{array}$ & $\begin{array}{c}0.916^{* * *} \\
(0.144)\end{array}$ & $\begin{array}{c}1.033^{* * *} \\
(0.144)\end{array}$ & $\begin{array}{c}1.128^{* * *} \\
(0.149)\end{array}$ & $\begin{array}{c}1.064^{* * *} \\
(0.217)\end{array}$ \\
\hline & & & & & & & & & & & & & & \\
\hline & & & & & & & & & & & & & & 0.206 \\
\hline F test & 0 & 0 & 0 & 0 & 0 & 0 & 0 & 0 & 0 & 0 & 0 & 0 & 0 & 0 \\
\hline
\end{tabular}

Nota: Errores estándar en paréntesis ajustados con bootstrap de 100 replicaciones. ${ }^{* * *}$ significativo al $1 \%,{ }^{* *}$ significativo al $5 \%,{ }^{*}$ significativo al $10 \%$

Fuente: Elaboración propia en base a EPH 
Por último, se observa que para algunos años, los hijos de empleados domésticos perciben menores ingresos que los hijos de jefe de hogar empleados en el sector comercio.

Respecto a los efectos sobre el ingreso de acuerdo a la región de nacimiento en comparación con los nacidos en otros países, el coeficiente estimado para GBA es positivo y significativo al $5 \%$ y $1 \%$ para la mayoría de los años. Tanto los jóvenes nacidos en GBA como en Patagonia perciben mayores ingresos que los nacidos en otro país, en promedio, un $28 \%$ y $39 \%$ respectivamente. Por el contrario, los jóvenes nacidos en el norte del país tienen menos ingresos que los nacidos en otro país. Aquellos nacidos en NEA, perciben en promedio $14 \%$ menos de ingresos que los nacidos en otro país y los nacidos en NOA en promedio un $10 \%$ menos de ingreso.

Como se esperaba los años de educación tienen un efecto significativo al $1 \%$ y positivo, un año adicional de educación incrementa en promedio un $7 \%$ el ingreso, manteniendo todas las demás variables constantes.

Las estimaciones del modelo reducido corregido por doble selección que se presentan en el Cuadro 4, muestran que el coeficiente estimado de la variable hombre, a diferencia del modelo estructural, deja de ser significativo para la mayoría de los años y los valores bajos de los estimadores significativos sugieren un menor efecto de esta variable en los ingresos.

La educación del jefe de hogar continúa teniendo efectos positivos y significativos al 1\%. En promedio, un año más de educación del jefe de hogar manteniendo todo lo demás constante, incrementa en $4 \%$ los ingresos de sus hijos. En cuanto a la ocupación del jefe de hogar la estructura de ingresos no varía en relación al modelo estructural. Los hijos de jefe de hogar ocupado en el sector financiero, administrativo e industrial, ceteris paribus, perciben mayores ingresos mientras que los hijos con jefe de hogar ocupados en la construcción y empleos domésticos perciben menores ingresos. Respecto a la región de nacimiento los efectos positivos de haber nacido en GBA y en Patagonia son menores que en el modelo estructural mientras que los efectos negativos de haber nacido en NEA y NOA se intensifican. 
Cuadro 4: Estimaciones del modelo reducido corregido por sesgo de selección, 2004-2010

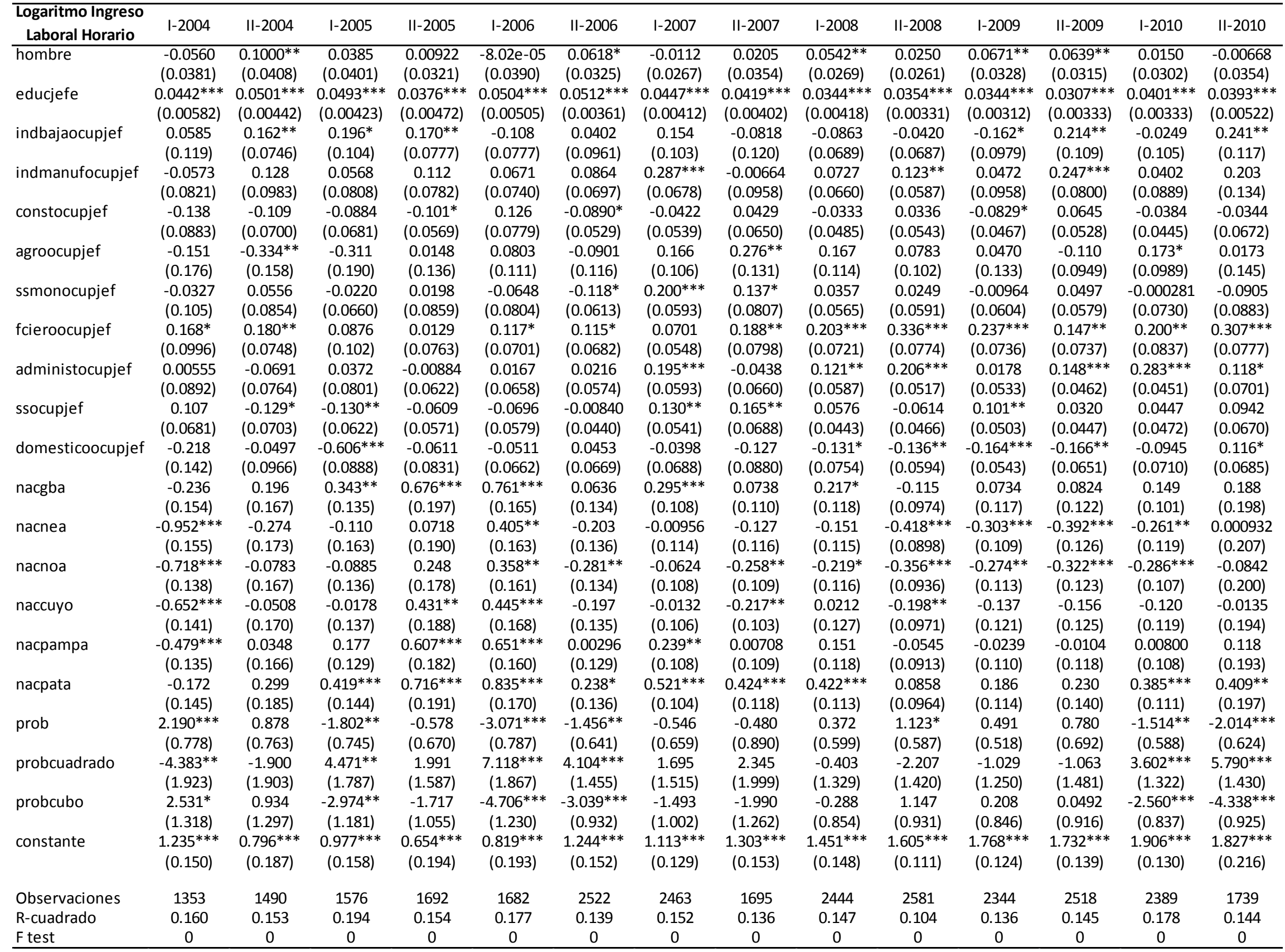

Nota: Errores estándar en paréntesis ajustados con bootstrap de 100 replicaciones. ${ }^{* \star}$ significativo al $1 \%,{ }^{* *}$ significativo al $5 \%,{ }^{*}$ significativo al $10 \%$

Fuente: Elaboración propia en base a EPH 
Al analizar las estimaciones del modelo estructural y reducido con sesgo tratado y las estimaciones sin tratarse se encuentra que el sesgo de doble selección subestima el efecto de la variable género y sobreestima el efecto de la educación del jefe de hogar y años de educación ${ }^{3}$. También se halla que en la mayoría de los años analizados el sesgo subestima el efecto de las variables dummies de ocupación del jefe de hogar. No obstante todavía no es claro cuál es el efecto del sesgo en la distribución del ingreso y oportunidades, el mismo se analiza en la sección 7.

Cuando se analizan las ecuaciones de las variables aceptables (Cuadro A2 y A3 en Anexo), ceteris paribus, para el caso de educación se observa que el coeficiente de género es negativo y significativo al $1 \%$, es decir que las mujeres están más tiempo educándose. Como se esperaba, la educación del jefe de hogar tiene un efecto positivo y significativo en los años de educación de sus hijos. En los últimos años, los jóvenes con jefes de hogar ocupados en el sector de industria manufacturera y financiero tienen más años de educación que aquellos cuyos jefes de hogar pertenecen al sector de construcción ó poseen empleo doméstico. No se observa un patrón específico para el caso de las regiones de nacimiento.

En el caso de la ecuación de la variable aceptable migración, la educación del jefe hogar no incide en la decisión de migración de los hijos. El coeficiente estimado de educación del jefe de hogar es en algunos años estadísticamente no significativo y en otros económicamente no significativo.

Por el lado de ocupación del jefe de hogar si bien no hay un patrón específico es más probable que sean migrantes los individuos cuyos jefes de hogar trabajan en empleos domésticos y en el sector construcción. Finalmente, como es de esperar es menos probable que sean migrantes las personas nacidas en GBA que las nacidas en el norte y la región patagónica del país.

En resumen, las estimaciones se adecuan a la evidencia empírica. Como es usual en esta literatura se encuentra para la muestra joven que la variable educación del jefe de hogar es significativa y positiva para todo el período de análisis y aunque no se observa un patrón definido, la ocupación del jefe de hogar tiene efectos en los ingresos de los hijos positivos o negativos según en qué sector se encuentre ocupado.

\footnotetext{
${ }^{3}$ Los resultados de las estimaciones del modelo estructural y reducido de igualdad de oportunidad sin corregir por sesgo de selección están disponibles para quien lo solicite.
} 


\section{7- Análisis de igualdad de oportunidades}

En esta sección se aborda el análisis de desigualdad de oportunidades haciendo uso de indicadores de desigualdad de Gini y Theil. Como se dijo anteriormente se entiende por desigualdad de oportunidades en ingresos a la proporción de desigualdad de ingresos que podría disminuir si las variables socialmente no aceptables no afectaran los ingresos de los individuos.

Con el objeto de medir la desigualdad de oportunidades se estiman ingresos individuales, eliminando el efecto de las variables no aceptables, a partir de los coeficientes estimados de la sección anterior para cada año del período considerado. Para calcular estos ingresos, se parte de una línea base donde a todos los individuos de la muestra se les imputan las mismas características socialmente no aceptables.

Se asume que todos los individuos de la muestra joven son hombres, nacidos en GBA, sus jefes de hogar poseen la misma educación (se les imputa la media de años de educación de cada año del período de interés) y trabajan en el sector construcción. A partir de estos supuestos se computa a cada individuo su ingreso estimado. Luego de este procedimiento se calculan los índices de desigualdad de Gini y de Theil de las nuevas distribuciones de ingresos.

Se consideran dos tipos de ingresos contrafácticos, el primero se estima a partir de la ecuación ( $3^{\prime}$ ) del modelo reducido:

$$
\widetilde{w}_{i}=e^{\widehat{\delta}_{0}+\widehat{\delta} \bar{X}_{N A} g(\bar{p})+\widehat{\omega}_{i}},
$$

en donde se supone que todos los individuos de la muestra co-residen con sus padres y poseen empleo, es decir que la probabilidad conjunta $p$ es 1 .

Es fácil notar que al calcular los ingresos contrafácticos $\widetilde{w}$, se elimina el efecto directo de las variables no aceptables e implícitamente el efecto indirecto de las mismas que generan a través de las variables aceptables. Es decir, que la diferencia entre los ingresos proviene de las características no observables (los residuos estimados, $\widehat{\omega}_{i}$ ). Para analizar el efecto total de las variables no aceptables sobre la distribución de ingresos, se calculan los índices de desigualdad de los ingresos contrafácticos $\widetilde{w}^{4}$.

Por otro lado, también es interesante analizar cuál es el efecto directo que tienen las variables no aceptables sobre los ingresos, para ello se utiliza las estimaciones de los

\footnotetext{
${ }^{4}$ Cabe notar que si la distribución de los inobservables estimados $\widehat{\omega}_{\mathrm{i}}$ no es independiente de las variables no aceptables o algunas variables no aceptables son inobservables, no se estaría eliminando el efecto total de las mismas en la distribución de los ingresos sino sólo una parte.
} 
coeficientes del modelo estructural y una vez más se estiman los ingresos suponiendo que las variables no aceptables son las mismas para todos los individuos. En este caso al calcular los ingresos contrafácticos $\breve{w}^{d}$ se eliminan las diferencias en los ingresos por factores no aceptables, no así por variables aceptables y no observables:

$$
\breve{W}_{i}^{d}=e^{\widehat{\beta}_{0}+\widehat{\beta}_{N A} \bar{X}_{N A}+\widehat{\beta}_{A} X_{A i}+g(\bar{p})+\widehat{\eta}_{i}} .
$$

El Gráfico 1 muestra los índices de Gini y de Theil de la distribución del ingreso real observada, de los ingresos contrafácticos $\widetilde{w}$ y los ingresos contrafácticos directos que se calculan a partir de $\breve{w}^{d}$. También se incluyen los índices de desigualdad de la distribución de los ingresos contrafácticos en el caso que las variables aceptables son tratadas como variables no aceptables.

\section{Gráfico 1: Índices de Gini y de Theil, 2004-2010}

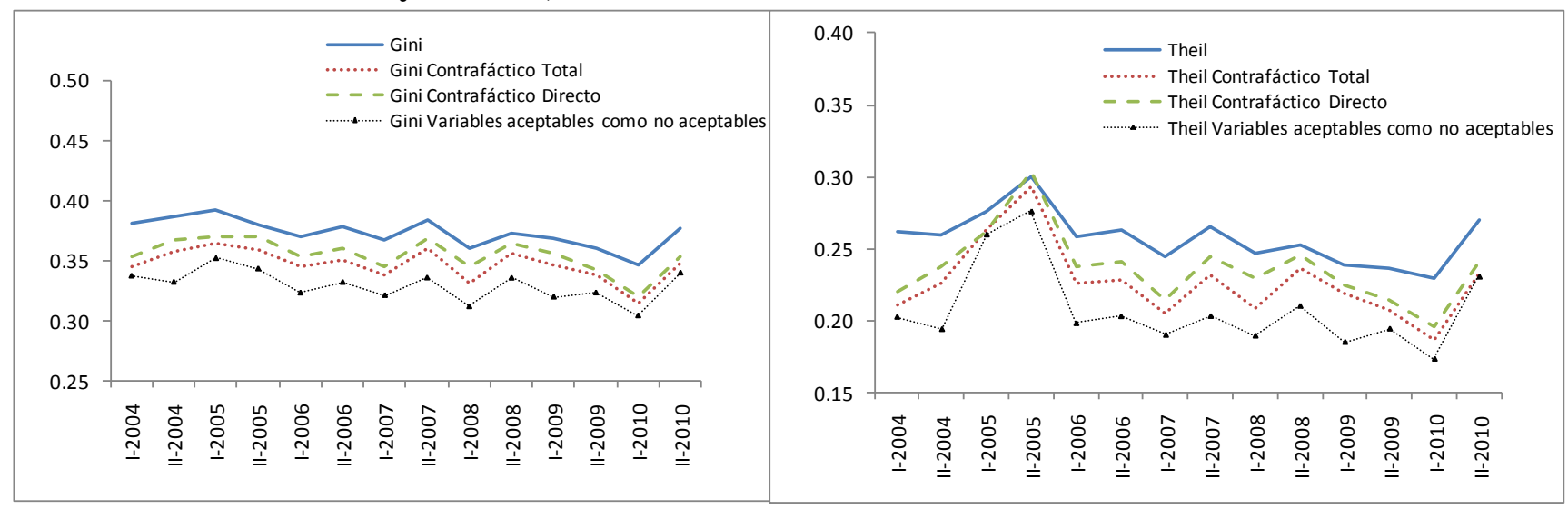

Fuente: Elaboración propia en base a EPH

En ambos gráficos se observa una leve tendencia de los índices a la baja. Si bien tanto los valores estimados como los observados de ambos índices presentan una tendencia similar, los valores estimados son más bajos que los observados, lo que sugeriría la existencia de desigualdad de oportunidades. Es decir, si los individuos tuviesen las mismas oportunidades, la desigualdad de ingresos sería menor. Es interesante observar que los índices directos son mayores a los totales, lo que estaría sugiriendo que las variables aceptables, años de educación y status migratorio, están afectadas por las variables no aceptables, generando una mayor desigualdad de ingresos.

En un extremo, la menor desigualdad de ingresos que es posible obtener eliminando el efecto de las cuatro variables no aceptables propuestas en este estudio corresponde a la desigualdad de la distribución de ingresos contrafácticos donde las variables aceptables, 
educación y status migratorio, son consideradas variables no aceptables. Esto es porque se supone que en el límite la educación y migración son determinadas completamente por factores no aceptables y la distribución de las variables inobservables no está afectada por las variables no aceptables.

Con el objeto de dar robustez a los resultados encontrados se utilizan técnicas de bootstrap con 100 repeticiones y se obtienen intervalos de confianza del 95\%. En el Cuadro 5 se presentan los índices de Gini y Theil calculados con sus respectivos intervalos de confianza del $95 \%$.

Cuadro 5: Análisis de desigualdad de ingresos. Índices Gini y Theil, 2004-2010.

\begin{tabular}{|c|c|c|c|c|c|c|c|c|c|}
\hline \multirow{3}{*}{ Año } & \multicolumn{3}{|c|}{ Gini } & \multicolumn{3}{|c|}{ Gini Contrafáctico Total } & \multicolumn{3}{|c|}{ Gini Contrafáctico Directo } \\
\hline & \multirow{2}{*}{ Coeficiente } & \multicolumn{2}{|c|}{ Intervalo $95 \%$ de confianza } & \multirow{2}{*}{ Coeficiente } & \multicolumn{2}{|c|}{ Intervalo 95\% de confianza } & \multirow{2}{*}{ Coeficiente - } & \multicolumn{2}{|c|}{ Intervalo 95\% de confianza } \\
\hline & & Inferior & Superior & & Inferior & Superior & & Inferior & Superior \\
\hline $1-2004$ & 0.382 & 0.359 & 0.409 & 0.345 & 0.320 & 0.364 & 0.353 & 0.336 & 0.391 \\
\hline II-2004 & 0.386 & 0.368 & 0.405 & 0.358 & 0.340 & 0.384 & 0.367 & 0.345 & 0.390 \\
\hline I-2005 & 0.392 & 0.371 & 0.427 & 0.364 & 0.329 & 0.416 & 0.370 & 0.347 & 0.422 \\
\hline II-2005 & 0.380 & 0.356 & 0.416 & 0.359 & 0.326 & 0.397 & 0.370 & 0.350 & 0.409 \\
\hline I-2006 & 0.369 & 0.349 & 0.394 & 0.345 & 0.327 & 0.365 & 0.353 & 0.338 & 0.383 \\
\hline II-2006 & 0.378 & 0.357 & 0.408 & 0.351 & 0.331 & 0.377 & 0.360 & 0.342 & 0.385 \\
\hline |-2007 & 0.367 & 0.346 & 0.396 & 0.338 & 0.319 & 0.362 & 0.345 & 0.322 & 0.363 \\
\hline II-2007 & 0.385 & 0.361 & 0.416 & 0.360 & 0.344 & 0.383 & 0.369 & 0.334 & 0.390 \\
\hline $1-2008$ & 0.360 & 0.340 & 0.386 & 0.331 & 0.316 & 0.347 & 0.344 & 0.332 & 0.372 \\
\hline II-2008 & 0.372 & 0.351 & 0.390 & 0.356 & 0.336 & 0.378 & 0.364 & 0.346 & 0.390 \\
\hline $\mathrm{I}-2009$ & 0.368 & 0.352 & 0.390 & 0.346 & 0.328 & 0.373 & 0.356 & 0.340 & 0.400 \\
\hline II-2009 & 0.360 & 0.341 & 0.378 & 0.338 & 0.320 & 0.354 & 0.342 & 0.324 & 0.360 \\
\hline I-2010 & 0.346 & 0.329 & 0.379 & 0.314 & 0.295 & 0.332 & 0.320 & 0.304 & 0.344 \\
\hline \multirow[t]{2}{*}{$\mathrm{II}-2010$} & 0.377 & 0.352 & 0.401 & 0.348 & 0.326 & 0.370 & 0.354 & 0.315 & 0.382 \\
\hline & \multicolumn{3}{|c|}{ Theil } & \multicolumn{3}{|c|}{ Theil Contrafáctico Total } & \multicolumn{3}{|c|}{ Theil Contrafáctico Directo } \\
\hline $\mathrm{I}-2004$ & 0.262 & 0.211 & 0.309 & 0.211 & 0.184 & 0.248 & 0.221 & 0.202 & 0.253 \\
\hline II-2004 & 0.260 & 0.231 & 0.302 & 0.226 & 0.197 & 0.267 & 0.238 & 0.211 & 0.272 \\
\hline $\mathrm{I}-2005$ & 0.276 & 0.239 & 0.351 & 0.263 & 0.194 & 0.366 & 0.262 & 0.202 & 0.361 \\
\hline II-2005 & 0.300 & 0.208 & 0.402 & 0.293 & 0.207 & 0.406 & 0.303 & 0.232 & 0.453 \\
\hline I-2006 & 0.258 & 0.221 & 0.327 & 0.226 & 0.175 & 0.270 & 0.237 & 0.198 & 0.305 \\
\hline II-2006 & 0.263 & 0.233 & 0.323 & 0.228 & 0.188 & 0.294 & 0.241 & 0.203 & 0.297 \\
\hline I-2007 & 0.244 & 0.204 & 0.282 & 0.205 & 0.183 & 0.226 & 0.214 & 0.190 & 0.249 \\
\hline II-2007 & 0.265 & 0.232 & 0.308 & 0.232 & 0.188 & 0.261 & 0.245 & 0.215 & 0.274 \\
\hline I-2008 & 0.247 & 0.211 & 0.318 & 0.209 & 0.175 & 0.250 & 0.229 & 0.196 & 0.305 \\
\hline II-2008 & 0.253 & 0.217 & 0.289 & 0.236 & 0.194 & 0.272 & 0.246 & 0.212 & 0.288 \\
\hline |-2009 & 0.238 & 0.206 & 0.277 & 0.219 & 0.184 & 0.244 & 0.225 & 0.200 & 0.256 \\
\hline II-2009 & 0.236 & 0.207 & 0.296 & 0.207 & 0.177 & 0.236 & 0.214 & 0.191 & 0.260 \\
\hline I-2010 & 0.229 & 0.185 & 0.273 & 0.186 & 0.161 & 0.213 & 0.195 & 0.165 & 0.236 \\
\hline II-2010 & 0.270 & 0.233 & 0.337 & 0.232 & 0.193 & 0.291 & 0.241 & 0.192 & 0.288 \\
\hline
\end{tabular}
Fuente: Elaboración propia en base a $E P H$

El índice de Gini observado es superior, en promedio, en un 7\% y 5\% respecto a los índices de Gini de la distribución de ingresos estimados $\widetilde{w}$ y $\breve{w}^{d}$. Los intervalos corroboran dicha diferencia, los límites superiores del Gini observado y el Gini del contrafáctico total, en promedio, se diferencian un 7,5\% y el Gini directo en un 5\%. Los inferiores presentan una diferencia menor de $7 \%$ y $4 \%$, respectivamente. 
Por su parte, el índice de Theil observado es alrededor del 12\% y 8\%, en promedio, más grande que el índice de Theil del contrafáctico total y el Theil del contrafáctico directo, respectivamente. Al igual que el índice de Gini, los intervalos de confianza robustecen estas diferencias. Los límites superiores presentan mayores diferencias entre el índice de Theil observado y los estimados, en promedio $14 \%$ y 7,5\%, y los inferiores también presentan diferencias en promedio del $13 \%$ y $7 \%$.

Estos resultados sugerirían la existencia de desigualdad de oportunidad. En el Cuadro 6 se presenta el índice de oportunidad que representa el porcentaje de desigualdad de ingreso generado por desigualdades de oportunidades y se descompone en efecto directo e indirecto. El mismo muestra cuánto disminuiría el índice de desigualdad de ingresos si las variables no aceptables no tuvieran efectos sobre los ingresos.

Cuadro 6: Contribución de la desigualdad de oportunidades a la desigualdad de ingresos, 2004-2010

\begin{tabular}{|c|r|r|r|r|r|r|}
\hline \multirow{2}{*}{ Año } & \multicolumn{6}{|c|}{ Índice de Oportunidad (IO) } \\
\cline { 2 - 6 } & \multicolumn{2}{|c|}{ Índice de Gini } & \multicolumn{2}{|c|}{ Índice de Theil } \\
\cline { 2 - 6 } & IO Total & IO Directo & IO Indirecto & IO Total & \multicolumn{1}{|c|}{ IO Directo } & IO Indirecto \\
\hline I-2004 & $9.5 \%$ & $7.4 \%$ & $2.0 \%$ & $19.2 \%$ & $15.7 \%$ & $3.6 \%$ \\
II-2004 & $7.3 \%$ & $5.0 \%$ & $2.3 \%$ & $13.1 \%$ & $8.5 \%$ & $4.6 \%$ \\
I-2005 & $7.1 \%$ & $5.7 \%$ & $1.4 \%$ & $4.6 \%$ & $5.2 \%$ & $-0.6 \%$ \\
II-2005 & $5.4 \%$ & $2.6 \%$ & $2.8 \%$ & $2.4 \%$ & $-1.0 \%$ & $3.4 \%$ \\
I-2006 & $6.6 \%$ & $4.4 \%$ & $2.2 \%$ & $12.3 \%$ & $8.2 \%$ & $4.1 \%$ \\
II-2006 & $7.2 \%$ & $4.9 \%$ & $2.4 \%$ & $13.3 \%$ & $8.2 \%$ & $5.1 \%$ \\
I-2007 & $7.8 \%$ & $5.8 \%$ & $2.0 \%$ & $15.8 \%$ & $12.3 \%$ & $3.6 \%$ \\
II-2007 & $6.4 \%$ & $4.1 \%$ & $2.4 \%$ & $12.7 \%$ & $7.8 \%$ & $4.8 \%$ \\
I-2008 & $8.0 \%$ & $4.4 \%$ & $3.6 \%$ & $15.3 \%$ & $7.1 \%$ & $8.2 \%$ \\
II-2008 & $4.2 \%$ & $2.1 \%$ & $2.1 \%$ & $6.6 \%$ & $2.8 \%$ & $3.8 \%$ \\
I-2009 & $6.0 \%$ & $3.3 \%$ & $2.6 \%$ & $7.9 \%$ & $5.7 \%$ & $2.2 \%$ \\
II-2009 & $6.2 \%$ & $5.1 \%$ & $1.1 \%$ & $12.2 \%$ & $9.1 \%$ & $3.0 \%$ \\
I-2010 & $9.2 \%$ & $7.7 \%$ & $1.6 \%$ & $18.9 \%$ & $14.9 \%$ & $4.0 \%$ \\
II-2010 & $7.7 \%$ & $6.2 \%$ & $1.5 \%$ & $13.9 \%$ & $10.7 \%$ & $3.2 \%$ \\
\hline
\end{tabular}

Fuente: Elaboración propia en base a $E P H$

Los índices de desigualdad de Gini podrían ser entre $9,5 \%$ y $4 \%$ más bajos que los observados si las variables no aceptables no fuesen un factor determinante de los ingresos. Por su parte, los índices de desigualdad de Theil también podrían ser menores alrededor de $19 \%$ y $2,4 \%^{5}$.

\footnotetext{
${ }^{5}$ Si bien no son estrictamente comparables, en Bourguignon y otros (2007) el índice de oportunidad total y directo en base a Theil de los jóvenes entre 26 y 30 años de Brasil en 1996 es 12,8\% y 10,2\% respectivamente. Para América Latina, según Ferreira y Gignoux (2011), los índices de oportunidad de Theil calculados para una muestra entre 30 y 49 años en base a ingresos laborales ronda alrededor de $11 \%$ en Perú y de $30 \%$ en Brasil, respecto a ingresos per cápita familiar toma valores entre $26 \%$ de Colombia y $37 \%$ de Guatemala y en relación al gasto en el consumo éste oscila entre el 27\% de Colombia y 52\% de Guatemala.
} 
Entre 2004 y 2010, el índice de oportunidad en base a Gini y Theil ha disminuido un $19 \%$ y $32 \%$ respectivamente, lo que estaría sugiriendo una mejora en oportunidades. Sin embargo, mientras que la tendencia de la desigualdad del ingreso ha sido a la baja en el total del período, el índice de oportunidad presenta fluctuaciones sin un patrón definido.

Como se observa gráficamente el período considerado presenta dos episodios de baja desigualdad de oportunidad, el segundo semestre de 2005 y 2008. Los restantes subperíodos muestran un aumento considerable del índice directo lo que explica gran parte de la desigualdad de oportunidad (alrededor de un 80\%). El componente indirecto es más estable y presenta valores más bajos. Es así que la desigualdad de oportunidades, se explica principalmente por el efecto directo que tienen las variables no aceptables sobre los ingresos. En los últimos dos años, los índices de desigualdad de oportunidad total en base a Gini y Theil han aumentado; los altos niveles de los índices de oportunidad de estos años indican una posible tendencia a la suba.

Gráfico 2: Índice de desigualdad de oportunidad, 2004-2010

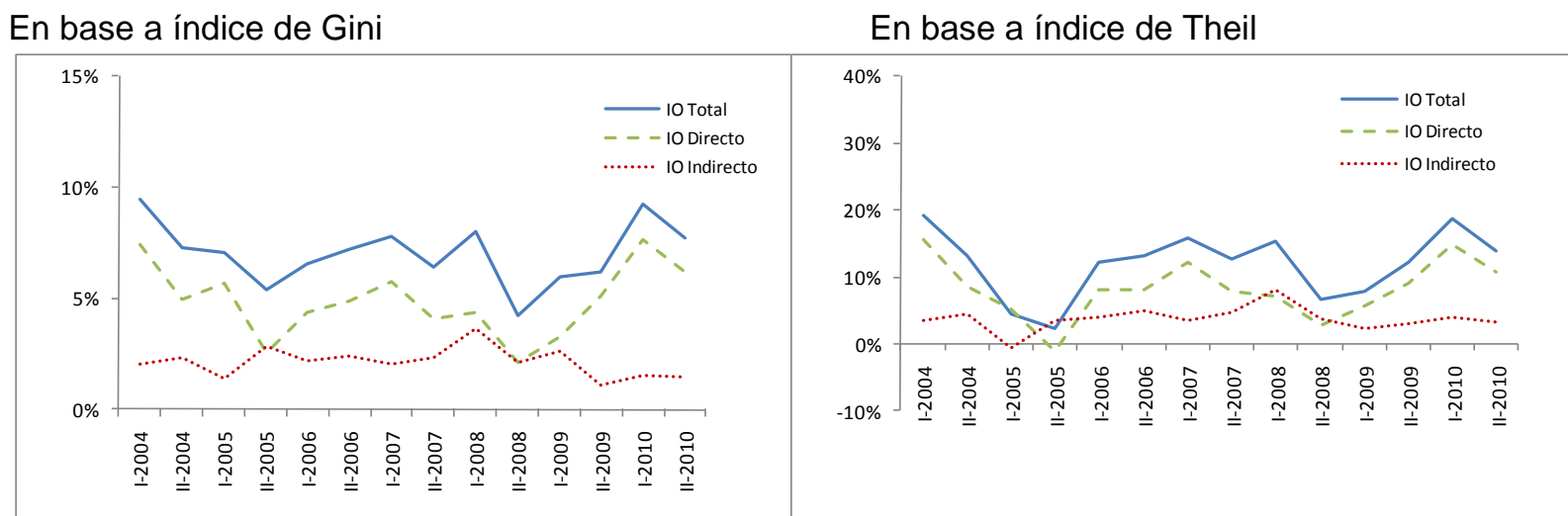

Fuente: Elaboración propia en base a EPH

Debido a que el lapso considerado en este estudio corresponde a un período de baja desigualdad de ingresos y de mercado laboral en expansión, es interesante extender el trabajo a otros períodos. A continuación se presenta la evolución del índice de desigualdad de oportunidad para un período más extenso ${ }^{6}$. Se incorpora la segunda mitad de la década del noventa por ser un período de desigualdad de ingresos en ascenso y tasas de empleos rígidas.

\footnotetext{
${ }^{6}$ Los resultados correspondientes al período 1996-2003, están disponibles para quien lo solicite
} 


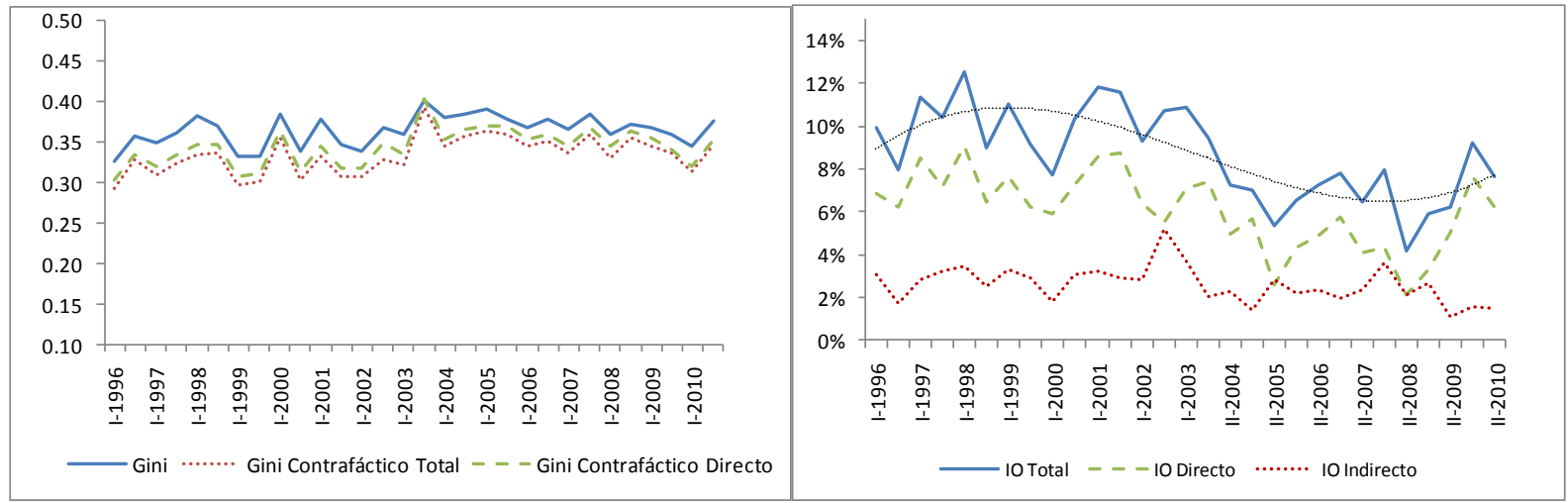

En base a índice de Theil

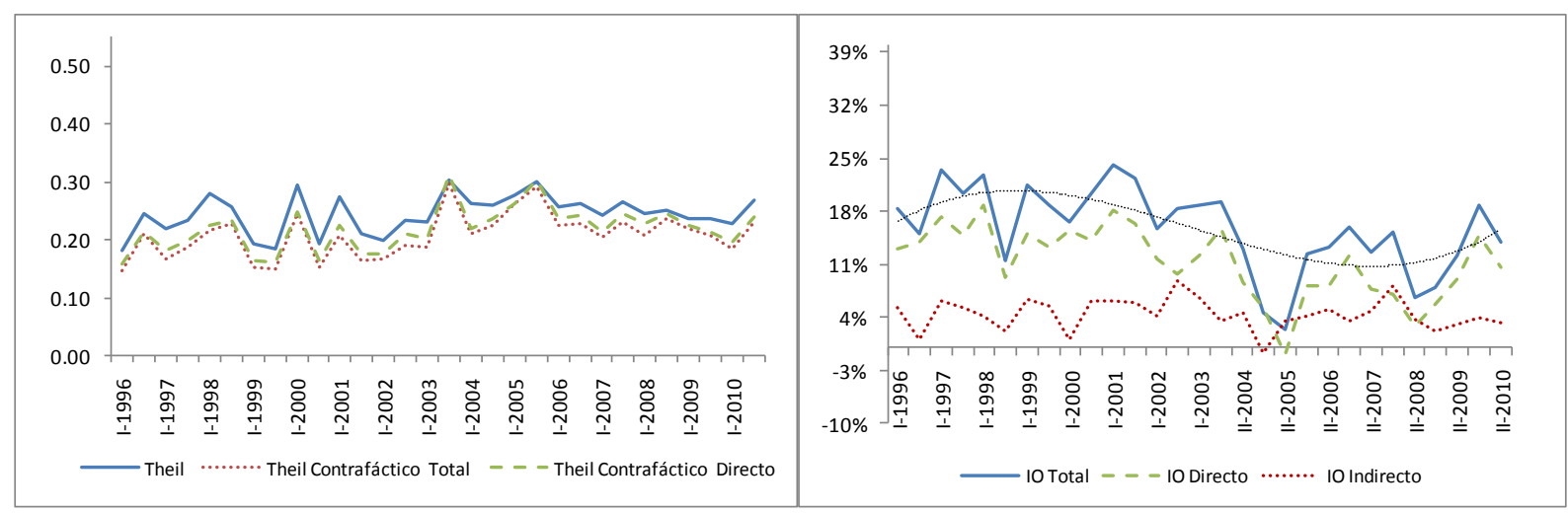

Fuente: Elaboración propia en base a $E P H$

De los gráficos se desprende que las distribuciones de ingresos estimadas son menos desiguales en términos de Gini y de Theil que la observada. El efecto directo continúa explicando la mayor parte de la desigualdad de oportunidad mientras que el componente indirecto es pequeño y más estable.

La tendencia del índice de desigualdad de oportunidad en el período 1996-2003 es no lineal. En los primeros años del período se observa una alta desigualdad de oportunidad mientras que para los años siguientes la misma ha disminuido.

En síntesis, la distribución del ingreso podría ser menos desigual en términos de Gini y de Theil, si todos los jóvenes tuvieran las mismas oportunidades. Las variables socialmente no aceptables no sólo afectan directamente los ingresos de los jóvenes sino que también influyen a través de las variables socialmente aceptables, pero en menor medida. Por último, cabe destacar que la evolución del índice de desigualdad de oportunidad no presenta un patrón definido.

Cuando se analizan los resultados no tratados por el sesgo de selección doble, se halla que el porcentaje de desigualdad que disminuiría si todos los jóvenes de la muestra enfrentaran las mismas oportunidades es menor al calculado anteriormente. Es decir, si 
no se corrige por el sesgo de selección por co-residencia y empleo los índices de desigualdad de ingreso estarían sobreestimados y por lo tanto la desigualdad de oportunidad sería subestimada.

Gráfico 4: Índices de desigualdad de oportunidad corregidos y no corregidos por sesgo de selección por co-residencia y dentro del empleo, 2004-2010

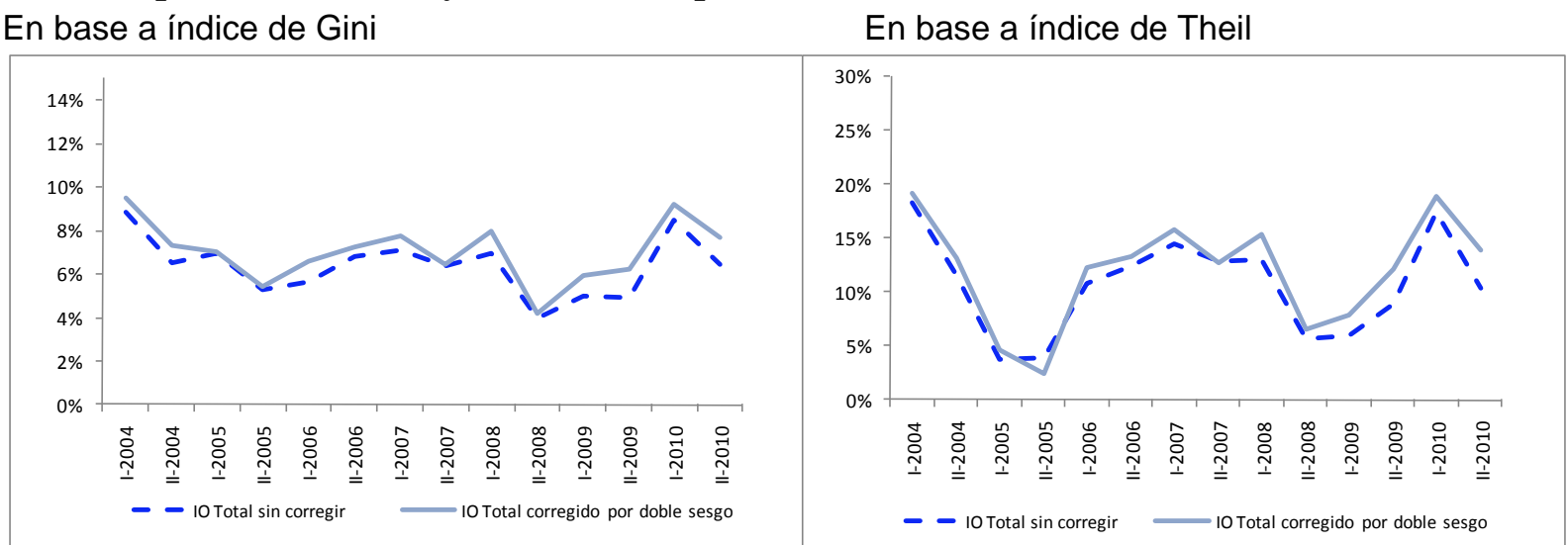

Fuente: Elaboración propia en base a $E P H$

Como sugieren los resultados, la dispersión de las variables no aceptables en la muestra es lo que genera la desigualdad de oportunidad que conlleva a distribuciones de ingresos desiguales. El impacto de las variables no aceptables en la desigualdad de oportunidad se ve reflejado en las diferencias entre el índice de desigualdad de ingresos real y el estimado. Es así que resulta interesante analizar el impacto individual de cada variable no aceptable en la distribución del ingreso.

Con el objeto de analizar la contribución de cada variable no aceptable, se computa un ingreso a cada individuo suponiendo que la variable no aceptable de interés tiene el mismo valor para todos mientras que las demás variables del modelo reducido no. Luego de obtener la distribución del ingreso contrafactual, se calculan los índices de desigualdad de Gini y Theil y se comparan con los reales. En el Cuadro 7 se exponen los resultados de los índices de desigualdad estimados y sus respectivos intervalos de confianza del $95 \%$.

Según los resultados encontrados, la variable que más impacta en la desigualdad de ingresos es la educación del jefe de hogar como proxy de la educación de los padres. La variable ocupación del jefe de hogar es la segunda variable con mayor impacto junto con la región de nacimiento. Por último, la variable con menor impacto es la variable de género. 
Cuadro 7: Análisis de contribución de variables no aceptables, 2004-2010

\begin{tabular}{|c|c|c|c|c|c|c|c|c|c|c|c|c|c|c|}
\hline Gini & I-2004 & II-2004 & I-2005 & II-2005 & $\mathrm{I}-2006$ & II-2006 & I-2007 & II-2007 & I-2008 & II-2008 & I-2009 & II-2009 & I-2010 & II-2010 \\
\hline \multirow[t]{2}{*}{ Total observado } & 0.382 & 0.386 & 0.392 & 0.380 & 0.369 & 0.378 & 0.367 & 0.385 & 0.360 & 0.372 & 0.368 & 0.360 & 0.346 & 0.377 \\
\hline & 0.413 & 0.394 & 0.419 & 0.406 & 0.388 & 0.414 & 0.384 & 0.406 & 0.377 & 0.391 & 0.375 & 0.367 & 0.376 & 0.384 \\
\hline \multirow[t]{3}{*}{ Género } & 0.390 & 0.374 & 0.391 & 0.383 & 0.365 & 0.372 & 0.361 & 0.381 & 0.356 & 0.373 & 0.360 & 0.350 & 0.337 & 0.364 \\
\hline & 0.367 & 0.352 & 0.362 & 0.359 & 0.341 & 0.352 & 0.341 & 0.359 & 0.338 & 0.356 & 0.341 & 0.330 & 0.318 & 0.342 \\
\hline & 0.392 & 0.398 & 0.428 & 0.410 & 0.388 & 0.393 & 0.381 & 0.395 & 0.364 & 0.387 & 0.380 & 0.364 & 0.351 & 0.386 \\
\hline \multirow[t]{3}{*}{ Región de Nac. } & 0.365 & 0.376 & 0.386 & 0.372 & 0.359 & 0.372 & 0.356 & 0.376 & 0.347 & 0.367 & 0.356 & 0.348 & 0.332 & 0.363 \\
\hline & 0.339 & 0.354 & 0.363 & 0.351 & 0.338 & 0.348 & 0.333 & 0.357 & 0.328 & 0.342 & 0.332 & 0.324 & 0.306 & 0.345 \\
\hline & 0.414 & 0.395 & 0.421 & 0.406 & 0.387 & 0.388 & 0.371 & 0.402 & 0.368 & 0.391 & 0.381 & 0.362 & 0.353 & 0.392 \\
\hline \multirow[t]{3}{*}{ Ocupación Jefe } & 0.387 & 0.374 & 0.386 & 0.382 & 0.363 & 0.369 & 0.354 & 0.376 & 0.350 & 0.368 & 0.355 & 0.347 & 0.332 & 0.361 \\
\hline & 0.356 & 0.352 & 0.363 & 0.353 & 0.343 & 0.347 & 0.332 & 0.358 & 0.329 & 0.349 & 0.337 & 0.331 & 0.319 & 0.342 \\
\hline & 0.394 & 0.375 & 0.406 & 0.399 & 0.373 & 0.379 & 0.373 & 0.386 & 0.370 & 0.388 & 0.371 & 0.360 & 0.338 & 0.383 \\
\hline \multirow[t]{2}{*}{ Educación Jefe } & 0.369 & 0.361 & 0.373 & 0.369 & 0.347 & 0.352 & 0.348 & 0.366 & 0.342 & 0.364 & 0.349 & 0.343 & 0.322 & 0.351 \\
\hline & 0.350 & 0.342 & 0.350 & 0.344 & 0.327 & 0.333 & 0.327 & 0.344 & 0.322 & 0.347 & 0.332 & 0.320 & 0.307 & 0.332 \\
\hline Theil & I-2004 & II-2004 & $\mathrm{I}-2005$ & II-2005 & $\mathrm{I}-2006$ & II-2006 & $\mathrm{I}-2007$ & II-2007 & $\mathrm{I}-2008$ & II-2008 & I-2009 & II-2009 & $\mathrm{I}-2010$ & II-2010 \\
\hline \multirow[t]{2}{*}{ Total observado } & 0.262 & 0.260 & 0.276 & 0.300 & 0.258 & 0.263 & 0.244 & 0.265 & 0.247 & 0.253 & 0.238 & 0.236 & 0.229 & 0.270 \\
\hline & 0.308 & 0.271 & 0.374 & 0.391 & 0.316 & 0.304 & 0.277 & 0.301 & 0.303 & 0.296 & 0.263 & 0.246 & 0.289 & 0.298 \\
\hline \multirow[t]{3}{*}{ Género } & 0.271 & 0.246 & 0.279 & 0.300 & 0.252 & 0.253 & 0.235 & 0.261 & 0.243 & 0.252 & 0.228 & 0.222 & 0.219 & 0.247 \\
\hline & 0.228 & 0.213 & 0.235 & 0.253 & 0.210 & 0.221 & 0.201 & 0.234 & 0.200 & 0.212 & 0.195 & 0.189 & 0.183 & 0.207 \\
\hline & 0.277 & 0.285 & 0.394 & 0.395 & 0.296 & 0.301 & 0.262 & 0.301 & 0.296 & 0.290 & 0.255 & 0.257 & 0.259 & 0.297 \\
\hline \multirow[t]{3}{*}{ Región de Nac. } & 0.238 & 0.249 & 0.280 & 0.311 & 0.242 & 0.256 & 0.228 & 0.256 & 0.231 & 0.247 & 0.224 & 0.220 & 0.213 & 0.246 \\
\hline & 0.206 & 0.221 & 0.220 & 0.226 & 0.200 & 0.227 & 0.190 & 0.227 & 0.192 & 0.214 & 0.196 & 0.193 & 0.174 & 0.212 \\
\hline & 0.302 & 0.279 & 0.363 & 0.405 & 0.327 & 0.319 & 0.258 & 0.291 & 0.290 & 0.290 & 0.271 & 0.243 & 0.251 & 0.288 \\
\hline \multirow[t]{3}{*}{ Ocupación Jefe } & 0.264 & 0.246 & 0.273 & 0.299 & 0.250 & 0.250 & 0.222 & 0.254 & 0.232 & 0.249 & 0.225 & 0.217 & 0.211 & 0.246 \\
\hline & 0.223 & 0.218 & 0.222 & 0.232 & 0.207 & 0.219 & 0.198 & 0.222 & 0.193 & 0.220 & 0.192 & 0.189 & 0.178 & 0.208 \\
\hline & 0.303 & 0.258 & 0.383 & 0.380 & 0.289 & 0.274 & 0.274 & 0.266 & 0.267 & 0.283 & 0.264 & 0.254 & 0.236 & 0.267 \\
\hline \multirow[t]{2}{*}{ Educación Jefe } & 0.240 & 0.229 & 0.262 & 0.280 & 0.230 & 0.227 & 0.221 & 0.239 & 0.221 & 0.242 & 0.221 & 0.213 & 0.197 & 0.232 \\
\hline & 0.211 & 0.204 & 0.195 & 0.223 & 0.182 & 0.187 & 0.186 & 0.211 & 0.189 & 0.212 & 0.186 & 0.181 & 0.173 & 0.190 \\
\hline
\end{tabular}

Nota: Intervalos de confianza a partir de bootstrap con 100 repeticiones y significatividad del $95 \%$

Fuente: Elaboración propia en base a EPH 
El ranking de impacto de las variables, concuerda con la idea de Becker (1994) de que los padres tienen una gran influencia en la educación, valores, hábitos y otras dimensiones de la vida de sus hijos. En particular, según Nuñez y Risco (2004), la educación del padre tiene dos efectos sobre el ingreso de sus hijos. En primer lugar, un padre con mayor nivel educativo tiene mayores ingresos y, por lo tanto, puede invertir un monto mayor en capital humano para su hijo. Por otro lado, la educación del padre ejerce un efecto directo tanto en la salud y educación como en otros aspectos de la vida de sus hijos que pueden traducirse en un mayor nivel de ingresos para estos últimos.

\section{8- Conclusión}

En este trabajo se intentó medir la desigualdad de oportunidad en Argentina para jóvenes entre 26 y 35 años durante el periodo 2004-2010. En primer lugar, se utiliza una muestra restringida de jóvenes empleados que residen con el jefe de hogar. De esta manera, se pudo incluir en el estudio las variables educación y ocupación del jefe de hogar.

Siguiendo a Gasparini (2002) se opta por clasificar las variables en socialmente aceptables y no aceptables. Se seleccionó el género, la región de nacimiento y la educación y ocupación de los padres como variables no aceptables y los años de educación y el status de migrante como variables aceptables. Sin embargo, la discusión sobre esta clasificación es extensa y está estrechamente relacionada con los conceptos normativos y principios de equidad y justicia de cada sociedad.

Luego para analizar la desigualdad de oportunidades proveniente de variables que son consideradas socialmente no aceptables, se utilizó el modelo de igualdad de oportunidades presentado en Bourguignon y otros (2007). Para solucionar el problema de selección muestral se trabajó con una generalización del modelo clásico de selección de Heckman (1979).

A partir de las estimaciones halladas, se generaron ingresos contrafácticos suponiendo que los individuos de la muestra poseen las mismas características socialmente no aceptables y se calcularon los índices de desigualdad de Gini y de Theil de las nuevas distribuciones de ingresos estimadas. Los mismos resultaron ser menores a los índices de la distribución de ingresos reales. Con lo cual, los resultados sugieren que la desigualdad de ingreso está influenciada por las variables socialmente no aceptables creando desigualdades de oportunidades entre los jóvenes. 
Ante tal resultado, se computó el índice de desigualdad de oportunidades que refleja el porcentaje de desigualdad que disminuiría si todos los jóvenes de la muestra enfrentaran las mismas oportunidades; la evolución de este índice no presenta un patrón claro. Cuando se descompone el índice de desigualdad de oportunidades, se encuentra que el efecto directo es importante y fluctuante, mientras que el efecto de las variables no aceptables es menor cuando influyen indirectamente a través de las variables aceptables (el índice de desigualdad de oportunidades indirecto es bastante estable y se mantiene en valores bajos). Por último, se analizó la contribución individual de cada variable no aceptable a la desigualdad de oportunidad, del que se concluye que la educación del jefe de hogar es la variable más relevante.

Finalmente, según la evidencia empírica de este estudio el contexto socioeconómico condiciona los ingresos de los jóvenes generando una mayor brecha de ingresos. Siempre que la sociedad considere injusta esta situación, la desigualdad de oportunidades deberá ser objeto de política económico-social para alcanzar una desigualdad de ingresos socialmente aceptable.

Como línea futura de investigación sería interesante analizar una estrategia para solucionar el problema de variables omitidas que presenta el modelo estimado e incorporar otros métodos semiparamétricos y no paramétricos al análisis. Además resulta relevante extender el estudio a otras fuentes de información y a otras variables socialmente aceptables y no aceptables además de las utilizadas en este trabajo. 


\section{Referencias}

Arnerson, Richard J. (1989). "Equality and Equal Opportunity for Welfare." Philosophical Studies, Vol. 56 (1): 77-93.

Ashish, Singh (2010). "Inequality of Opportunity: Application to India." Working paper, Indira Gandhi Institute of Development Research, Mumbai, India.

Barros, Ricardo P., Francisco H. G. Ferreira, José R. Molinas Vega y Jaime Saavedra Chanduvi (2009). Measuring Inequality of Opportunities in Latin America and the Caribbean. Latin American Development Forum Series, The World Bank, Washington DC.

Becker, Gary S. (1994). Human Capital: a theoretical and empirical analysis, with special reference to education. University of Chicago Press, $3^{\circ} \mathrm{ed}$.

Bourguignon, François, Francesco H. G. Ferreira, y Marta Menéndez (2007). "Inequality of Opportunity in Brazil." Review of Income and Wealth, Series 53 (4): 585-618.

Brunello, Giorgio y Danielle Chechi (2006). "Does School Tracking Affect Equality of Opportunity? New International Evidence.” Discussion Paper Series, No. 2348, IZA.

De Luca, Giuseppe y Franco Peracchi (2007). "A sample selection model for unit and item nonresponse in cross- sectional surveys." Research Paper Series, Working Paper, Vol. 33 (99), CEIS, University of Rome Tor Vergata.

Cerrutti, Marcela y Alicia Maguid (2007). "Inserción laboral e ingresos de los migrantes de países limítrofes y peruanos en el Gran Buenos Aires." Notas de Población, No. 83, CEPAL.

Chechi, Daniele y Vitorocco Peragine (2005). "Regional Disparities and Inequality of Opportunity: The Case of Italy.” Discussion Paper Series, No. 1874, IZA.

Cohen, Gerald A. (1989). "On the Currency of Egalitarian Justice.” Ethics, Vol. 99 (4): 906944.

Fachini, Gabriel (2011). Igualdad de Oportunidades en Salud: Evidencia usando registros administrativos en Chaco. Tesis de Maestría en Economía, Universidad Nacional de La Plata, Buenos Aires, Argentina.

Ferreira, Francisco H. G. y Jérémie Gignoux (2011). "The Measurement of Inequality of Opportunity: Theory and an application to Latin America." Review of Income and Wealth, First published online: 21 JUL 2011, DOI: 10.1111/j.1475-4991.2011.00467.x

Garlatti, Adrian (2011). Equity of Education Quality: Argentina and the world. Tesis de Maestría en Economía, Universidad Nacional de La Plata, Buenos Aires, Argentina.

Gasparini, Leonardo C. (2002). "On the measurement of unfairness. An application to high school attendance in Argentina." Social Choice and Welfare, Vol. 19(4): 795-810.

Gasparini, Leonardo C. and Santiago M. Pinto (2006). "Equality of opportunity and optimal cash and in-kind policies." Journal of Public Economics, Vol. 90 (1-2): 143-169.

Gasparini, Leonardo C. y Guillermo Cruces (2008) "A Distribution in Motion: The Case of Argentina." Documento de Trabajo, No. 78, CEDLAS, Universidad Nacional de La Plata, Buenos Aires, Argentina.

Ham, John C. (1982), "Estimation of a Labour Supply Model with Censoring due to Unemployment and Underemployment." Review of Economic Studies, Vol. 49: 335-354.

Heckman, James J. (1979). "Sample selection as a specification error." Econometrica, Vol. 47(1): 153-161. 
Hindriks, Jean, Marijn Verschelde, Glenn Rayp, and Koen Schoors (2010). "Ability tracking, social segregation and educational opportunity: evidence from Belgium." Discussion Paper, Center for Operations Research and Econometrics, Bélgica.

Jiménez, Maribel y Mónica Jiménez (2009). "La Movilidad Intergeneracional del Ingreso: Evidencia para Argentina." Documento de Trabajo, No. 84, CEDLAS, Universidad Nacional de La Plata, Buenos Aires, Argentina.

Jiménez, Maribel (2011). "Un Análisis Empírico de las No Linealidades en la Movilidad Intergeneracional del Ingreso. El caso de la Argentina." Documento de Trabajo, No. 114, CEDLAS, Universidad Nacional de La Plata, Buenos Aires, Argentina.

Lefranc, Arnaud, Nicolas Pistolesi and Alain Trannoy (2008). "Inequality of opportunities vs. inequality of outcomes: Are Western Societies all alike?" Review of Income and Wealth.Vol. 54(4): 513-546.

Nicoletti, Cheti (2008). "Multiple Sample Selection in the Estimation of Intergenerational Occupational Mobility." Working Paper Series, No 20, Institute for Social and Economic Research, University of Essex

Nicoletti, Cheti, and Marco Francesconi (2006). "Intergenerational mobility and sample selection in short panels." Journal of Applied Econometrics. Vol. 21(8): 1265-93.

Núñez, Javier y Cristina Risco (2004). "Movilidad Intergeneracional de Ingresos en un País en Desarrollo: El Caso de Chile.” Working Paper N²10, Department of Economics, University of Chile.

Poirier, Dale J. (1980), "Partial Observability in Bivariate Probit Models." Journal of Econometrics, Vol. 12: 209-217.

Roemer, John E. (1998). Equality of Opportunity. Harvard University Press, Cambridge.

Waltenberg, Fabio D. and Vincent Vandenberghe (2007). "What Does It Take to Achieve Equality of Opportunity in Education? An Empirical Investigation Based on Brazilian Data." Economics of Education Review. Vol. 26(6): 709-723.

Yalonetzky, Gastón (2010). "A dissimilarity index of multidimensional inequality of opportunity." Journal of Economic Inequality. First published online: 22 DIC 2010, DOI 10.1007/s10888-010-9162-z.

www.sedlac.econo.unlp.edu.ar (Socio-Economic Database for Latin America and the Caribbean. CEDLAS y Banco Mundial, 2011).

www.indec.gov.ar (Instituto Nacional de Estadísticas y Censos. Marzo, 2011). 
ANEXO 
Cuadro A1: Estimaciones del modelo de probabilidad bivariado de la selección de co-residencia y empleo, 2004-2010

\begin{tabular}{|c|c|c|c|c|c|c|c|c|c|c|c|c|c|c|c|c|}
\hline \multirow{2}{*}{ Variables } & \multicolumn{2}{|c|}{ I-2004 } & \multicolumn{2}{|c|}{ II-2004 } & \multicolumn{2}{|c|}{ I-2005 } & \multicolumn{2}{|c|}{ II-2005 } & \multicolumn{2}{|c|}{ I-2006 } & \multicolumn{2}{|c|}{ II-2006 } & \multicolumn{2}{|c|}{ 1-2007 } & \multicolumn{2}{|c|}{ II-2007 } \\
\hline & Coresidencia & Empleo & Coresidencia & Empleo & Coresidencia & Empleo & Coresidencia & Empleo & Coresidencia & Empleo & Coresidencia & Empleo & Coresidencia & Empleo & Coresidencia & Empleo \\
\hline aedu & & $\begin{array}{l}0.0427^{* * *} \\
(0.0120)\end{array}$ & & $\begin{array}{l}0.0406^{* * *} \\
(0.0117)\end{array}$ & & $\begin{array}{l}0.0382^{* * *} \\
(0.0105)\end{array}$ & & $\begin{array}{l}0.0250^{* *} \\
(0.0104)\end{array}$ & & $\begin{array}{l}0.0188^{*} \\
(0.0112)\end{array}$ & & $\begin{array}{l}0.0458^{* * *} \\
(0.00991)\end{array}$ & & $\begin{array}{l}0.0341^{* * *} \\
(0.0111)\end{array}$ & & $\begin{array}{l}0.0404^{* * *} \\
(0.0140)\end{array}$ \\
\hline edad & $\begin{array}{l}-0.0734^{* * *} \\
(0.0111)\end{array}$ & $\begin{array}{l}0.351 \\
(0.283)\end{array}$ & $\begin{array}{l}-0.0722^{* * *} \\
(0.0103)\end{array}$ & $\begin{array}{l}0.0288 \\
(0.318)\end{array}$ & \begin{tabular}{|l}
$-0.0788^{* * *}$ \\
$(0.0105)$
\end{tabular} & $\begin{array}{l}-0.00398 \\
(0.313)\end{array}$ & $\begin{array}{l}-0.0830^{* * *} \\
(0.0100)\end{array}$ & $\begin{array}{l}0.121 \\
(0.299)\end{array}$ & $\begin{array}{l}-0.0715^{* * *} \\
(0.0104)\end{array}$ & $\begin{array}{l}0.0771 \\
(0.334)\end{array}$ & $\begin{array}{l}-0.0532^{* * *} \\
(0.01000)\end{array}$ & $\begin{array}{l}0.316 \\
(0.354)\end{array}$ & $\begin{array}{l}-0.0783^{* * *} \\
(0.0100)\end{array}$ & $\begin{array}{l}0.159 \\
(0.340)\end{array}$ & $\begin{array}{l}-0.0632^{* * *} \\
(0.0126)\end{array}$ & $\begin{array}{l}0.176 \\
(0.479)\end{array}$ \\
\hline edad2 & & $\begin{array}{l}-0.00540 \\
(0.00465)\end{array}$ & & $\begin{array}{l}4.83 e-05 \\
(0.00524)\end{array}$ & & $\begin{array}{l}0.000180 \\
(0.00516)\end{array}$ & & $\begin{array}{l}-0.00178 \\
(0.00493)\end{array}$ & & $\begin{array}{l}-0.00104 \\
(0.00550)\end{array}$ & & $\begin{array}{l}-0.00458 \\
(0.00584)\end{array}$ & & $\begin{array}{l}-0.00223 \\
(0.00564)\end{array}$ & & $\begin{array}{l}-0.00247 \\
(0.00780)\end{array}$ \\
\hline casado & $\begin{array}{l}-2.419 * * * \\
(0.0774)\end{array}$ & $\begin{array}{l}0.0800 \\
(0.0774)\end{array}$ & $\begin{array}{l}-2.349 * * * \\
(0.0718)\end{array}$ & $\begin{array}{l}0.118 \\
(0.0786)\end{array}$ & $\begin{array}{l}-2.326 * * * \\
(0.0734)\end{array}$ & $\begin{array}{l}-0.0174 \\
(0.0774)\end{array}$ & $\begin{array}{l}-2.418^{* * *} \\
(0.0742)\end{array}$ & $\begin{array}{l}0.0248 \\
(0.0757)\end{array}$ & $\begin{array}{l}-2.294 * * * \\
(0.0718)\end{array}$ & $\begin{array}{l}0.0416 \\
(0.0791)\end{array}$ & $\begin{array}{l}-2.262^{* * *} \\
(0.0696)\end{array}$ & $\begin{array}{l}-0.0597 \\
(0.0823)\end{array}$ & $\begin{array}{l}-2.168^{* * *} \\
(0.0682)\end{array}$ & $\begin{array}{l}0.0327 \\
(0.0881)\end{array}$ & $\begin{array}{l}-2.388^{* * *} \\
(0.0951)\end{array}$ & $\begin{array}{l}-0.117 \\
(0.110)\end{array}$ \\
\hline asiste & $\begin{array}{l}0.172^{* *} \\
(0.0871)\end{array}$ & $\begin{array}{l}-8.868 * * * \\
(0.0864)\end{array}$ & \begin{tabular}{|l}
0.103 \\
$(0.0840)$
\end{tabular} & $\begin{array}{l}-8.919^{* * *} \\
(0.0792)\end{array}$ & $\begin{array}{l}0.253^{* * *} \\
(0.0876)\end{array}$ & $\begin{array}{l}-8.586^{* * *} \\
(0.0758)\end{array}$ & $\begin{array}{l}0.0130 \\
(0.0829)\end{array}$ & $\begin{array}{l}-8.889 * * * \\
(0.0946)\end{array}$ & $\begin{array}{l}0.255^{* * *} \\
(0.0760)\end{array}$ & $\begin{array}{l}-8.708^{* * *} \\
(0.0877)\end{array}$ & $\begin{array}{l}0.109 \\
(0.0804)\end{array}$ & $\begin{array}{l}-9.106^{* * *} \\
(0.0913)\end{array}$ & $\begin{array}{l}0.0948 \\
(0.0866)\end{array}$ & $\begin{array}{l}-8.933^{* * *} \\
(0.0756)\end{array}$ & $\begin{array}{l}-0.0642 \\
(0.0976)\end{array}$ & $\begin{array}{l}-8.872^{* * *} \\
(0.108)\end{array}$ \\
\hline hombre & $\begin{array}{l}0.195^{* * *} \\
(0.0633)\end{array}$ & $\begin{array}{l}0.480^{* * *} \\
(0.0744)\end{array}$ & $\begin{array}{l}0.120^{* *} \\
(0.0583)\end{array}$ & $\begin{array}{l}0.455^{* * *} \\
(0.0748)\end{array}$ & $\begin{array}{l}0.212^{* * *} \\
(0.0614)\end{array}$ & $\begin{array}{l}0.394^{* * *} \\
(0.0765)\end{array}$ & $\begin{array}{l}0.159 * * * \\
(0.0576)\end{array}$ & $\begin{array}{l}0.458^{* * *} \\
(0.0793)\end{array}$ & $\begin{array}{l}0.108^{*} \\
(0.0569)\end{array}$ & $\begin{array}{l}0.479 * * * \\
(0.0822)\end{array}$ & $\begin{array}{l}0.225 * * * \\
(0.0555)\end{array}$ & $\begin{array}{l}0.633^{* * *} \\
(0.0861)\end{array}$ & $\begin{array}{l}0.174^{* * *} \\
(0.0570)\end{array}$ & $\begin{array}{l}0.364^{* * *} \\
(0.0846)\end{array}$ & $\begin{array}{l}0.181^{* *} \\
(0.0758)\end{array}$ & $\begin{array}{l}0.376 * * * \\
(0.106)\end{array}$ \\
\hline asistencia & & $\begin{array}{l}-1.785^{* * *} \\
(0.0922)\end{array}$ & & $\begin{array}{l}-1.705^{* * *} \\
(0.0870)\end{array}$ & & $\begin{array}{l}-1.732^{* * *} \\
(0.0927)\end{array}$ & & $\begin{array}{l}-1.699 * * * \\
(0.0896)\end{array}$ & & $\begin{array}{l}-1.558^{* * *} \\
(0.0943)\end{array}$ & & $\begin{array}{l}-1.334^{* * *} \\
(0.105)\end{array}$ & & $\begin{array}{l}-1.025^{* * *} \\
(0.119)\end{array}$ & & $\begin{array}{l}-0.942^{* * *} \\
(0.150)\end{array}$ \\
\hline gba & $\begin{array}{l}0.328^{* * *} \\
(0.106)\end{array}$ & $\begin{array}{l}-0.0766 \\
(0.133)\end{array}$ & $\begin{array}{l}0.244^{* *} \\
(0.103)\end{array}$ & $\begin{array}{l}-0.0883 \\
(0.142)\end{array}$ & $\begin{array}{l}0.389 * * * \\
(0.107)\end{array}$ & $\begin{array}{l}-0.291^{* *} \\
(0.143)\end{array}$ & $\begin{array}{l}0.198^{*} \\
(0.113)\end{array}$ & $\begin{array}{l}0.0591 \\
(0.162)\end{array}$ & $\begin{array}{l}0.467 * * * \\
(0.110)\end{array}$ & $\begin{array}{l}-0.195 \\
(0.143)\end{array}$ & $\begin{array}{l}0.220^{* *} \\
(0.0900)\end{array}$ & $\begin{array}{l}-0.127 \\
(0.110)\end{array}$ & $\mid \begin{array}{l}0.224^{* * *} \\
(0.0780)\end{array}$ & $\begin{array}{l}-0.136 \\
(0.102)\end{array}$ & $\begin{array}{l}0.255^{* * *} \\
(0.0918)\end{array}$ & $\begin{array}{l}-0.136 \\
(0.132)\end{array}$ \\
\hline pampa & $\begin{array}{l}0.210^{* *} \\
(0.104)\end{array}$ & $\begin{array}{l}-0.158 \\
(0.130)\end{array}$ & $\begin{array}{l}0.182^{*} \\
(0.101)\end{array}$ & $\begin{array}{l}-0.0180 \\
(0.139)\end{array}$ & $\begin{array}{l}0.205^{* *} \\
(0.104)\end{array}$ & $\begin{array}{l}-0.205 \\
(0.141)\end{array}$ & $\begin{array}{l}0.00517 \\
(0.112)\end{array}$ & $\begin{array}{l}-0.123 \\
(0.155)\end{array}$ & $\begin{array}{l}0.304^{* * *} \\
(0.108)\end{array}$ & $\begin{array}{l}-0.285^{* *} \\
(0.139)\end{array}$ & $\begin{array}{l}0.185 * * \\
(0.0862)\end{array}$ & $\begin{array}{l}-0.108 \\
(0.104)\end{array}$ & $\begin{array}{l}0.237 * * * \\
(0.0717)\end{array}$ & $\begin{array}{l}-0.134 \\
(0.0983)\end{array}$ & $\begin{array}{l}0.282^{* * *} \\
(0.0832)\end{array}$ & $\begin{array}{l}-0.100 \\
(0.122)\end{array}$ \\
\hline cuyo & $\begin{array}{l}0.396 * * * \\
(0.122)\end{array}$ & $\begin{array}{l}-0.0742 \\
(0.152)\end{array}$ & $\begin{array}{l}0.367^{* * *} \\
(0.116)\end{array}$ & $\begin{array}{l}0.0531 \\
(0.158)\end{array}$ & $\begin{array}{l}0.491 * * * \\
(0.118)\end{array}$ & $\begin{array}{l}-0.236 \\
(0.158)\end{array}$ & $\begin{array}{l}0.274^{* *} \\
(0.126)\end{array}$ & $\begin{array}{l}-0.0486 \\
(0.175)\end{array}$ & $\begin{array}{l}0.453^{* * *} \\
(0.119)\end{array}$ & $\begin{array}{l}-0.291^{*} \\
(0.152)\end{array}$ & $\begin{array}{l}0.286 * * * \\
(0.0975)\end{array}$ & $\begin{array}{l}-0.306^{* *} \\
(0.126)\end{array}$ & $\begin{array}{l}0.270^{* * *} \\
(0.0899)\end{array}$ & $\begin{array}{l}-0.0960 \\
(0.124)\end{array}$ & $\begin{array}{l}0.191^{* *} \\
(0.0944)\end{array}$ & $\begin{array}{l}-0.133 \\
(0.159)\end{array}$ \\
\hline nea & $\begin{array}{l}0.103 \\
(0.124)\end{array}$ & $\begin{array}{l}-0.224 \\
(0.140)\end{array}$ & $\begin{array}{l}0.0811 \\
(0.121)\end{array}$ & $\begin{array}{l}-0.196 \\
(0.150)\end{array}$ & $\begin{array}{l}0.0633 \\
(0.127)\end{array}$ & $\begin{array}{l}-0.172 \\
(0.154)\end{array}$ & $\begin{array}{l}-0.0851 \\
(0.133)\end{array}$ & $\begin{array}{l}-0.183 \\
(0.168)\end{array}$ & $\begin{array}{l}0.123 \\
(0.129)\end{array}$ & $\begin{array}{l}-0.290^{*} \\
(0.156)\end{array}$ & $\begin{array}{l}0.0916 \\
(0.101)\end{array}$ & $\begin{array}{l}-0.356^{* * *} \\
(0.113)\end{array}$ & $\begin{array}{l}0.0587 \\
(0.0915)\end{array}$ & $\begin{array}{l}-0.180 \\
(0.111)\end{array}$ & $\begin{array}{l}0.114 \\
(0.100)\end{array}$ & $\begin{array}{l}-0.214 \\
(0.136)\end{array}$ \\
\hline noa & $\begin{array}{l}0.175 \\
(0.112)\end{array}$ & $\begin{array}{l}-0.360^{* * *} \\
(0.132)\end{array}$ & $\begin{array}{l}0.0741 \\
(0.109)\end{array}$ & $\begin{array}{l}-0.103 \\
(0.142)\end{array}$ & $\begin{array}{l}0.228^{* *} \\
(0.111)\end{array}$ & $\begin{array}{l}-0.402^{* * *} \\
(0.144)\end{array}$ & $\begin{array}{l}0.0984 \\
(0.118)\end{array}$ & $\begin{array}{l}-0.239 \\
(0.159)\end{array}$ & $\begin{array}{l}0.264^{* *} \\
(0.112)\end{array}$ & $\begin{array}{l}-0.450^{* * *} \\
(0.140)\end{array}$ & $\begin{array}{l}0.167^{*} \\
(0.0912)\end{array}$ & $\begin{array}{l}-0.323^{* * *} \\
(0.104)\end{array}$ & $\begin{array}{l}0.197^{* *} \\
(0.0784)\end{array}$ & $\begin{array}{l}-0.287^{* * *} \\
(0.0953)\end{array}$ & $\begin{array}{l}0.215^{* *} \\
(0.0903)\end{array}$ & $\begin{array}{l}-0.239^{* *} \\
(0.121)\end{array}$ \\
\hline cuartos & $\begin{array}{l}-0.148^{* * *} \\
(0.0221)\end{array}$ & & $\begin{array}{l}-0.141^{* * *} \\
(0.0208)\end{array}$ & & $\begin{array}{l}-0.134^{* * *} \\
(0.0203)\end{array}$ & & $\begin{array}{l}-0.133^{* * *} \\
(0.0211)\end{array}$ & & $\begin{array}{l}-0.0866 * * * \\
(0.0197)\end{array}$ & & $\begin{array}{l}-0.145^{* * *} \\
(0.0208)\end{array}$ & & $\begin{array}{l}-0.129 * * * \\
(0.0210)\end{array}$ & & $\begin{array}{l}-0.181^{* * *} \\
(0.0275)\end{array}$ & \\
\hline propinm & $\begin{array}{l}0.494^{* * *} \\
(0.0707)\end{array}$ & & $\begin{array}{l}0.482^{* * *} \\
(0.0691)\end{array}$ & & $\begin{array}{l}0.415^{* * *} \\
(0.0696)\end{array}$ & & $\begin{array}{l}0.482^{* * *} \\
(0.0694)\end{array}$ & & $\begin{array}{l}0.458^{* * *} \\
(0.0658)\end{array}$ & & $\begin{array}{l}0.516 * * * \\
(0.0640)\end{array}$ & & $\begin{array}{l}0.505^{* * *} \\
(0.0624)\end{array}$ & & $\begin{array}{l}0.757^{* * *} \\
(0.0936)\end{array}$ & \\
\hline miembros & $\begin{array}{l}0.325 * * * \\
(0.0212)\end{array}$ & & $\begin{array}{l}0.310^{* * *} \\
(0.0189)\end{array}$ & & $\begin{array}{l}0.287^{* * *} \\
(0.0190)\end{array}$ & & $\begin{array}{l}0.260^{* * *} \\
(0.0208)\end{array}$ & & $\begin{array}{l}0.292 * * * \\
(0.0197)\end{array}$ & & $\begin{array}{l}0.260^{* * *} \\
(0.0173)\end{array}$ & & $\begin{array}{l}0.287^{* * *} \\
(0.0181)\end{array}$ & & $\begin{array}{l}0.232 * * * \\
(0.0252)\end{array}$ & \\
\hline constante & $\begin{array}{l}1.093^{* * *} \\
(0.357)\end{array}$ & $\begin{array}{l}-4.643 \\
(4.274)\end{array}$ & $\begin{array}{l}1.180^{* * *} \\
(0.331)\end{array}$ & $\begin{array}{l}0.0536 \\
(4.765)\end{array}$ & $\begin{array}{l}1.328^{* * *} \\
(0.339)\end{array}$ & $\begin{array}{l}1.348 \\
(4.725)\end{array}$ & $\begin{array}{l}1.793 * * * \\
(0.327)\end{array}$ & $\begin{array}{l}-0.610 \\
(4.520)\end{array}$ & $\begin{array}{l}0.979 * * * \\
(0.340)\end{array}$ & $\begin{array}{l}0.259 \\
(5.037)\end{array}$ & $\begin{array}{l}0.766^{* *} \\
(0.316)\end{array}$ & $\begin{array}{l}-4.000 \\
(5.324)\end{array}$ & $\begin{array}{l}1.334^{* * *} \\
(0.322)\end{array}$ & $\begin{array}{l}-1.372 \\
(5.124)\end{array}$ & $\begin{array}{l}1.240^{* * *} \\
(0.410)\end{array}$ & $\begin{array}{l}-1.574 \\
(7.256)\end{array}$ \\
\hline athrho & $\begin{array}{l}-0.204^{* * *} \\
(0.0592)\end{array}$ & & $\begin{array}{l}-0.238^{* * *} \\
(0.0558)\end{array}$ & & $\begin{array}{l}-0.0373 \\
(0.0629)\end{array}$ & & $\begin{array}{l}-0.186 * * * \\
(0.0635)\end{array}$ & & \begin{tabular}{|l}
0.0469 \\
$(0.0681)$
\end{tabular} & & $\begin{array}{l}-0.0353 \\
(0.0577)\end{array}$ & & \begin{tabular}{|l|}
$0.107^{*}$ \\
$(0.0604)$
\end{tabular} & & $\begin{array}{l}-0.0103 \\
(0.0751)\end{array}$ & \\
\hline rho & \begin{tabular}{|l}
-0.201 \\
$(0.0567)$
\end{tabular} & & \begin{tabular}{|l}
-0.234 \\
$(0.0527)$
\end{tabular} & & \begin{tabular}{|l}
-0.037 \\
$(0.0628)$
\end{tabular} & & \begin{tabular}{|l}
-0.184 \\
$(0.0614)$
\end{tabular} & & $\begin{array}{l}0.047 \\
(0.0679)\end{array}$ & & \begin{tabular}{|l}
-0.035 \\
$(0.0576)$
\end{tabular} & & $\begin{array}{l}0.107 \\
(0.0597)\end{array}$ & & $\begin{array}{l}-0.0103 \\
(0.0751)\end{array}$ & \\
\hline $\begin{array}{l}\text { Wald Test rho [p-value] } \\
\text { Log pseudolikelihood }\end{array}$ & $\mid \begin{array}{l}11.878 \\
-1097827\end{array}$ & {$[0.0006]$} & \begin{tabular}{|l}
18.275 \\
-1174958
\end{tabular} & {$[0.0000]$} & \begin{tabular}{|l}
0.352 \\
-1110530
\end{tabular} & [0.5529] & \begin{tabular}{|l}
8.615 \\
-1096970
\end{tabular} & {$[0.0033]$} & \begin{tabular}{|l}
0.475 \\
-1139759
\end{tabular} & [0.4909] & $\begin{array}{l}0.373 \\
-1169265\end{array}$ & {$[0.5413]$} & \begin{tabular}{|l}
3.161 \\
-1181299
\end{tabular} & [0.0754] & \begin{tabular}{|l}
0.019 \\
-1130436
\end{tabular} & {$[0.8904]$} \\
\hline Observaciones & 6813 & 6813 & 7198 & 7198 & 7080 & 7080 & 7510 & 7510 & 7423 & 7423 & 10620 & 10620 & 10141 & 10141 & 6514 & 6514 \\
\hline F test & 0 & 0 & 0 & 0 & 0 & 0 & 0 & 0 & 0 & 0 & 0 & 0 & 0 & 0 & 0 & 0 \\
\hline
\end{tabular}

Nota: Errores estándar robustos en paréntesis. ${ }^{* \star *}$ significativo al $1 \%,{ }^{* *}$ significativo al $5 \%$, * significativo al $10 \%$

Fuente: Elaboración propia en base a $E P H$ 


\begin{tabular}{|c|c|c|c|c|c|c|c|c|c|c|c|c|}
\hline \multirow{2}{*}{ Variables } & \multicolumn{2}{|c|}{ I-2008 } & \multicolumn{2}{|c|}{ II-2008 } & \multicolumn{2}{|c|}{ I-2009 } & \multicolumn{2}{|c|}{ II-2009 } & \multicolumn{2}{|c|}{ I-2010 } & \multicolumn{2}{|c|}{ II-2010 } \\
\hline & Coresidencia & Empleo & Coresidencia & Empleo & Coresidencia & Empleo & Coresidencia & Empleo & Coresidencia & Empleo & Coresidencia & Empleo \\
\hline aedu & & $\begin{array}{l}0.00686 \\
(0.0113)\end{array}$ & & $\begin{array}{l}0.0385^{* *} \\
(0.0168)\end{array}$ & & $\begin{array}{l}0.0409 * * * \\
(0.0146)\end{array}$ & & $\begin{array}{l}0.0376^{* * *} \\
(0.0129)\end{array}$ & & $\begin{array}{l}0.0109 \\
(0.0167)\end{array}$ & & $\begin{array}{l}0.0127 \\
(0.0144)\end{array}$ \\
\hline edad & $\begin{array}{l}-0.0699 * * * \\
(0.00985)\end{array}$ & $\begin{array}{l}0.397 \\
(0.309)\end{array}$ & $\begin{array}{l}-0.0649 * * * \\
(0.00956)\end{array}$ & $\begin{array}{l}0.592^{*} \\
(0.330)\end{array}$ & $\begin{array}{l}-0.0629^{* * *} \\
(0.0103)\end{array}$ & $\begin{array}{l}0.0366 \\
(0.342)\end{array}$ & $\begin{array}{l}-0.0651^{* * *} \\
(0.0105)\end{array}$ & $\begin{array}{l}0.204 \\
(0.365)\end{array}$ & $\begin{array}{l}-0.0640^{* * *} \\
(0.0112)\end{array}$ & $\begin{array}{l}-0.371 \\
(0.413)\end{array}$ & $\begin{array}{l}-0.0589 * * * \\
(0.0118)\end{array}$ & $\begin{array}{l}0.0475 \\
(0.524)\end{array}$ \\
\hline edad2 & & $\begin{array}{l}-0.00582 \\
(0.00505)\end{array}$ & & $\begin{array}{l}-0.00896 * \\
(0.00540)\end{array}$ & & $\begin{array}{l}0.000251 \\
(0.00568)\end{array}$ & & $\begin{array}{l}-0.00279 \\
(0.00602)\end{array}$ & & $\begin{array}{l}0.00656 \\
(0.00676)\end{array}$ & & $\begin{array}{l}-0.000349 \\
(0.00867)\end{array}$ \\
\hline casado & $\begin{array}{l}-2.299 * * * \\
(0.0790)\end{array}$ & $\begin{array}{l}0.0364 \\
(0.0841)\end{array}$ & $\begin{array}{l}-2.221^{* * *} \\
(0.0727)\end{array}$ & $\begin{array}{l}-0.140 \\
(0.0927)\end{array}$ & $\begin{array}{l}-2.109 * * * \\
(0.0692)\end{array}$ & $\begin{array}{l}0.00346 \\
(0.0887)\end{array}$ & $\begin{array}{l}-2.261^{* * *} \\
(0.0868)\end{array}$ & $\begin{array}{l}-0.140 \\
(0.0963)\end{array}$ & $\begin{array}{l}-2.109^{* * *} \\
(0.0740)\end{array}$ & $\begin{array}{l}-0.0835 \\
(0.0940)\end{array}$ & $\begin{array}{l}-2.299 * * * \\
(0.0843)\end{array}$ & $\begin{array}{l}0.157 \\
(0.111)\end{array}$ \\
\hline asiste & $\begin{array}{l}0.169^{*} \\
(0.0956)\end{array}$ & $\begin{array}{l}-8.769 * * * \\
(0.0665)\end{array}$ & $\begin{array}{l}0.127 \\
(0.0809)\end{array}$ & $\begin{array}{l}-9.178^{* * *} \\
(0.130)\end{array}$ & \begin{tabular}{|l}
0.113 \\
$(0.0842)$
\end{tabular} & $\begin{array}{l}-9.021^{* * *} \\
(0.110)\end{array}$ & $\begin{array}{l}-0.0804 \\
(0.0777)\end{array}$ & $\begin{array}{l}-8.992^{* * *} \\
(0.0930)\end{array}$ & $\begin{array}{l}0.0819 \\
(0.0902)\end{array}$ & $\begin{array}{l}-8.855^{* * *} \\
(0.109)\end{array}$ & $\begin{array}{l}0.263^{* * *} \\
(0.0917)\end{array}$ & $\begin{array}{l}-8.725^{* * *} \\
(0.100)\end{array}$ \\
\hline hombre & $\begin{array}{l}0.123^{* *} \\
(0.0584)\end{array}$ & $\begin{array}{l}0.278^{* * *} \\
(0.0805)\end{array}$ & $\begin{array}{l}0.162^{* * *} \\
(0.0577)\end{array}$ & $\begin{array}{l}0.507^{* * *} \\
(0.104)\end{array}$ & $\begin{array}{l}0.182^{* * *} \\
(0.0583)\end{array}$ & $\begin{array}{l}0.200^{* *} \\
(0.102)\end{array}$ & $\begin{array}{l}0.243^{* * *} \\
(0.0597)\end{array}$ & $\begin{array}{l}0.254^{* * *} \\
(0.0954)\end{array}$ & $\begin{array}{l}0.175^{* * *} \\
(0.0589)\end{array}$ & $\begin{array}{l}0.327^{* * *} \\
(0.105)\end{array}$ & $\begin{array}{l}0.398^{* * *} \\
(0.0691)\end{array}$ & $\begin{array}{l}0.0495 \\
(0.107)\end{array}$ \\
\hline asistencia & & $\begin{array}{l}-0.817^{* * *} \\
(0.135)\end{array}$ & & $\begin{array}{l}-0.537^{* * *} \\
(0.172)\end{array}$ & & $\begin{array}{l}-0.411^{* * *} \\
(0.156)\end{array}$ & & $\begin{array}{l}-0.227 \\
(0.171)\end{array}$ & & $\begin{array}{l}-0.468^{* * *} \\
(0.181)\end{array}$ & & $\begin{array}{l}-0.0431 \\
(0.242)\end{array}$ \\
\hline gba & $\begin{array}{l}0.281^{* * *} \\
(0.0736)\end{array}$ & $\begin{array}{l}0.0201 \\
(0.0974)\end{array}$ & $\begin{array}{l}0.125^{*} \\
(0.0700)\end{array}$ & $\begin{array}{l}-0.0746 \\
(0.123)\end{array}$ & \begin{tabular}{|l}
0.0924 \\
$(0.0688)$
\end{tabular} & $\begin{array}{l}-0.554^{* * *} \\
(0.115)\end{array}$ & $\begin{array}{l}0.165^{* *} \\
(0.0734)\end{array}$ & $\begin{array}{l}-0.156 \\
(0.113)\end{array}$ & $\begin{array}{l}0.268^{* * *} \\
(0.0726)\end{array}$ & $\begin{array}{l}-0.326^{* * *} \\
(0.124)\end{array}$ & $\begin{array}{l}0.261 * * * \\
(0.0854)\end{array}$ & $\begin{array}{l}0.109 \\
(0.137)\end{array}$ \\
\hline pampa & $\begin{array}{l}0.109 \\
(0.0684)\end{array}$ & $\begin{array}{l}0.0817 \\
(0.0902)\end{array}$ & \begin{tabular}{|l}
0.0523 \\
$(0.0658)$
\end{tabular} & $\begin{array}{l}-0.0610 \\
(0.122)\end{array}$ & $\begin{array}{c}-0.00954 \\
(0.0650)\end{array}$ & $\begin{array}{l}-0.325^{* * *} \\
(0.113)\end{array}$ & $\begin{array}{l}0.157^{* *} \\
(0.0659)\end{array}$ & $\begin{array}{l}0.0132 \\
(0.111)\end{array}$ & $\begin{array}{l}0.223^{* * *} \\
(0.0651)\end{array}$ & $\begin{array}{l}-0.0114 \\
(0.119)\end{array}$ & $\begin{array}{l}0.270^{* * *} \\
(0.0785)\end{array}$ & $\begin{array}{l}0.0225 \\
(0.118)\end{array}$ \\
\hline cuyo & $\begin{array}{l}0.171^{* *} \\
(0.0812)\end{array}$ & $\begin{array}{l}0.0327 \\
(0.115)\end{array}$ & $\begin{array}{l}0.203^{* *} \\
(0.0790)\end{array}$ & $\begin{array}{l}-0.240^{*} \\
(0.136)\end{array}$ & \begin{tabular}{|l}
0.109 \\
$(0.0783)$
\end{tabular} & $\begin{array}{l}-0.475^{* * *} \\
(0.132)\end{array}$ & $\begin{array}{l}0.312^{* * *} \\
(0.0810)\end{array}$ & $\begin{array}{l}0.0411 \\
(0.145)\end{array}$ & $\begin{array}{l}0.383^{* * *} \\
(0.0817)\end{array}$ & $\begin{array}{l}-0.0504 \\
(0.145)\end{array}$ & $\begin{array}{l}0.237^{* *} \\
(0.103)\end{array}$ & $\begin{array}{l}-0.0127 \\
(0.164)\end{array}$ \\
\hline nea & \begin{tabular}{|l}
0.0556 \\
$(0.0812)$
\end{tabular} & $\begin{array}{l}0.190^{*} \\
(0.113)\end{array}$ & $\begin{array}{l}0.00700 \\
(0.0764)\end{array}$ & $\begin{array}{l}-0.313^{* *} \\
(0.129)\end{array}$ & $\begin{array}{l}-0.0195 \\
(0.0774)\end{array}$ & $\begin{array}{l}-0.176 \\
(0.145)\end{array}$ & \begin{tabular}{|l}
0.117 \\
$(0.0807)$
\end{tabular} & $\begin{array}{l}0.0818 \\
(0.142)\end{array}$ & $\begin{array}{l}0.198^{* *} \\
(0.0786)\end{array}$ & $\begin{array}{l}-0.179 \\
(0.135)\end{array}$ & $\begin{array}{l}0.132 \\
(0.107)\end{array}$ & $\begin{array}{l}-0.0887 \\
(0.150)\end{array}$ \\
\hline noa & $\begin{array}{l}0.0368 \\
(0.0744)\end{array}$ & $\begin{array}{l}-0.194^{* *} \\
(0.0913)\end{array}$ & $\begin{array}{l}0.0937 \\
(0.0673)\end{array}$ & $\begin{array}{l}-0.322^{* * *} \\
(0.114)\end{array}$ & $\begin{array}{l}0.0157 \\
(0.0682)\end{array}$ & $\begin{array}{l}-0.600^{* * *} \\
(0.109)\end{array}$ & $\begin{array}{l}0.193 * * * \\
(0.0721)\end{array}$ & $\begin{array}{l}-0.307^{* * *} \\
(0.104)\end{array}$ & $\begin{array}{l}0.242^{* * *} \\
(0.0701)\end{array}$ & $\begin{array}{l}-0.309^{* * *} \\
(0.118)\end{array}$ & $\begin{array}{l}0.175^{* *} \\
(0.0875)\end{array}$ & $\begin{array}{l}-0.232^{* *} \\
(0.118)\end{array}$ \\
\hline cuartos & \begin{tabular}{|l}
$-0.162^{* * *}$ \\
$(0.0225)$
\end{tabular} & & $\begin{array}{l}-0.135 * * * \\
(0.0202)\end{array}$ & & $\begin{array}{l}-0.152^{* * *} \\
(0.0207)\end{array}$ & & $\begin{array}{l}-0.167^{* * *} \\
(0.0212)\end{array}$ & & $\begin{array}{l}-0.166^{* * *} \\
(0.0232)\end{array}$ & & $\begin{array}{l}-0.150^{* * *} \\
(0.0250)\end{array}$ & \\
\hline propinm & $\begin{array}{l}0.576^{* * *} \\
(0.0701)\end{array}$ & & $\begin{array}{l}0.500^{* * *} \\
(0.0671)\end{array}$ & & $\begin{array}{l}0.473 * * * \\
(0.0635)\end{array}$ & & $\begin{array}{l}0.460^{* * *} \\
(0.0654)\end{array}$ & & $\begin{array}{l}0.591 * * * \\
(0.0722)\end{array}$ & & $\begin{array}{l}0.531^{* * *} \\
(0.0799)\end{array}$ & \\
\hline miembros & $\begin{array}{l}0.317^{* * *} \\
(0.0224)\end{array}$ & & $\begin{array}{l}0.290^{* * *} \\
(0.0184)\end{array}$ & & $\begin{array}{l}0.272^{* * *} \\
(0.0165)\end{array}$ & & $\begin{array}{l}0.300^{* * *} \\
(0.0294)\end{array}$ & & $\begin{array}{l}0.278^{* * *} \\
(0.0191)\end{array}$ & & $\begin{array}{l}0.361^{* * *} \\
(0.0205)\end{array}$ & \\
\hline constante & $\begin{array}{l}1.171^{* * *} \\
(0.305)\end{array}$ & $\begin{array}{l}-4.997 \\
(4.716)\end{array}$ & $\begin{array}{l}1.109 * * * \\
(0.297)\end{array}$ & $\begin{array}{l}-8.145 \\
(5.013)\end{array}$ & $\begin{array}{l}1.150 * * * \\
(0.320)\end{array}$ & $\begin{array}{l}0.427 \\
(5.025)\end{array}$ & $\begin{array}{l}1.068^{* * *} \\
(0.328)\end{array}$ & $\begin{array}{l}-1.979 \\
(5.491)\end{array}$ & $\begin{array}{l}0.972 * * * \\
(0.352)\end{array}$ & $\begin{array}{l}7.027 \\
(6.271)\end{array}$ & $\begin{array}{l}0.381 \\
(0.368)\end{array}$ & $\begin{array}{l}0.623 \\
(7.835)\end{array}$ \\
\hline athrho & $\begin{array}{l}-0.154^{* *} \\
(0.0655)\end{array}$ & & $\begin{array}{l}0.0565 \\
(0.0696)\end{array}$ & & $\begin{array}{l}-0.0321 \\
(0.0731)\end{array}$ & & $\begin{array}{l}0.0257 \\
(0.0922)\end{array}$ & & $\begin{array}{l}0.0428 \\
(0.0790)\end{array}$ & & $\begin{array}{l}-0.0142 \\
(0.0710)\end{array}$ & \\
\hline rho & $\begin{array}{l}-0.153 \\
(0.06395)\end{array}$ & & \begin{tabular}{|l}
0.056 \\
$(0.0693)$
\end{tabular} & & $\begin{array}{l}-0.032 \\
(0.0730)\end{array}$ & & $\begin{array}{l}0.026 \\
(0.0922)\end{array}$ & & $\begin{array}{l}0.043 \\
(0.0789)\end{array}$ & & $\mid \begin{array}{l}-0.014 \\
(0.07095)\end{array}$ & \\
\hline $\begin{array}{l}\text { Wald Test rho [p-value] } \\
\text { Log pseudolikelihood }\end{array}$ & $\begin{array}{l}5.555 \\
-1100108\end{array}$ & [0.0184] & $\begin{array}{l}0.659 \\
-1137530\end{array}$ & {$[0.4169]$} & $\begin{array}{l}0.192 \\
-1205653\end{array}$ & [0.6609] & $\begin{array}{l}0.078 \\
-1131996\end{array}$ & [0.7804] & $\begin{array}{l}0.294 \\
-1236144\end{array}$ & [0.5877] & $\begin{array}{l}0.0398 \\
-635428\end{array}$ & {$[0.8418]$} \\
\hline Observaciones & 10090 & 10090 & 10136 & 10136 & 9876 & 9876 & 10189 & 10189 & 9960 & 9960 & 7454 & 7454 \\
\hline $\mathrm{F}$ test & 0 & 0 & 0 & 0 & 0 & 0 & 0 & 0 & 0 & 0 & 0 & 0 \\
\hline
\end{tabular}

Nota: Errores estándar robustos en paréntesis. ${ }^{* * *}$ significativo al $1 \%,{ }^{* *}$ significativo al $5 \%,{ }^{*}$ significativo al $10 \%$

Fuente: Elaboración propia en base a EPH 
Cuadro A2: Estimaciones de la variable aceptable años de educación del modelo estructural corregido por sesgo de selección, 2004-2010

\begin{tabular}{|c|c|c|c|c|c|c|c|c|c|c|c|c|c|c|}
\hline Años de Educación & I-2004 & II-2004 & I-2005 & II-2005 & I-2006 & $11-2006$ & I-2007 & II-2007 & $1-2008$ & II-2008 & I-2009 & II-2009 & $\mathrm{I}-2010$ & $\mathrm{II}-2010$ \\
\hline \multirow[t]{2}{*}{ hombre } & $-1.583^{* * *}$ & $-1.239 * * *$ & $-1.193^{* * *}$ & $-1.492^{* * *}$ & $-1.293^{* * *}$ & $-0.973 * * *$ & $-1.057^{* * *}$ & $-0.923^{* * *}$ & $-1.294^{* * *}$ & $-1.601^{* * *}$ & $-1.234^{* * *}$ & $-1.169^{* * *}$ & $-1.177^{* * *}$ & $-1.123^{* * *}$ \\
\hline & $(0.152)$ & $(0.136)$ & (0.145) & $(0.135)$ & $(0.143)$ & (0.104) & $(0.105)$ & $(0.135)$ & $(0.116)$ & $(0.104)$ & (0.108) & $(0.116)$ & (0.0994) & $(0.138)$ \\
\hline \multirow[t]{2}{*}{ educjefe } & $0.446 * * *$ & $0.395^{* * *}$ & $0.384^{* * *}$ & $0.422^{* * *}$ & $0.404^{* * *}$ & $0.406^{* * *}$ & $0.400^{* * *}$ & $0.360 * * *$ & $0.398^{* * *}$ & $0.387^{* * *}$ & $0.387^{* * *}$ & $0.335^{* * *}$ & $0.350 * * *$ & $0.379^{* * *}$ \\
\hline & (0.0196) & $(0.0162)$ & $(0.0182)$ & $(0.0175)$ & $(0.0180)$ & $(0.0119)$ & $(0.0156)$ & $(0.0178)$ & $(0.0129)$ & $(0.0136)$ & $(0.0133)$ & $(0.0157)$ & $(0.0151)$ & $(0.0189)$ \\
\hline \multirow[t]{2}{*}{ indbajaocupjef } & 0.105 & 0.0741 & $-0.715 *$ & $1.047^{* * *}$ & $-0.934 * * *$ & 0.200 & 0.0882 & -0.187 & $0.587^{* *}$ & 0.00473 & -0.445 & 0.0137 & 0.338 & $1.078^{* * *}$ \\
\hline & $(0.423)$ & (0.395) & $(0.382)$ & $(0.356)$ & $(0.306)$ & $(0.330)$ & $(0.308)$ & $(0.328)$ & $(0.232)$ & $(0.253)$ & $(0.325)$ & $(0.332)$ & $(0.280)$ & $(0.361)$ \\
\hline \multirow[t]{2}{*}{ indmanufocupjef } & 0.416 & 0.0702 & -0.163 & -0.254 & 0.115 & -0.0792 & 0.117 & -0.563 & $1.531^{* * *}$ & $1.201^{* * *}$ & $1.332 * * *$ & $1.723^{* * *}$ & $0.877^{* *}$ & $1.059^{* * *}$ \\
\hline & (0.299) & (0.398) & $(0.269)$ & (0.349) & $(0.297)$ & $(0.328)$ & $(0.275)$ & (0.411) & $(0.274)$ & $(0.278)$ & $(0.312)$ & $(0.331)$ & $(0.341)$ & $(0.403)$ \\
\hline \multirow[t]{2}{*}{ constocupjef } & $0.958^{* * *}$ & -0.466 & -0.485 & -0.168 & -0.259 & $-0.616 * * *$ & $-0.418^{*}$ & $-0.656 * *$ & -0.0368 & -0.222 & $-0.511^{* *}$ & $-0.682^{* * *}$ & $-0.636 * * *$ & $-0.463^{*}$ \\
\hline & $(0.353)$ & $(0.364)$ & $(0.377)$ & $(0.315)$ & $(0.298)$ & $(0.234)$ & $(0.245)$ & $(0.279)$ & $(0.200)$ & (0.191) & $(0.210)$ & $(0.233)$ & $(0.230)$ & $(0.250)$ \\
\hline \multirow[t]{2}{*}{ agroocupjef } & 0.0385 & -1.008 & $-2.957^{* * *}$ & 0.491 & 0.741 & -0.273 & $1.157^{* * *}$ & $1.195 * *$ & 0.791 & 0.561 & -0.425 & 0.304 & $0.652^{* *}$ & 0.437 \\
\hline & (0.679) & $(0.821)$ & $(0.921)$ & $(0.888)$ & $(0.460)$ & (0.402) & (0.439) & $(0.563)$ & (0.502) & $(0.567)$ & (0.592) & $(0.500)$ & $(0.330)$ & (0.492) \\
\hline \multirow[t]{2}{*}{ ssmonocupjef } & 0.0408 & $1.120^{* * *}$ & $0.541^{*}$ & 0.431 & -0.0520 & $-0.638^{* *}$ & $0.689 * * *$ & 0.170 & $1.068^{* * *}$ & 0.182 & -0.0291 & 0.322 & $-0.494 *$ & 0.184 \\
\hline & $(0.385)$ & $(0.386)$ & $(0.284)$ & $(0.279)$ & $(0.271)$ & $(0.264)$ & $(0.212)$ & $(0.340)$ & $(0.251)$ & $(0.278)$ & (0.249) & $(0.255)$ & (0.273) & (0.278) \\
\hline \multirow[t]{2}{*}{ fcieroocupjef } & 0.406 & $0.799 * * *$ & $1.018^{* * *}$ & 0.439 & 0.0452 & 0.357 & -0.208 & $1.509 * * *$ & $0.533^{*}$ & $0.558^{*}$ & 0.296 & $0.727^{* * *}$ & $0.727 * *$ & 0.511 \\
\hline & $(0.338)$ & $(0.244)$ & $(0.313)$ & (0.311) & $(0.405)$ & (0.311) & $(0.258)$ & $(0.358)$ & $(0.286)$ & $(0.313)$ & $(0.298)$ & $(0.277)$ & (0.311) & (0.336) \\
\hline \multirow[t]{2}{*}{ administocupjef } & -0.115 & 0.0586 & -0.258 & 0.293 & $-0.774^{* *}$ & 0.0707 & 0.0222 & 0.166 & 0.287 & $0.642^{* * *}$ & $0.432 *$ & -0.166 & 0.202 & -0.0473 \\
\hline & (0.329) & $(0.266)$ & $(0.295)$ & $(0.277)$ & $(0.303)$ & $(0.188)$ & $(0.220)$ & $(0.270)$ & $(0.269)$ & (0.198) & $(0.221)$ & $(0.218)$ & $(0.208)$ & $(0.257)$ \\
\hline \multirow[t]{2}{*}{ ssocupjef } & -0.230 & $-0.523^{* *}$ & 0.225 & -0.180 & $0.453^{* *}$ & -0.0949 & $0.307^{*}$ & $0.505^{*}$ & -0.0546 & 0.0854 & 0.211 & -0.0564 & -0.142 & -0.0818 \\
\hline & $(0.268)$ & $(0.225)$ & $(0.214)$ & $(0.207)$ & $(0.204)$ & (0.188) & $(0.187)$ & $(0.288)$ & $(0.182)$ & $(0.168)$ & (0.199) & (0.188) & $(0.220)$ & (0.204) \\
\hline \multirow[t]{2}{*}{ domesticoocupjef } & $-0.894^{* *}$ & $-0.892^{*}$ & $-2.011 * * *$ & 0.391 & -0.362 & $-0.610^{* *}$ & $-0.923 * * *$ & $-1.307^{* * *}$ & $-0.851^{* * *}$ & $-0.610^{* * *}$ & -0.0632 & $-0.493^{*}$ & -0.377 & 0.262 \\
\hline & $(0.377)$ & (0.474) & (0.494) & $(0.356)$ & $(0.320)$ & $(0.270)$ & (0.304) & (0.339) & $(0.291)$ & (0.224) & $(0.298)$ & $(0.284)$ & $(0.266)$ & $(0.307)$ \\
\hline \multirow[t]{2}{*}{ nacgba } & -0.198 & -0.962 & $-1.022^{* *}$ & -0.213 & 0.257 & $1.202^{*}$ & 0.0436 & $1.205^{*}$ & 0.537 & 0.446 & -0.297 & $-0.854^{* *}$ & $-0.820 * *$ & 0.109 \\
\hline & (0.626) & $(0.640)$ & $(0.517)$ & (0.647) & (0.674) & $(0.659)$ & (0.549) & $(0.715)$ & (0.513) & (0.471) & (0.479) & $(0.425)$ & $(0.401)$ & (0.422) \\
\hline \multirow[t]{2}{*}{ nacnea } & -0.922 & -0.633 & $-2.079 * * *$ & -0.697 & 0.831 & $1.695 * * *$ & 0.314 & $1.931^{* * *}$ & $1.053^{* *}$ & $0.974 * *$ & -0.3 & $-1.098 * *$ & -0.622 & -0.174 \\
\hline & (0.677) & (0.654) & $(0.526)$ & (0.691) & (0.656) & $(0.630)$ & (0.543) & $(0.731)$ & (0.511) & (0.491) & $(0.529)$ & $(0.442)$ & $(0.427)$ & (0.418) \\
\hline \multirow[t]{2}{*}{ nacnoa } & -0.168 & $-1.401^{* *}$ & $-1.333^{* *}$ & -0.283 & 0.300 & $1.666 * * *$ & 0.215 & $1.519 * *$ & 0.715 & $0.877^{*}$ & -0.339 & $-1.054^{* *}$ & $-0.723 *$ & 0.557 \\
\hline & $(0.595)$ & $(0.653)$ & $(0.527)$ & (0.649) & (0.657) & $(0.642)$ & (0.539) & (0.709) & $(0.518)$ & $(0.489)$ & $(0.507)$ & $(0.412)$ & $(0.423)$ & (0.401) \\
\hline \multirow[t]{2}{*}{ naccuyo } & -0.00677 & -0.724 & -0.605 & -0.0337 & 0.434 & $1.248^{*}$ & -0.0760 & $1.488^{* *}$ & $0.939 *$ & $0.848^{*}$ & -0.340 & -0.660 & $-0.985^{* *}$ & 0.0517 \\
\hline & $(0.668)$ & $(0.666)$ & $(0.542)$ & $(0.706)$ & $(0.628)$ & (0.652) & $(0.570)$ & $(0.692)$ & $(0.515)$ & (0.506) & (0.539) & $(0.485)$ & $(0.408)$ & (0.433) \\
\hline \multirow[t]{2}{*}{ nacpampa } & -0.271 & -0.745 & -0.674 & 0.431 & 0.444 & $1.614^{* *}$ & 0.255 & $1.349 * *$ & $1.033^{* *}$ & 0.751 & -0.214 & $-1.060 * * *$ & $-0.666^{*}$ & 0.127 \\
\hline & (0.629) & $(0.608)$ & $(0.515)$ & (0.644) & (0.624) & $(0.652)$ & $(0.547)$ & $(0.677)$ & $(0.500)$ & $(0.483)$ & $(0.497)$ & $(0.410)$ & (0.393) & (0.393) \\
\hline \multirow[t]{2}{*}{ nacpata } & 0.424 & -0.691 & -0.489 & -0.179 & 0.291 & $1.689 * *$ & 0.105 & $1.567^{* *}$ & 0.812 & $0.914^{*}$ & 0.309 & $-0.913^{*}$ & $-0.717^{*}$ & 0.290 \\
\hline & (0.638) & $(0.657)$ & $(0.582)$ & (0.749) & $(0.731)$ & $(0.725)$ & $(0.560)$ & (0.689) & $(0.545)$ & $(0.516)$ & $(0.515)$ & $(0.476)$ & $(0.407)$ & (0.398) \\
\hline \multirow[t]{2}{*}{ prob } & $6.683^{* *}$ & $7.526 * *$ & $-9.834^{* * *}$ & -3.653 & $-11.04 * * *$ & -2.352 & $-5.194^{* *}$ & -3.747 & $-10.11^{* * *}$ & -0.497 & -3.434 & -2.519 & $-9.385 * * *$ & $-6.652^{* *}$ \\
\hline & (3.142) & (3.085) & (2.558) & (3.170) & (3.206) & (2.324) & (2.610) & (3.426) & (2.269) & (2.114) & (2.532) & (2.596) & $(2.523)$ & $(2.856)$ \\
\hline \multirow[t]{2}{*}{ probcuadrado } & -8.049 & -11.91 & $26.82^{* * *}$ & $13.70^{*}$ & $31.07 * * *$ & $12.21 * *$ & $14.80^{* *}$ & $15.64 * *$ & $29.65 * * *$ & 6.635 & $12.25^{* *}$ & 7.827 & $24.86 * * *$ & $22.22 * * *$ \\
\hline & (7.259) & (7.632) & (6.033) & (7.262) & (7.307) & (5.497) & (6.177) & (7.899) & (5.393) & (5.031) & $(5.745)$ & (5.653) & (5.695) & (6.614) \\
\hline probcubo & 1.473 & 4.989 & $-19.78^{* * *}$ & $-11.05 * *$ & $-22.63^{* * *}$ & $-10.93 * * *$ & $-11.32 * * *$ & $-13.30 * * *$ & $-22.53 * * *$ & $-6.771 * *$ & $-10.83^{* * *}$ & $-6.968^{* *}$ & $-17.82^{* * *}$ & $-17.19 * * *$ \\
\hline & $(4.846)$ & (5.254) & (3.984) & $(4.751)$ & (4.648) & (3.601) & $(4.140)$ & (5.072) & (3.611) & (3.422) & (3.766) & (3.488) & (3.675) & $(4.253)$ \\
\hline constante & $\begin{array}{c}8.220 * * * \\
(0.658)\end{array}$ & $\begin{array}{c}9.060 * * * \\
(0.753)\end{array}$ & $\begin{array}{c}11.06 * * * \\
(0.588)\end{array}$ & $\begin{array}{c}8.747 * * * \\
(0.757)\end{array}$ & $\begin{array}{c}9.269 * * * \\
(0.686)\end{array}$ & $\begin{array}{c}7.229 * * * \\
(0.648)\end{array}$ & $\begin{array}{c}9.383 * * * \\
(0.660)\end{array}$ & $\begin{array}{c}7.747 * * * \\
(0.730)\end{array}$ & $\begin{array}{c}8.994 * * * \\
(0.588)\end{array}$ & $\begin{array}{c}8.224^{* * *} \\
(0.559)\end{array}$ & $\begin{array}{c}9.784^{* * *} \\
(0.613)\end{array}$ & $\begin{array}{c}11.01^{* * *} \\
(0.538)\end{array}$ & $\begin{array}{c}11.09 * * * \\
(0.449)\end{array}$ & $\begin{array}{c}9.083^{* * *} \\
(0.495)\end{array}$ \\
\hline Observaciones & 1353 & 1490 & 1576 & 1692 & 1682 & 2522 & 2463 & 1695 & 2444 & 2581 & 2344 & 2518 & 2389 & 1739 \\
\hline R-cuadrado & 0.389 & 0.334 & 0.368 & 0.340 & 0.320 & 0.329 & 0.310 & 0.326 & 0.338 & 0.342 & 0.332 & 0.276 & 0.318 & 0.330 \\
\hline F test & 0 & 0 & 0 & 0 & 0 & 0 & 0 & 0 & 0 & 0 & 0 & 0 & 0 & 0 \\
\hline
\end{tabular}

Nota: Errores estándar en paréntesis ajustados con bootstrap de 100 replicaciones. ${ }^{* \star \star}$ significativo al $1 \%,{ }^{* \star}$ significativo al $5 \%,{ }^{*}$ significativo al $10 \%$

Fuente: Elaboración propia en base a EPH 
Cuadro A3: Estimaciones de la variable aceptable migración del modelo estructural, corregido por sesgo de selección 2004-2010

\begin{tabular}{|c|c|c|c|c|c|c|c|c|c|c|c|c|c|c|c|}
\hline Migrante & II-2003 & $\mathrm{I}-2004$ & II-2004 & $\mathrm{I}-2005$ & II-2005 & $\mathrm{I}-2006$ & II-2006 & $\mathrm{I}-2007$ & II-2007 & $\mathrm{I}-2008$ & II-2008 & I-2009 & II-2009 & $\mathrm{I}-2010$ & $\mathrm{II}-2010$ \\
\hline \multirow[t]{2}{*}{ hombre } & 0.00285 & 0.0258 & -0.00772 & -0.00221 & 0.00811 & -0.00594 & 0.00391 & -0.00316 & -0.0170 & 0.0122 & 0.000153 & 0.00920 & -0.0279* & 0.00923 & $0.0324^{*}$ \\
\hline & $(0.0212)$ & (0.0195) & (0.0184) & (0.0166) & (0.0169) & (0.0173) & $(0.0132)$ & (0.0149) & $(0.0173)$ & $(0.0142)$ & $(0.0154)$ & $(0.0130)$ & $(0.0155)$ & $(0.0127)$ & $(0.0170)$ \\
\hline \multirow[t]{2}{*}{ educjefe } & -0.00170 & -0.00204 & -0.00360 & $-0.00700^{* * *}$ & $-0.00481 *$ & $-0.00570^{* *}$ & $-0.00331 *$ & -0.00186 & -0.00202 & 0.00160 & 0.00147 & -0.00195 & 0.00293* & -0.000939 & -0.00115 \\
\hline & $(0.00280)$ & $(0.00248)$ & $(0.00252)$ & (0.00221) & $(0.00263)$ & $(0.00238)$ & (0.00184) & $(0.00193)$ & $(0.00232)$ & (0.00187) & (0.00191) & (0.00192) & $(0.00165)$ & $(0.00175)$ & (0.00238) \\
\hline \multirow[t]{2}{*}{ indbajaocupjef } & 0.0712 & 0.0632 & -0.0487 & $0.0826^{*}$ & 0.0261 & -0.00662 & -0.0232 & -0.0318 & 0.0109 & -0.0196 & 0.000369 & -0.0269 & -0.0333 & $-0.0571^{*}$ & -0.0181 \\
\hline & (0.0581) & (0.0474) & (0.0416) & (0.0473) & $(0.0452)$ & (0.0399) & $(0.0340)$ & $(0.0412)$ & $(0.0530)$ & $(0.0403)$ & (0.0386) & $(0.0397)$ & $(0.0356)$ & (0.0329) & $(0.0405)$ \\
\hline \multirow[t]{2}{*}{ indmanufocupjef } & $0.0779 *$ & -0.0494 & -0.0277 & 0.00304 & $-0.0552 * *$ & -0.0246 & 0.0340 & $0.0610^{*}$ & $0.146 * * *$ & $0.0959 * * *$ & & -0.0215 & $0.222^{* * *}$ & -0.00849 & $-0.0807 * *$ \\
\hline & $(0.0434)$ & $(0.0358)$ & $(0.0407)$ & (0.0331) & $(0.0264)$ & $(0.0230)$ & $(0.0325)$ & $(0.0359)$ & $(0.0522)$ & $(0.0345)$ & $(0.0407)$ & $(0.0338)$ & $(0.0583)$ & $(0.0425)$ & 348) \\
\hline \multirow[t]{2}{*}{ constocupjef } & -0.00440 & -0.0573 & 0.00143 & 0.00 & 0.0358 & $0.0858^{* *}$ & 0.00 & $0.0641^{*}$ & 0.00894 & $0.0860 * * *$ & -0.0 & 442 & & & \\
\hline & (0.05 & $(0.0449)$ & $(0.0414)$ & $(0.04$ & (0.03 & $(0.0429)$ & $(0.02$ & $(0.03$ & $(0.0437)$ & $(0.0290)$ & $(0.0$ & $(0.0$ & & 295) & \\
\hline \multirow[t]{2}{*}{ agroocupjef } & 0.0148 & 0.0382 & 0.0398 & 0.0694 & -0.0927 & 0.0617 & $0.202^{* * *}$ & 0.0409 & $0.158^{*}$ & 0.136 & & 328 & $0.106 *$ & 356 & \\
\hline & $(0.0966)$ & $(0.0946)$ & $(0.113)$ & $(0.102)$ & $(0.0663)$ & $(0.0774)$ & $(0.0772)$ & $(0.0743)$ & $(0.0885)$ & (0.0898) & $(0.0$ & & & 430) & \\
\hline \multirow[t]{2}{*}{ ssmonocupjef } & 0.0296 & 0.0344 & 0.0273 & -0.00750 & -0.0185 & -0.0351 & 0.0225 & 0.0385 & 0.0353 & $0.0954^{* * *}$ & -0.0427 & 0.00274 & 0.0405 & -0.0402 & 0.0428 \\
\hline & $(0.0539)$ & $(0.0423)$ & $(0.0415)$ & $(0.0337)$ & $(0.0345)$ & $(0.0327)$ & $(0.0343)$ & $(0.0340)$ & $(0.0354)$ & $(0.0316)$ & (0.0268) & $(0.0307)$ & $(0.0354)$ & (0.0344) & $(0.0343)$ \\
\hline \multirow[t]{2}{*}{ fcieroocupjef } & $-0.0786 *$ & -0.0420 & -0.0306 & 0.0386 & 0.0420 & 0.0311 & 0.0601 & $0.0961^{* *}$ & 0.00756 & -0.0232 & -0.0476 & $0.0803^{*}$ & 0.0198 & 0.0290 & -0.00461 \\
\hline & $(0.0472)$ & (0.0394) & $(0.0335)$ & $(0.0398)$ & $(0.0441)$ & $(0.0481)$ & $(0.0398)$ & $(0.0436)$ & $(0.0387)$ & $(0.0348)$ & (0.0419) & $(0.0453)$ & (0.0444) & $(0.0418)$ & $(0.0461)$ \\
\hline \multirow[t]{2}{*}{ administocupjef } & $-0.0836 * *$ & -0.0401 & -0.0335 & 0.0265 & -0.00384 & 0.0425 & -0.0322 & -0.0235 & -0.0322 & 0.0115 & -0.00951 & $-0.0713 * *$ & 0.0377 & -0.0261 & $-0.0820 * * *$ \\
\hline & $(0.0329)$ & $(0.0426)$ & $(0.0362)$ & $(0.0389)$ & $(0.0301)$ & $(0.0357)$ & $(0.0288)$ & $(0.0268)$ & $(0.0380)$ & $(0.0356)$ & $(0.0306)$ & $(0.0285)$ & $(0.0272)$ & $(0.0249)$ & (0.0307) \\
\hline \multirow[t]{2}{*}{ ssocupjef } & 0.0292 & 0.0179 & 0.0142 & $0.0730 * * *$ & 0.0426 & 0.0253 & 0.0358 & $0.128 * * *$ & 0.0278 & 0.0 & -0.0 & 345 & -0.0357 & $-0.0415^{*}$ & 203 \\
\hline & $(0.0408)$ & $(0.0366)$ & (0.0291) & $(0.0270)$ & (0.0294) & $(0.0268)$ & (0.0271) & $(0.0262)$ & $(0.0313)$ & $(0.0300)$ & $(0.0327)$ & $(0.0227)$ & $(0.02$ & $(0.0239)$ & 282) \\
\hline \multirow[t]{2}{*}{ domesticoocupjef } & -0.0323 & 0.00 & 0.0 & 0.0278 & -0.0 & 0.0253 & 0.07 & 0.12 & -0.00 & 0.000 & 270 & 130 & $0.0668^{*}$ & 466 & $0.122^{* *}$ \\
\hline & $(0.0567)$ & (0.0424) & $(0.0540)$ & $(0.0558)$ & (0.0439) & $(0.0405)$ & $(0.0410)$ & (0.0396) & $(0.0449)$ & $(0.03$ & $(0.0313)$ & $(0.0429)$ & $(0.0$ & $(0.0362)$ & 91) \\
\hline \multirow[t]{2}{*}{ nacgba } & $-0.974 * * *$ & $-0.991 * * *$ & $-0.966 * * *$ & $-0.938 * * *$ & $-0.983 * * *$ & $-0.976 * * *$ & $-0.984 * * *$ & $-0.929 * * *$ & $-0.974 * * *$ & $-0.983 * * *$ & $-0.969 * * *$ & $-0.986 * * *$ & $-0.950 * * *$ & $-0.975^{* * *}$ & $-0.952 * * *$ \\
\hline & $(0.0243)$ & $(0.0156)$ & $(0.0222)$ & $(0.0171)$ & $(0.0103)$ & $(0.0187)$ & $(0.0163)$ & $(0.01$ & (0.0159) & (0.0168) & $(0.0$ & $(0.0127)$ & (0.0171) & 140) & 207) \\
\hline \multirow[t]{2}{*}{ nacnea } & $-0.423 * * *$ & $-0.695 * * *$ & $-0.724 * * *$ & $-0.503^{* * *}$ & $-0.500 * * *$ & $-0.593 * * *$ & $-0.652 * * *$ & $-0.611 * * *$ & $-0.663 * * *$ & $-0.667 * * *$ & $-0.644 * * *$ & $-0.758 * * *$ & $-0.691 * * *$ & $-0.805^{* * *}$ & $-0.613^{* * *}$ \\
\hline & $(0.0493)$ & $(0.0423)$ & $(0.0374)$ & (0.0389) & $(0.0362)$ & $(0.0308)$ & $(0.0268)$ & $(0.0262)$ & $(0.0371)$ & $(0.0313)$ & $(0.0232)$ & $(0.0247)$ & $(0.0255)$ & $(0.0233)$ & $(0.0316)$ \\
\hline \multirow[t]{2}{*}{ nacnoa } & $-0.686 * * *$ & $-0.788^{* * *}$ & $-0.725^{* * *}$ & $-0.757 * * *$ & $-0.781 * * *$ & $-0.752 * * *$ & $-0.804^{* * *}$ & $-0.735^{* * *}$ & $-0.844 * * *$ & $-0.854^{* * *}$ & $-0.818^{* * *}$ & $-0.824 * * *$ & $-0.804^{* * *}$ & $-0.867 * * *$ & $-0.899 * * *$ \\
\hline & (0.0349) & $(0.0227)$ & $(0.0310)$ & $(0.0239)$ & $(0.0215)$ & $(0.0235)$ & $(0.0204)$ & (0.0172) & $(0.0224)$ & (0.0179) & $(0.0180)$ & (0.0171) & (0.0179) & $(0.0165)$ & (0.0177) \\
\hline \multirow[t]{2}{*}{ naccuyo } & $-0.920 * * *$ & $-0.895^{* * *}$ & $-0.893 * * *$ & $-0.906^{* * *}$ & $-0.884^{* * *}$ & $-0.951 * * *$ & $-0.914 * * *$ & $-0.841 * * *$ & $-0.884 * * *$ & $-0.893 * * *$ & $-0.908 * * *$ & $-0.927 * * *$ & $-0.908^{* * *}$ & $-0.886 * * *$ & $-0.821^{* * *}$ \\
\hline & $(0.0313)$ & $(0.0260)$ & $(0.0319)$ & $(0.0262)$ & $(0.0243)$ & $(0.0274)$ & $(0.0245)$ & $(0.0248)$ & $(0.0298)$ & $(0.0237)$ & $(0.0234)$ & $(0.0207)$ & $(0.0246)$ & $(0.0212)$ & $(0.0327)$ \\
\hline \multirow[t]{2}{*}{ nacpampa } & $-0.753^{* * *}$ & $-0.814^{* * *}$ & $-0.786 * * *$ & $-0.832^{* * *}$ & $-0.804 * * *$ & $-0.778 * * *$ & $-0.834^{* * *}$ & $-0.749 * * *$ & $-0.851^{* * *}$ & $-0.880 * * *$ & $-0.859 * * *$ & $-0.866 * * *$ & $-0.857^{* * *}$ & $-0.851^{* * *}$ & $-0.866 * * *$ \\
\hline & (0.0279) & $(0.0223)$ & & $(0.0206)$ & & $(0.0253)$ & & $(0.0187)$ & & & & & $(0.0183)$ & & \\
\hline \multirow[t]{2}{*}{ nacpata } & $-0.624 * * *$ & $-0.646 * * *$ & $-0.627 * * *$ & $-0.758^{* * *}$ & $-0.794 * * *$ & $-0.740 * * *$ & $-0.719 * * *$ & $-0.621 * * *$ & $-0.800 * * *$ & $-0.717 * * *$ & $-0.732^{* * *}$ & $-0.778 * * *$ & $-0.830 * * *$ & $-0.692 * * *$ & $-0.569 * * *$ \\
\hline & $(0.0517)$ & $(0.0514)$ & $(0.0496)$ & $(0.0544)$ & $(0.0476)$ & $(0.0510)$ & $(0.0328)$ & $(0.0276)$ & $(0.0305)$ & $(0.0254)$ & $(0.0224)$ & & $(0.02$ & & \\
\hline \multirow[t]{2}{*}{ prob } & $1.191^{* * *}$ & 0.0128 & 0.309 & 0.411 & 0.226 & -0.0696 & -0.528 & -0.340 & -0.161 & -0.221 & 0.1 & -0 . & -0.179 & 0.1 & -0.243 \\
\hline & & & & & & $(0.378)$ & & & & & & & & & \\
\hline probcuadrado & $-3.199 * * *$ & -0.153 & -0.774 & -1.035 & -0.428 & 0.0822 & 1.269 & 0.709 & 0.0104 & 0.446 & -0.555 & 1.094 & 0.765 & -0.00949 & 0.860 \\
\hline & & $(0.810)$ & (0.869) & $(0.870)$ & $(0.760)$ & $(0.851)$ & & & & (0.847) & $(0.703)$ & $(0.703)$ & & $(0.732)$ & $(0.722)$ \\
\hline probcubo & $2.337^{* * *}$ & 0.185 & 0.519 & 0.702 & 0.250 & 0.0292 & $-0.826^{*}$ & -0.440 & 0.130 & -0.325 & 0.445 & $-0.768^{*}$ & -0.609 & -0.119 & -0.705 \\
\hline & $(0.743)$ & $(0.543)$ & $(0.603)$ & (0.584) & $(0.485)$ & (0.544) & (0.501) & (0.479) & (0.684) & $(0.553)$ & $(0.446)$ & $(0.453)$ & $(0.516)$ & (0.469) & $(0.443)$ \\
\hline constante & $0.906 * * *$ & $1.005^{* * *}$ & $1.002^{* * *}$ & $0.997^{* * *}$ & $0.992 * * *$ & $1.040^{* * *}$ & $1.059 * * *$ & $0.976^{* * *}$ & $1.078 * * *$ & $1.018^{* * *}$ & $0.981^{* * *}$ & $1.043^{* * *}$ & $0.962^{* * *}$ & $0.982^{* * *}$ & $1.003^{* * *}$ \\
\hline & $(0.0513)$ & $(0.0526)$ & $(0.0503)$ & $(0.0480)$ & $(0.0466)$ & $(0.0508)$ & $(0.0484)$ & $(0.0453)$ & $(0.0559)$ & $(0.0364)$ & $(0.0389)$ & $(0.0438)$ & $(0.0483)$ & $(0.0377)$ & $(0.0505)$ \\
\hline Observaciones & 1236 & 1353 & 1490 & 1576 & 1692 & 1682 & 2522 & 2463 & 1695 & 2444 & 2581 & 2344 & 2518 & 2389 & 1739 \\
\hline R-cuadrado & 0.284 & 0.294 & 0.240 & 0.266 & 0.323 & 0.299 & 0.313 & 0.224 & 0.249 & 0.256 & 0.251 & 0.246 & 0.210 & 0.280 & 0.211 \\
\hline F test & 0 & 0 & 0 & 0 & 0 & 0 & 0 & 0 & 0 & 0 & 0 & 0 & 0 & 0 & 0 \\
\hline
\end{tabular}

Nota: Errores estándar en paréntesis ajustados con bootstrap de 100 replicaciones. ${ }^{* * *}$ significativo al $1 \%,{ }^{* *}$ significativo al $5 \%,{ }^{*}$ significativo al $10 \%$

Fuente: Elaboración propia en base a EPH 
Cuadro A4: Índices de desigualdad con sesgo de selección corregido, 2004-2010

\begin{tabular}{|c|c|c|c|c|c|c|}
\hline \multirow{3}{*}{ Año } & \multicolumn{3}{|c|}{$\begin{array}{l}\text { Gini Contrafáctico Variables Aceptables } \\
\text { tratadas como No Aceptables }\end{array}$} & \multicolumn{3}{|c|}{$\begin{array}{c}\text { Theil Contrafáctico Variables Aceptables } \\
\text { tratadas como No Aceptables }\end{array}$} \\
\hline & \multirow{2}{*}{ Coeficiente } & \multicolumn{2}{|c|}{ Intervalo 95\% de confianza } & \multirow{2}{*}{ Coeficiente } & \multicolumn{2}{|c|}{ Intervalo 95\% de confianza } \\
\hline & & Inferior & Superior & & Inferior & Superior \\
\hline I-2004 & 0.338 & 0.322 & 0.384 & 0.203 & 0.173 & 0.237 \\
\hline II-2004 & 0.332 & 0.315 & 0.345 & 0.194 & 0.170 & 0.225 \\
\hline $\mathrm{I}-2005$ & 0.352 & 0.322 & 0.406 & 0.260 & 0.167 & 0.430 \\
\hline II-2005 & 0.344 & 0.314 & 0.387 & 0.276 & 0.207 & 0.399 \\
\hline I-2006 & 0.323 & 0.308 & 0.342 & 0.198 & 0.163 & 0.259 \\
\hline II-2006 & 0.332 & 0.313 & 0.354 & 0.203 & 0.176 & 0.232 \\
\hline I-2007 & 0.321 & 0.306 & 0.341 & 0.190 & 0.164 & 0.238 \\
\hline II-2007 & 0.336 & 0.319 & 0.359 & 0.203 & 0.177 & 0.229 \\
\hline $\mathrm{I}-2008$ & 0.312 & 0.293 & 0.338 & 0.189 & 0.160 & 0.234 \\
\hline II-2008 & 0.336 & 0.319 & 0.362 & 0.210 & 0.173 & 0.243 \\
\hline I-2009 & 0.320 & 0.303 & 0.340 & 0.185 & 0.165 & 0.231 \\
\hline II-2009 & 0.323 & 0.305 & 0.350 & 0.194 & 0.165 & 0.233 \\
\hline I-2010 & 0.304 & 0.291 & 0.316 & 0.173 & 0.151 & 0.218 \\
\hline II-2010 & 0.340 & 0.307 & 0.367 & 0.231 & 0.186 & 0.283 \\
\hline
\end{tabular}

Nota: Intervalos de confianza a partir de bootstrap con 100 repeticiones y significatividad del 95\%.

Fuente: Elaboración propia en base a EPH

Cuadro A5: Índices de desigualdad sin corregir sesgo de selección, 2004-2010

\begin{tabular}{|c|c|c|c|c|c|c|c|c|c|}
\hline \multirow{3}{*}{ Año } & \multicolumn{3}{|c|}{ Gini } & \multicolumn{3}{|c|}{ Gini Contrafáctico Total } & \multicolumn{3}{|c|}{ Gini Contrafáctico Directo } \\
\hline & \multirow{2}{*}{ Coeficiente } & \multicolumn{2}{|c|}{ Intervalo 95\% de confianza } & \multirow{2}{*}{ Coeficiente - } & \multicolumn{2}{|c|}{ Intervalo 95\% de confianza } & \multirow{2}{*}{ Coeficiente } & \multicolumn{2}{|c|}{ Intervalo $95 \%$ de confianza } \\
\hline & & Inferior & Superior & & Inferior & Superior & & Inferior & Superior \\
\hline I-2004 & 0.382 & 0.361 & 0.416 & 0.348 & 0.327 & 0.369 & 0.356 & 0.330 & 0.376 \\
\hline II-2004 & 0.386 & 0.368 & 0.411 & 0.361 & 0.344 & 0.378 & 0.369 & 0.354 & 0.392 \\
\hline I-2005 & 0.392 & 0.367 & 0.422 & 0.365 & 0.330 & 0.421 & 0.371 & 0.339 & 0.415 \\
\hline II-2005 & 0.380 & 0.348 & 0.401 & 0.359 & 0.333 & 0.382 & 0.371 & 0.349 & 0.423 \\
\hline I-2006 & 0.369 & 0.349 & 0.392 & 0.349 & 0.332 & 0.371 & 0.357 & 0.343 & 0.388 \\
\hline II-2006 & 0.378 & 0.355 & 0.403 & 0.353 & 0.334 & 0.381 & 0.361 & 0.340 & 0.388 \\
\hline I-2007 & 0.367 & 0.338 & 0.387 & 0.340 & 0.322 & 0.367 & 0.347 & 0.329 & 0.374 \\
\hline II-2007 & 0.385 & 0.363 & 0.408 & 0.360 & 0.341 & 0.381 & 0.369 & 0.349 & 0.391 \\
\hline $1-2008$ & 0.360 & 0.341 & 0.378 & 0.335 & 0.318 & 0.353 & 0.348 & 0.328 & 0.367 \\
\hline II-2008 & 0.372 & 0.349 & 0.396 & 0.357 & 0.336 & 0.390 & 0.365 & 0.343 & 0.387 \\
\hline I-2009 & 0.368 & 0.349 & 0.384 & 0.350 & 0.330 & 0.380 & 0.359 & 0.341 & 0.377 \\
\hline II-2009 & 0.360 & 0.343 & 0.381 & 0.343 & 0.327 & 0.362 & 0.347 & 0.333 & 0.363 \\
\hline I-2010 & 0.346 & 0.325 & 0.366 & 0.317 & 0.296 & 0.337 & 0.322 & 0.303 & 0.338 \\
\hline \multirow{2}{*}{ II-2010 } & 0.377 & 0.356 & 0.411 & 0.353 & 0.328 & 0.383 & 0.359 & 0.337 & 0.396 \\
\hline & \multicolumn{3}{|c|}{ Theil } & \multicolumn{3}{|c|}{ Theil Contrafáctico Total } & \multicolumn{3}{|c|}{ Theil Contrafáctico Directo } \\
\hline I-2004 & 0.262 & 0.221 & 0.301 & 0.214 & 0.186 & 0.241 & 0.223 & 0.204 & 0.252 \\
\hline II-2004 & 0.260 & 0.224 & 0.294 & 0.230 & 0.198 & 0.255 & 0.240 & 0.212 & 0.268 \\
\hline I-2005 & 0.276 & 0.232 & 0.325 & 0.266 & 0.196 & 0.408 & 0.268 & 0.206 & 0.410 \\
\hline II-2005 & 0.300 & 0.230 & 0.379 & 0.288 & 0.205 & 0.401 & 0.301 & 0.233 & 0.425 \\
\hline I-2006 & 0.258 & 0.212 & 0.319 & 0.230 & 0.186 & 0.287 & 0.241 & 0.201 & 0.319 \\
\hline II-2006 & 0.263 & 0.229 & 0.312 & 0.230 & 0.197 & 0.280 & 0.243 & 0.215 & 0.285 \\
\hline I-2007 & 0.244 & 0.211 & 0.300 & 0.209 & 0.181 & 0.248 & 0.217 & 0.187 & 0.253 \\
\hline II-2007 & 0.265 & 0.223 & 0.325 & 0.231 & 0.210 & 0.267 & 0.244 & 0.217 & 0.293 \\
\hline $1-2008$ & 0.247 & 0.207 & 0.318 & 0.215 & 0.190 & 0.268 & 0.234 & 0.198 & 0.303 \\
\hline II-2008 & 0.253 & 0.219 & 0.298 & 0.238 & 0.209 & 0.285 & 0.248 & 0.212 & 0.293 \\
\hline I-2009 & 0.238 & 0.207 & 0.275 & 0.224 & 0.198 & 0.265 & 0.228 & 0.198 & 0.258 \\
\hline II-2009 & 0.236 & 0.206 & 0.284 & 0.215 & 0.190 & 0.256 & 0.221 & 0.198 & 0.253 \\
\hline |-2010 & 0.229 & 0.191 & 0.302 & 0.189 & 0.166 & 0.238 & 0.198 & 0.169 & 0.242 \\
\hline $\mathrm{II}-2010$ & 0.270 & 0.222 & 0.332 & 0.242 & 0.205 & 0.300 & 0.249 & 0.205 & 0.306 \\
\hline
\end{tabular}

Nota: Intervalos de confianza a partir de técnicas de bootstrap con 100 repeticiones y significatividad del $95 \%$.

Fuente: Elaboración propia en base a EPH 
Cuadro A6: Índices de desigualdad de oportunidad sin corregir sesgo de selección, 2004-2010

\begin{tabular}{|c|r|r|r|r|r|r|}
\hline \multirow{2}{*}{ Año } & \multicolumn{6}{|c|}{ Índice de Oportunidad (IO) } \\
\cline { 2 - 7 } & \multicolumn{2}{|c|}{ Índice de Gini } & \multicolumn{3}{|c|}{ Índice de Theil } \\
\cline { 2 - 7 } & \multicolumn{2}{|c|}{ IO Total } & IO Directo & IO Indirecto & IO Total IO Directo IO Indirecto \\
\hline I-2004 & $8.9 \%$ & $6.8 \%$ & $2.0 \%$ & $18.3 \%$ & $14.8 \%$ & $3.6 \%$ \\
II-2004 & $6.5 \%$ & $4.5 \%$ & $2.0 \%$ & $11.5 \%$ & $7.7 \%$ & $3.8 \%$ \\
I-2005 & $7.0 \%$ & $5.3 \%$ & $1.6 \%$ & $3.8 \%$ & $2.8 \%$ & $1.0 \%$ \\
II-2005 & $5.3 \%$ & $2.4 \%$ & $2.9 \%$ & $3.9 \%$ & $-0.3 \%$ & $4.2 \%$ \\
I-2006 & $5.7 \%$ & $3.4 \%$ & $2.2 \%$ & $10.8 \%$ & $6.5 \%$ & $4.2 \%$ \\
II-2006 & $6.8 \%$ & $4.5 \%$ & $2.3 \%$ & $12.5 \%$ & $7.8 \%$ & $4.7 \%$ \\
I-2007 & $7.1 \%$ & $5.2 \%$ & $1.9 \%$ & $14.5 \%$ & $11.1 \%$ & $3.4 \%$ \\
II-2007 & $6.4 \%$ & $4.0 \%$ & $2.4 \%$ & $12.9 \%$ & $8.0 \%$ & $4.9 \%$ \\
I-2008 & $6.9 \%$ & $3.4 \%$ & $3.5 \%$ & $13.0 \%$ & $4.9 \%$ & $8.1 \%$ \\
II-2008 & $4.0 \%$ & $1.9 \%$ & $2.1 \%$ & $5.7 \%$ & $1.9 \%$ & $3.8 \%$ \\
I-2009 & $5.0 \%$ & $2.4 \%$ & $2.6 \%$ & $6.0 \%$ & $4.1 \%$ & $1.9 \%$ \\
II-2009 & $4.9 \%$ & $3.8 \%$ & $1.1 \%$ & $8.9 \%$ & $6.3 \%$ & $2.6 \%$ \\
I-2010 & $8.5 \%$ & $6.9 \%$ & $1.5 \%$ & $17.4 \%$ & $13.5 \%$ & $4.0 \%$ \\
II-2010 & $6.4 \%$ & $5.0 \%$ & $1.5 \%$ & $10.4 \%$ & $7.8 \%$ & $2.5 \%$ \\
\hline
\end{tabular}

Fuente: Elaboración propia en base a EPH 